\title{
Predictors of Perceived Multicultural Competence Among Neuropsychological Trainees
}

\author{
Hannah K. Greenbaum \\ West Virginia University, hkgreenbaum@mix.wvu.edu
}

Follow this and additional works at: https://researchrepository.wvu.edu/etd

Part of the Counseling Psychology Commons, Counselor Education Commons, Multicultural Psychology Commons, and the Philosophy of Science Commons

\section{Recommended Citation}

Greenbaum, Hannah K., "Predictors of Perceived Multicultural Competence Among Neuropsychological Trainees" (2019). Graduate Theses, Dissertations, and Problem Reports. 3897.

https://researchrepository.wvu.edu/etd/3897

This Dissertation is protected by copyright and/or related rights. It has been brought to you by the The Research Repository @ WVU with permission from the rights-holder(s). You are free to use this Dissertation in any way that is permitted by the copyright and related rights legislation that applies to your use. For other uses you must obtain permission from the rights-holder(s) directly, unless additional rights are indicated by a Creative Commons license in the record and/ or on the work itself. This Dissertation has been accepted for inclusion in WVU Graduate Theses, Dissertations, and Problem Reports collection by an authorized administrator of The Research Repository @ WVU.

For more information, please contact researchrepository@mail.wvu.edu. 
2019

\section{Predictors of Perceived Multicultural Competence Among Neuropsychological Trainees}

Hannah K. Greenbaum

Follow this and additional works at: https: / /researchrepository.wvu.edu/etd

Part of the Counseling Psychology Commons, Counselor Education Commons, Multicultural $\underline{\text { Psychology Commons, and the Philosophy of Science Commons }}$ 
Predictors of Perceived Multicultural Competence Among Neuropsychological Trainees

Hannah K. Greenbaum, M.A.

Dissertation submitted to the College of Education and Human Services

at West Virginia University

in partial fulfillment of the requirements for the degree of

Doctor of Philosophy

In Counseling Psychology

Christine J. Schimmel, Ed.D. \& John Blake, Ph.D., Chairs

Jeffrey Daniels, Ph.D.

Lisa F. Platt, Ph.D.

M Cecil Smith, Ph.D.

Department of Counseling, Rehabilitation Counseling, \& Counseling Psychology

\section{Morgantown, West Virginia}

2019

Keywords: Neuropsychology, training, racial identity, diversity, multicultural competence

Copyright 2019 Hannah K. Greenbaum 


\begin{abstract}
Predictors of Perceived Multicultural Competence Among Neuropsychological Trainees
\end{abstract}

Hannah K. Greenbaum

Multicultural competence is necessary to provide psychological services to an increasingly diverse population (Sue, 2001). It is established that multicultural competence is important for training in psychology (Bodin et al., 2014; Diaz-Santos \& Hill, 2016). Despite increased interest in recent years, multicultural competence in neuropsychology has not progressed in parallel with the focus of multiculturalism in psychology broadly (Rivera Mindt, Byrd, Saez, \& Manly, 2010). Little is known about multicultural assessment, and it is not yet known what factors in training contribute to perceived multicultural competence in neuropsychological trainees (ElbulokCharape, Rabin, Spadaccini, \& Barr, 2014). The primary purpose of this quantitative descriptive study was to examine several variables, alone or in various combination (age, training level, racial identity development phases, and multicultural training) that may contribute to perceived multicultural competence. Following completion of a self-report survey, data were analyzed from 97 neuropsychology trainees in doctoral, internship, or postdoctoral programs. Results of correlation analyses indicated that age, training level, racial identity developmental phases, and multicultural training were statistically significantly related to multicultural competence. Results of the primary analysis (hierarchical multiple regression) indicated that, after controlling for social desirability, age, training level, and racial identity development phases, multicultural training was a statistically significant predictor of perceived Total Multicultural Competence and Multicultural Knowledge. Findings indicated that models comprised of social desirability, age, training level, racial identity development phases, and multicultural training had a statistically significant effect on Total Multicultural Competence, Multicultural Knowledge, and Multicultural Awareness. Implications for training and future research are offered. 


\section{DEDICATION}

This dissertation is dedicated to anyone who has ever felt like an "other." 


\section{ACKNOWLEDGEMENTS}

The support and guidance of many made this dissertation possible. Thank you to my dissertation chairs, Dr. Christine Schimmel and Dr. John Blake. You showed me what it means to support and mentor a student. I am grateful for the countless hours you spent helping me gain expertise as a researcher. Thank you for your time and encouragement. Thank you, Drs. Lisa Platt, Jeffrey Daniels, and Cecil Smith, for serving on my committee and supporting me throughout my experience at West Virginia University. Thank you, Vicki Railing, for all that you do. The above-mentioned faculty and staff in the College of Education and Human Services (CEHS) at West Virginia University make it possible every day for students to reach their educational and professional goals. Thank you from the bottom of my heart for supporting me and for supporting all students. Thank you to those on the CEHS Professional Development Committee who help fund student research projects.

To my Dad teaching me the importance of "to love, to knowledge." To my Mom, you are my role model and champion. To my sister, your strength and perseverance teaches me lessons every day. Finally, to my husband. This dissertation would not have been possible without you. 


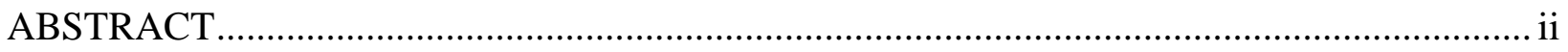

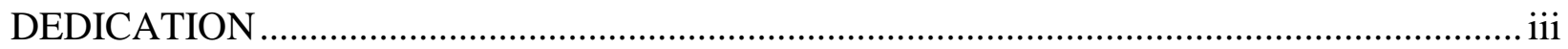

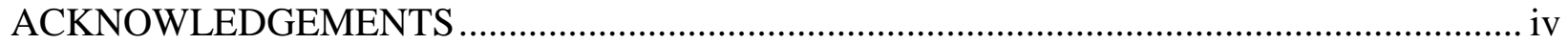

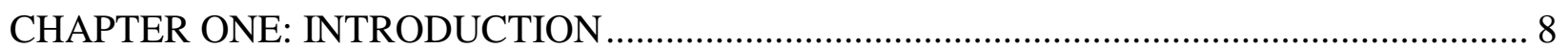

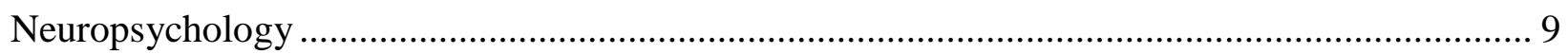

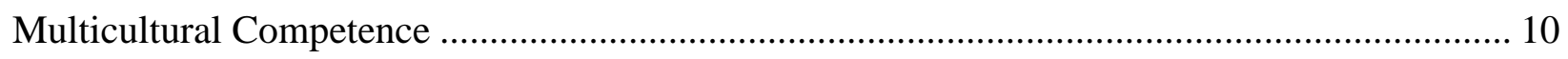

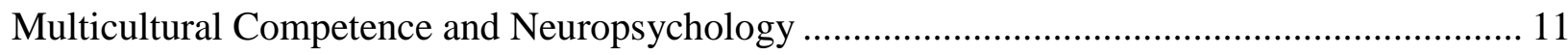

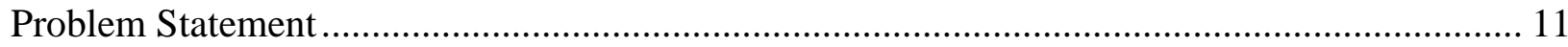

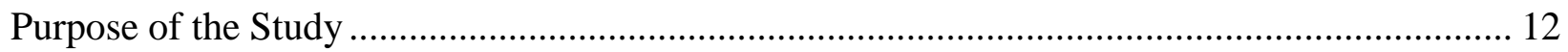

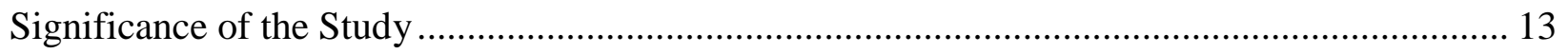

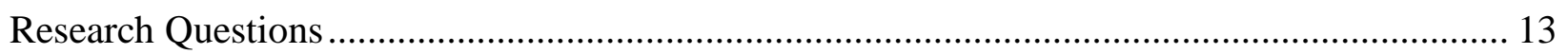

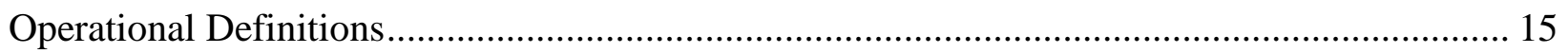

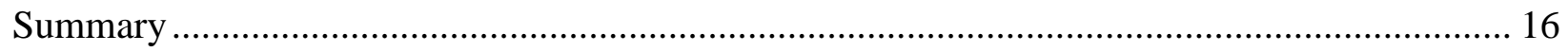

CHAPTER TWO: REVIEW OF THE LITERATURE …….............................................. 17

Multicultural Competence and Neuropsychological Assessment................................................ 17

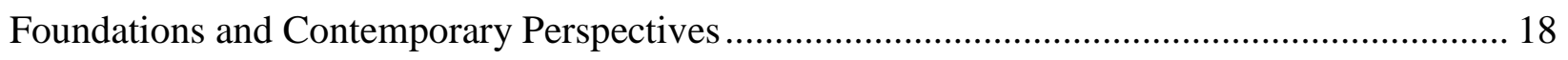

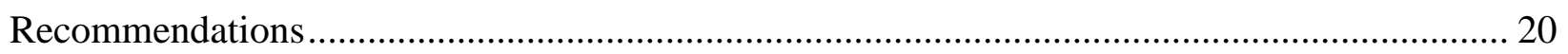

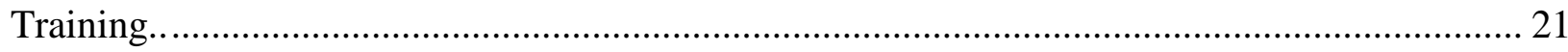

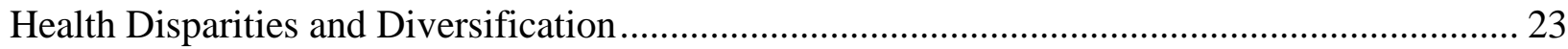

Training, Ethical, and Professional Standards ........................................................................ 24

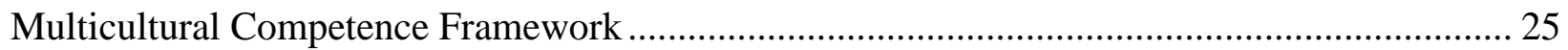

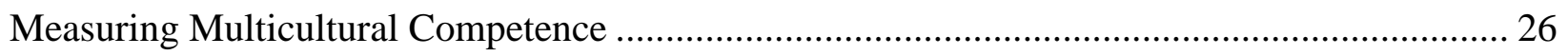

Variables Linked to Multicultural Competence........................................................................ 27

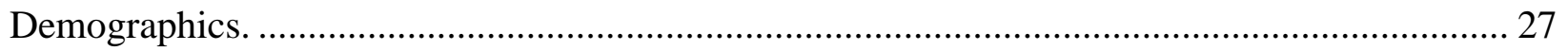

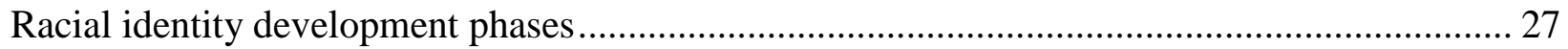

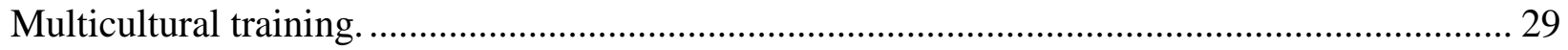

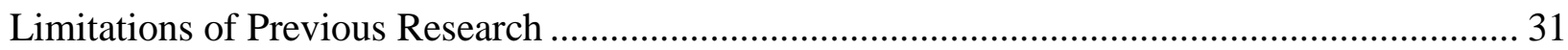

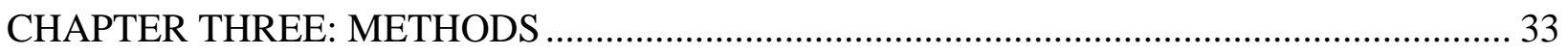

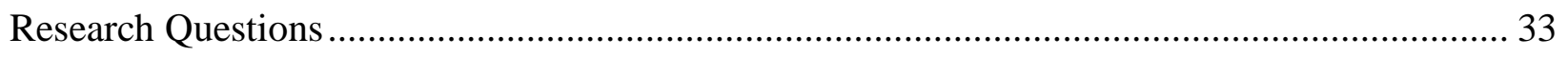

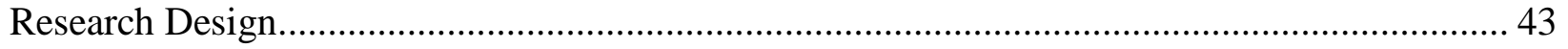

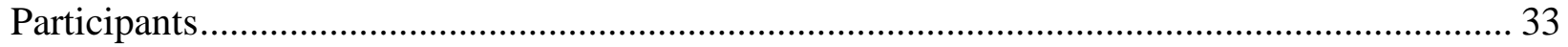

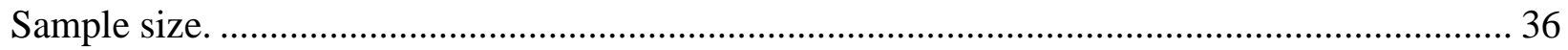

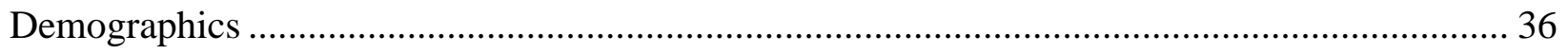




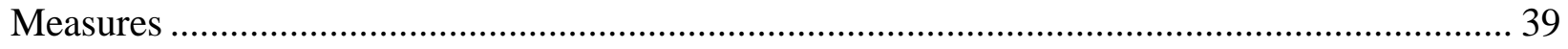

The Marlow Crowne Social Desirability Scale Short Form....................................................... 39

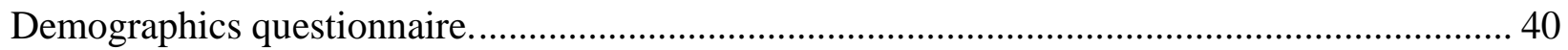

White Racial Identity Attitudes Scale................................................................................. 41

The Multicultural Counseling Knowledge and Awareness Scale............................................... 42

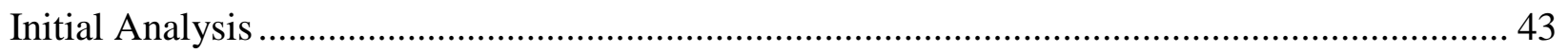

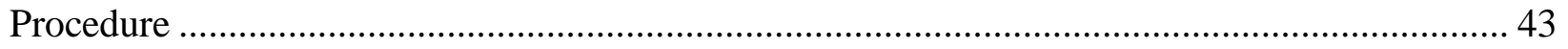

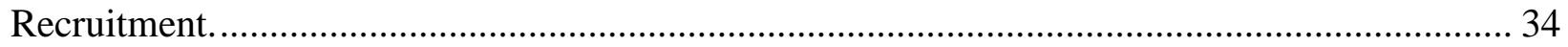

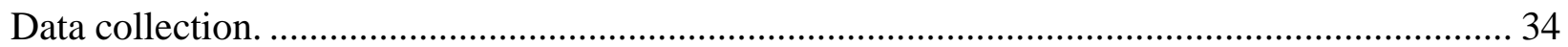

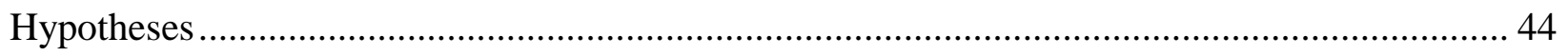

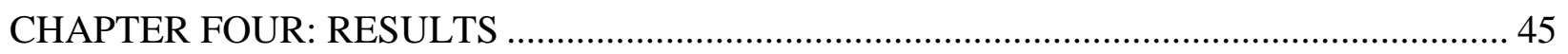

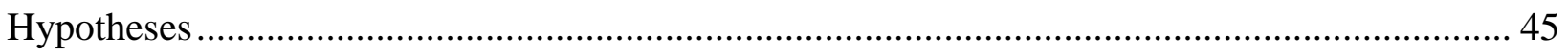

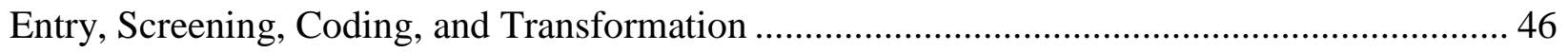

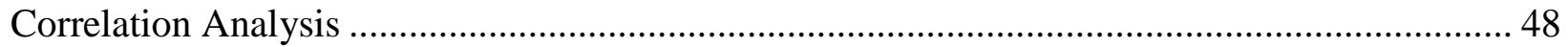

Investigated Variables Associated with the Outcome Variable.................................................... 48

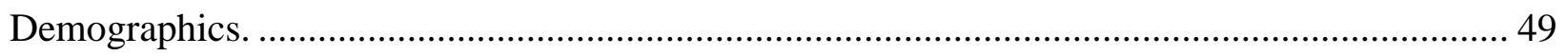

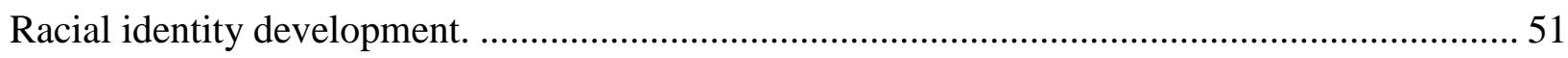

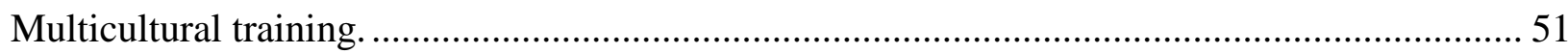

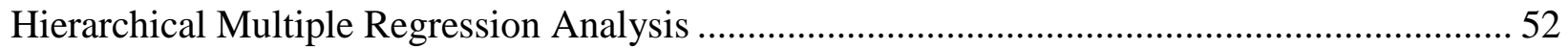

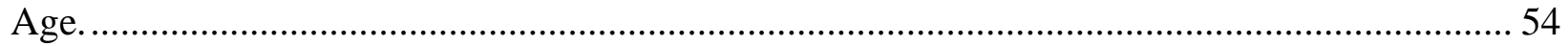

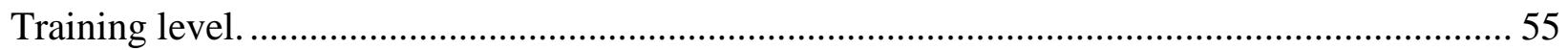

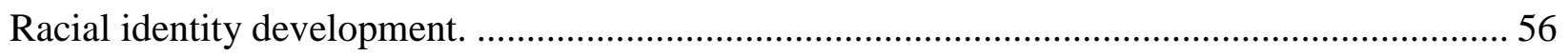

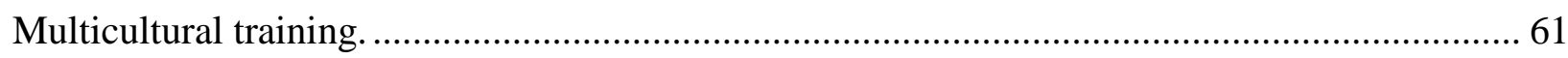

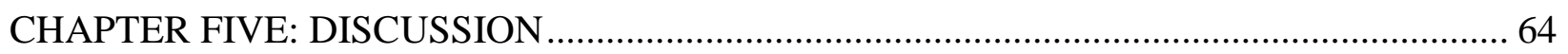

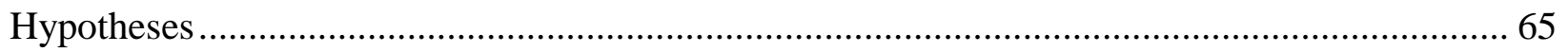

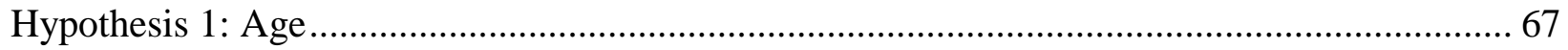

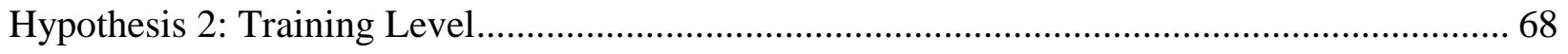

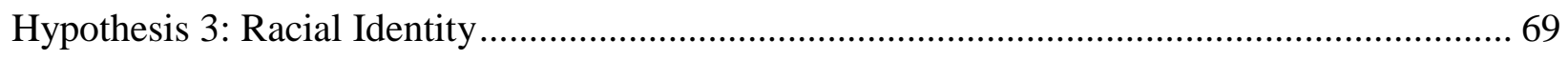

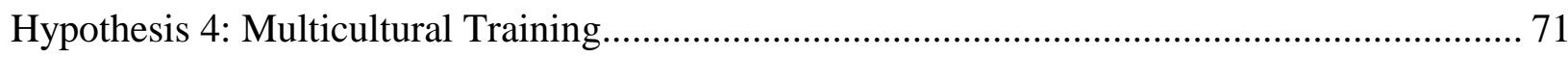

Hypothesis 5: Overall Model .................................................................................................. 74

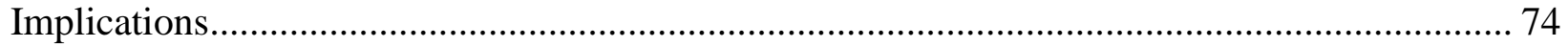

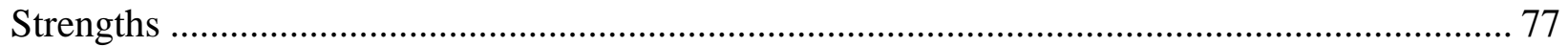

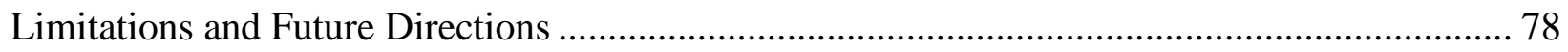




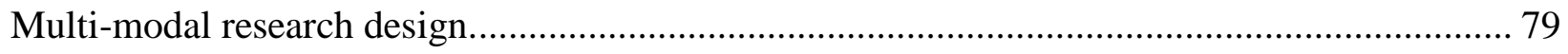

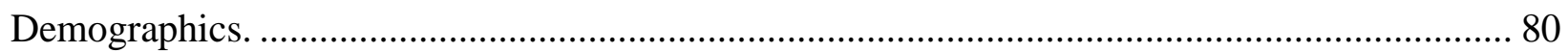

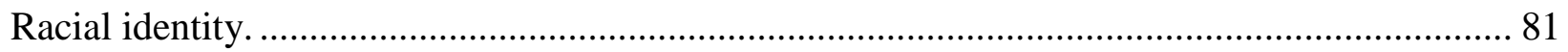

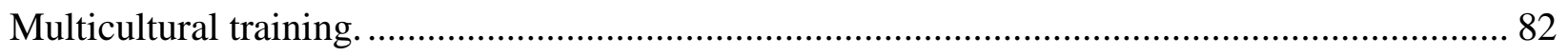

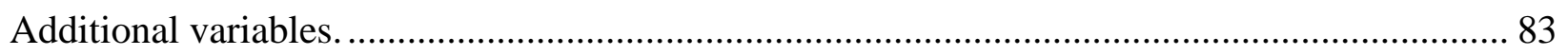

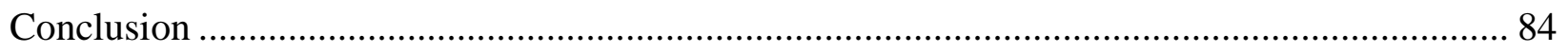

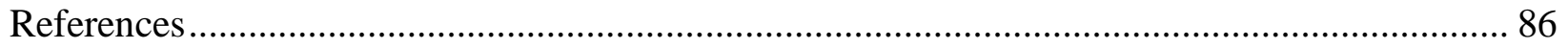

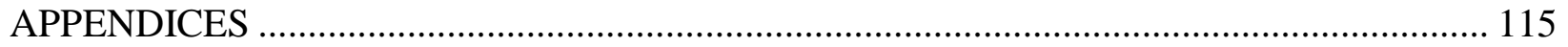

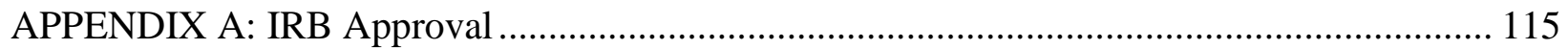

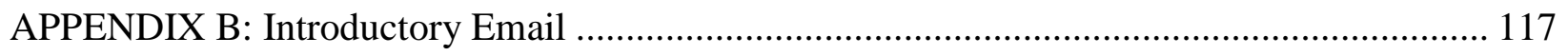

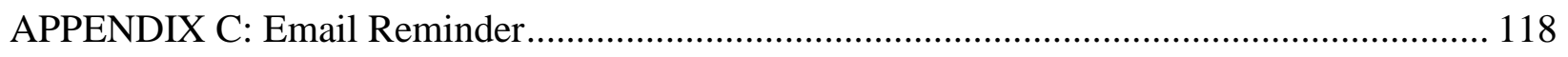

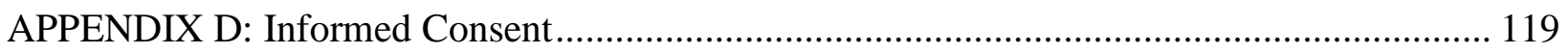

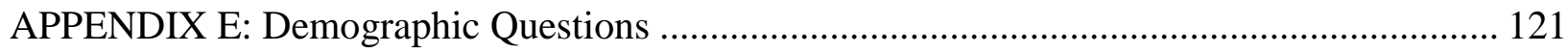

APPENDIX F: Marlow-Crowne Social Desirability Scale Short Form ................................ 124

APPENDIX G: Multicultural Counseling Knowledge and Awareness Scale .......................... 125

APPENDIX H: People of Color Racial Identity Attitudes Scale ........................................ 129

APPENDIX I: White Racial Identity Attitudes Scale...................................................... 130

APPENDIX J: Debrief and Resources.............................................................................. 131

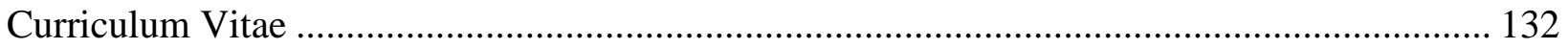




\section{CHAPTER ONE: INTRODUCTION}

While the cultural environment in the United States represents a pluralistic society with increasingly racial and ethnic minorities (REMs) seeking psychological and neuropsychological services, REMs practitioners and trainees remain underrepresented. This discrepancy highlights the importance of multicultural competencies when working with diverse groups, and previous research illustrates that multicultural competence (MC) is necessary to provide psychological services to diverse groups (American Psychological Association [APA] 2010; Cole Michalski, \& Fowler, 2017; Elbulok-Charcape, Rabin, Spadaccini, \& Barr, 2014; Furetes \& Brobst, 2002; Johnson \& Williams, 2016; Rivera Mindt, Byrd, Saez, \& Sue \& Sue, 2016; U.S. Census Bureau, 2011a). Multicultural research in neuropsychology is still developing and assessing REMs has been identified as a central challenge (Meyer et al., 2013; Wajman, Bertolucci, Mansur, \& Gauthier, 2015).

This is especially salient given that the available evidence suggests variables such as race and ethnicity influence the neuropsychological assessment process (Brickman, Cabo, \& Manly, 2006; O’Bryant, O’Jile, \& McCaffrey, 2004). Neuropsychology is a specialty within professional psychology that involves assessing cognitive and behavioral functioning (Bodin et al., 2014; Wajman et al., 2015). The APA guidelines for accreditation in professional psychology included recommendations to integrate cultural variables into training models, yet challenges related to neuropsychological evaluations with REMs persist (Puente, Perez-Garcia, Lopez, HidalgoRuzzante, \& Fasfous, 2013; Rivera Mindt et al., 2010). These challenges are due to a variety of factors including a lack of formalized guidelines providing neuropsychological services to REMs (Brickman et al., 2006; Echemendia, Harris, Congett, Diaz, \& Puente, 1997; Elbulok-Characape 
et al., 2014). The current study examined MC in neuropsychological trainees. In this chapter, neuropsychological assessment and the theoretical perspective of MC will be outlined.

The purpose of this chapter is to frame the background of neuropsychology and MC, and provide a statement of the problem, outline the purpose and significance of the study, and present the research questions that guide the investigation. Key terms will be defined, and an outline of the study will be provided. The rationale for studying MC will be delineated related to providing neuropsychological assessments to REMs.

\section{Neuropsychology}

Neuropsychology is a discipline within professional psychology that bridges the field of neurology and psychology by applying assessment practices to study brain-behavior relationships (Bodin, Roper, O’Toole, \& Haines, 2015; Jurado \& Peuyo, 2012; Nell, 2000). Neuropsychological evaluations are completed through the administration of assessments that measure different aspects of cognition. Neuropsychologists interpret test performance to evaluate individuals with "known or suspected" cognitive, psychiatric, or neurological deficits (Bodin et al., 2015, p. 99). The central role of a clinical neuropsychologist is assessment, a process that includes an intake, an interview recording relevant information, selection of appropriate tests, test administration, and scoring and interpretation of the test results. The final product is a clinical report coupled with verbal feedback to the client (Boake, 2008; Jurado \& Peuyo, 2012; Puente et al., 2013).

The practice of neuropsychological assessment was developed within a Western cultural milieu and applies cultural constructs to measure human cognition (Puente \& Agranovich, 2002). Foundational theories in neuropsychology (e.g., Sperry, 1961, 1965) delineate that all individuals should present the same behavior in response to "the same stimulus in the brain" (Puente \& 
Agranovich, 2002, p. 324). However, contemporary research clarifies that cultural variables influence neuropsychological test performance, regardless of the neurophysiology of the brain (Perez-Arce, \& Puente, 1996; Puente et al., 2013). Although the broader field of psychology developed cohesive models related to MC, the application of MC in neuropsychology is still developing (Cole, 1997; Elbulok-Characape et al., 2014; Puente et al., 2013; Rivera Mindt et al., 2010; Van Gorp, Meyers, \& Drake, 2000).

\section{Multicultural Competence}

The current study conceptualized MC as the multicultural knowledge, awareness, and skills needed to provide psychological services (Sue, Arredondo, \& McDavies, 1992; Sue et al., 1982; Sue \& Sue, 2016). Several factors led to the increased focus of MC in professional psychology, including: the racial diversification of the United States, empirical findings supporting the clinical necessity for MC, and revisions in the training, ethical, and professional standards set forth by the APA (D’Andrea, Daniels, \& Heck, 1991; Sue \& Sue, 2016). A salient area of multicultural research in the helping professions is consideration of the relationship between multicultural training and MC. Multicultural training (e.g., number of multicultural research projects and workshops, and time designated to multicultural/diversity themes in coursework and supervision) has been shown to contribute to perceived MC. Researchers have

identified additional variables as potential predictors of MC, including demographics and phases of racial identity development (Chao, Wei, Good, \& Flores, 2011; Chao, 2013; Constantine, 2002; D’Andrea et al., 1991; Dickson \& Jepsen, 2007; Hill, Vereen, McNeal, \& Stotesbury, 2013; Johnson \& Williams, 2015, Lee \& Khawaja, 2013; Middleton et al., 2005; Neville et al., 1996; Ready \& Veague, 2014). \& Williams, 2015; Middleton et al., 2005; Neville et al., 1996; Ready \& Veague, 2014). 


\section{Multicultural Competence and Neuropsychology}

There is a lack of research examining competencies necessary to assess REMs in neuropsychology (Wajman, et al., 2015). In fact, little is known about multicultural assessment practices within neuropsychology, and Elbulok-Characape et al. (2014) concluded that only one previous study investigated neuropsychological assessment practices with REMs (e.g., Echemendia et al., 1997). More information is available related to cross cultural neuropsychology, which compares neuropsychological assessment data from individuals from a minority group to those from a majority group (Judd et al., 2009; Perez-Arce \& Puente, 1996; Puente et al., 2013).

Empirical findings from this literature illustrate ethnic group differences in neuropsychological test performance, despite matching groups according to age, education, gender, and income (Artiola, Heaton, Hermosillo, 1998; Manly, Byrd, Touradji, \& Stern, 2004). Race and ethnicity are socially constructed concepts with little genetic or biological meaning, and recommendations include refining the tests and norms used to assess cognitive ability, as well as improving service delivery on the part of the provider. This includes expanding multicultural training and professional competencies related to assessing REMs (Echemendia et al., 1997; Elbulok-Charcape et al., 2014; Manly et al., 2004; Puente et al., 2013; Rivera Mindt et al., 2010).

\section{Problem Statement}

Researchers emphasized the need for clearer guidelines for "trainees, test publishers, researchers, and clinicians about the neuropsychological evaluation” of REMs (Wajman et al., 2015, p. 215). Despite evidence that neuropsychological assessment can be applied crossculturally, it "would be foolish" to assume that neuropsychological assessment is exempt from 
biases (Horton, 2008, p. 542). The application of MC in neuropsychology is still developing, and "the role of culture in neuropsychology has traditionally been ignored" (Puente \& Agranovich, 2004, p. 322). According to Rivera Mindt et al. (2010), there is a lack of integration of multicultural issues in training, resulting in a need for "culturally competent neuropsychological services" (p. 429). This is salient given that REMs face healthcare and diagnostic disparities within professional psychology (Bray, 2009; Rivera Mindt et al., 2010).

More than one decade ago, Van Gorp et al. (2000) called upon the neuropsychology subspecialty, arguing that neuropsychologists are not prepared to understand multicultural issues required by practice standards, and encouraging training programs to adhere to the multicultural guidelines set forth by the APA. One decade later, Rivera Mindt et al. (2010) called the specialty to action to improve the delivery of neuropsychological services to REMs, highlighting the need to integrate multicultural training. Bryd (2018) and Rivera Mindt (2018) additionally advocated for systemic changes to include cultural neuropsychology in teaching, training, and research. However, previous research did not develop a cohesive framework to conceptualize MC in up and coming neuropsychologists. A need remains for a model encompassing factors that contribute to MC in neuropsychological trainees. Thus far, no studies have utilized instruments to measure $\mathrm{MC}$ in neuropsychological trainees. This study is an initial step to investigate neuropsychological trainees' perceived MC.

\section{Purpose of the Study}

The primary purpose of this study was to assess the level of perceived MC among neuropsychological trainees at the doctoral, internship, and postdoctoral levels. This goal was achieved by surveying current neuropsychological trainees about demographics, phases of racial identity development, multicultural training, and perceived MC. Variables that predicted MC are 
outlined in the results section, and how trainees may potentially develop MC is offered. A set of applications that have specific value to develop MC in neuropsychology were revealed. Primary analysis focused on the relationships between variables that contribute to MC.

\section{Significance of the Study}

Health service psychology is required to meet the needs of a diverse society, and the literature calls for multicultural research in neuropsychology (Bray, 2009; Van Gorp et al., 2000; Rivera Mindt et al., 2010). Findings from the current study may be beneficial to training directors whose responsibility it is to prepare the next generation of psychologists to be professionally competent in a range of topics, including multiculturalism. The results may assist training programs in their efforts to train effective neuropsychologists and to adhere to the Multicultural Guidelines: An Ecological Approach to Context, Identity, and Intersectionality (APA, 2017). Finally, those interested in ways to improve neuropsychological practice may find the results meaningful. The following research questions were addressed in this study:

\section{Research Questions}

1. Does age predict perceived MC (as measured by an adapted version of the Multicultural Knowledge and Awareness Scale [MCKAS]; Kutalyi, 2004; Ponterotto et al., 2002)?

2. Does training level (e.g., graduate, internship, post doctorate) predict perceived MC (as measured by the MCKAS)?

3. Do racial identity development phases (as measured by the White Racial Identity Scale [WRIAS]; Helms \& Carter, 1990) predict perceived MC (as measured by the MCKAS)?

4. Does multicultural training (number of multicultural research projects and workshops and time designated to multicultural diversity themes in coursework and supervision) predict perceived MC (as measured by the MCKAS)? 
5. Overall, do models comprised of age, training level, WRIAS phases, and multicultural training (number of multicultural research projects and workshops and time designated to multicultural/diversity themes in coursework and supervision) have a statistically significant effect on perceived MC (as measured by the MCKAS)?

Hierarchical multiple regression analysis (HMRA) was performed to test four hypotheses. The hypotheses focused on the predictive ability of each predictor variable relative to the outcome variable, perceived MC. After controlling for social desirability (as measured by the Marlow-Crowne Social Desirability Scale-Short Form; MCSDS-SF) the following hypotheses were addressed in this study:

Hypothesis 1: Age will account for additional statistically significant variance in participant scores on the MCKAS. This was tested with HMRA, with MCKAS scores serving as the outcome variable, and age as the predictor variable.

Hypothesis 2: Training level will account for additional statistically significant variance in participant scores on the MCKAS. This was tested with HMRA, with MCKAS scores serving as the outcome variable, and training level as the predictor variable.

Hypothesis 3: Participant scores on the WRIAS will account for additional statistically significant variance in scores on the MCKAS. This was tested with HMRA, with MCKAS scores serving as the outcome variable and scores on the WRIAS as the predictor variable.

Hypothesis 4: Multicultural training (number of multicultural research projects and workshops and time designated to multicultural/diversity themes in coursework and supervision) will account for additional statistically significant variance in scores on the MCKAS. This was tested with HMRA, with MCKAS scores serving as the outcome variable and multicultural training as the predictor variable. 
Hypothesis 5: Overall, models comprised of age, training level, WRIAS Phases, and multicultural training (number of multicultural research projects and workshops and time designated to multicultural/diversity themes in coursework and supervision) will have a statistically significant effect on MCKAS scores. This was tested with HMRA, with MCKAS serving as the outcome and variable, and age, training level, WRIAS phases, and multicultural training as the predictor variables.

\section{Operational Definitions}

1. Social Desirability: as measured by the MCSDS-SF (Appendix F), is the tendency to respond in a way that reflects socially acceptable responses rather than authentic feelings or behaviors (Perinelli \& Gremigni, 2016).

2. Demographics: current level of training (i.e., doctoral, internship, postdoctoral), age, gender, target of discrimination based on social identity, proficiency in languages other than English, racial/ethnic diversity of community of origin, and visitation/residence in countries different from country of origin.

3. Racial Identity Development: as measured by the WRAIS (Appendix I). Refers to how people understand and feel about their race and the race of others and occurs in fluid phases (Bernard \& Goodyear, 2014; Helms, 1995a, Ladany, Brittan-Powell, \& Pannu 1997). The distinction between racial category (e.g., White or Black), and racial identity development is that racial category does not represent how people understand and feel about their race and the race of others (Helms, 1990).

4. Multicultural training: number of multicultural research projects and workshops, and time designated to multicultural/diversity themes in coursework and supervision. 
5. Multicultural Competence: as measured by an adapted version of the MCKAS (Appendix G), refers to the multicultural awareness, knowledge, and skills needed to provide psychological services to diverse groups (Sue \& Sue, 2016). The MCKAS is self-report measure, and MC is also referred to as self-reported MC and perceived MC.

6. Neuropsychological assessment: involves evaluating individuals with known or suspected brain injury or illness, with focus on specific regions in the brain associated with behavior and cognitive functioning (Bodin et al., 2015; Horton, 2008; Jurado \& Peuyo, 2012; Nell, 2000).

7. Racial and Ethnic Minorities: Used interchangeably with persons of color to refer to African Americans, Hispanics/Latinos, Asians/Asian Americans, Native Hawaiians and other Pacific Islanders, American Indians and Alaska Natives (Johnson \& Williams, 2015; U.S. Census Bureau, 2011b).

\section{Summary}

This study examined perceived MC and attempted to identify variables that predict MC in a sample of neuropsychological trainees. Multicultural research provides critical information to inform the field of psychology at large and professionals in neuropsychology to ensure a future of competent clinicians. The chapters that follow include a review of the literature, methodology for the research, results, and interpretations. In chapter two the literature in neuropsychology is reviewed, as well as studies that examined MC more broadly in psychology. In chapter three the methodology and research design are detailed, as well as the instrumentation and data collection procedures. In chapter four the results are presented, and in chapter five interpretations, limitations, and future directions are offered. 


\section{CHAPTER TWO: REVIEW OF THE LITERATURE}

This chapter provides a review of the literature that informs the rationale, study design, and context for investigating multicultural competence (MC) in neuropsychological trainees. Neuropsychological assessment and relevant MC literature are summarized, including the theoretical and historical underpinnings of each topic. Social desirability in relation to perceived MC is outlined, as well as variables that have been identified as predictors of MC. These variables include: (a) age, (b) training level, (c) racial identity development phases, and (d) multicultural training (Castillo, Brossart, Reyes, Conoley, \& Phoummarath, 2007; Chao, 2013; Chao, Meifen, Glenn, \& Flores, 2011; Constantine \& Ladany, 2002; D’Andrea, Daniels, \& Heck, 1991; Dickson \& Jepsen, 2007; Johnson \& Williams, 2015; Lee \& Khawaja, 2013; Middleton, Stradler, \& Simpson, 2005; Neville et al., 1996; Ottavi, Pope-Davis, \& Dings, 1994; Sodowsky, Kuo-Jackson, Richardson, \& Corey, 1998). Lastly, previous research limitations are presented.

\section{Multicultural Competence and Neuropsychological Assessment}

Multicultural competence defines the awareness, knowledge, and skills needed to provide psychological services to individuals from diverse backgrounds, while neuropsychology is a specialty within professional psychology that applies assessment practices to study brainbehavior relationships (Bodin, Roper, O’Toole, \& Haines, 2015; Jurado \& Peuyo, 2012; Nell, 2000; Sue \& Sue, 2016). Despite the diversification of the United States and those seeking neuropsychological services, REM trainees and practitioners remain underrepresented (Cope et al., 2016; Rivera Mindt et al., 2010; Wajman et al., 2015). This discrepancy highlights the importance of competencies for working with diverse groups. The past four decades represent multicultural trends in the broader field of psychology, however, sociocultural research within 
neuropsychology is still developing (Diaz-Santos \& Hough, 2016; Hill, et al., 2013; Pedraza \& Mungas, 2008; Puente et al., 2013; Rivera Mindt et al., 2010; Wajmam et al., 2015).

This is especially relevant given that cultural variables influence the neuropsychological assessment process. One way to address diagnostic disparities is to improve the tests available to assess REMs. For example, Puente et al. (2013) encouraged expansion of norms and tests that meet APA ethical standards. Researchers also recommended developing multicultural training standards, however it remains unclear how MC is integrated in neuropsychology training (Rivera Mindt, 2018). These limitations underscore the importance of culture in clinical neuropsychology and the relevant history of neuropsychological assessment (Agranovich \& Puente, 2007; Puente et al., 2013)

\section{Foundations and Contemporary Perspectives}

Early in the field of psychology between group differences on tests and measurements were attributed to genetic factors, while contemporary literature indicates that cultural variables, including inherent biases of assessments and unrepresentative normative samples, account for differences between groups. The artifacts of outdated beliefs, as well as traditionally less focus on cultural variables in neuropsychology have implications in the present and contribute to the challenges associated with assessing REMs (Neisser et al., 1996; Rivera Mindt et al., 2010).

The term neuropsychology was first used in 1913 and became a formalized specialty within psychology in the 1940s (Bodin et al., 2015). Commonly used neuropsychological assessments were developed and standardized with White, European American populations and are generally not applicable to other populations (Manly, 2018; Sashidharan, Pawlow, \& Pettibone, 2012). These foundational measurement devices are subject to content and construct biases in that tests developed to measure constructs in one culture may not be appropriate for 
other cultures. Unaccounted for cultural biases raise the likelihood for misdiagnosis of cognitivebased disorders (Elbulok Characpe et al., 2014; Puente et al., 2013; Wajman et al., 2015).

In fact, throughout the 1900s, results from cognitive assessments contributed to widely accepted inferior cognitive abilities of REMs (Shultz \& Shultz, 2014). Information from vocational assessment of returning soldiers from World War I indicated that individuals who identified as Black had lower intelligence quotients than individuals who identified as White. Yerkes (1920) and Goddard (1914) labeled Russians, Jews, Hungarians, and Italians whose mental ages were less than 13 years as "feeble minded," and assessment results were utilized to support policies to curtail immigration and control reproduction of REMs (Puente et al., 2013; Shultz \& Shultz, 2012). Although theorists such as Vygotsky (1978) and Luria (1976) laid the groundwork for cultural neuropsychology, Puente et al. (2013) underscored that the application of cultural perspectives in neuropsychology thereon has been limited.

Contemporary empirical findings indicate that REMs score lower on widely used cognitive assessments compared to White peers even after controlling for variables such as education (Puente et al., 2013). For example, Carlson, Brandt, Carson, and Kawas (1998) evaluated neuropsychological assessment data in a sample of 21 African American individuals and 51 European American individuals and found statistically significant lower scores in the African American group, despite equivalent education between groups (Carlson et al., 1998). Misinterpretations of these differences perpetuate racist attitudes and contribute to diagnostic disparities. For example, literature such as the The Bell Curve (Henderson \& Murry, 1994) and articles by Jenson and Lynn (2002) misattributed race and skin pigmentation to reflect “deeper biological differences” between populations (Pedraza \& Mungas, 2008, p. 184). These research agendas "lead to dangerous and irresponsible biological and genetic interpretations" of 
cognitive ability (Manly, 2005b, p. 272). Alternate explanations for between group differences include cultural variables such as the content and construct biases of commonly used neuropsychological tests, and limitations in test standardization, translation, and norming procedures (Gould, 1996; Rivera Mindt et al., 2010). Race is socially constructed with "insufficient basis in genetic or true biology," and the position that REMs have deficient genes stymies empirical research (Gould, 1996; Manly, 2005b; Puente et al., 2013; Wajman et al., 2015, p. 213).

It is important for up and coming neuropsychologists to be aware of the history of tests and measurement in psychology, as well as the limitations of neuropsychological assessments (Manly, 2005b; Rivera Mindt et al., 2010; Wong, Strickland, Fletcher, Janzen, Ardila, \& Reynolds, 2000). As such, the measure chosen to examine perceived MC in the current study, (MCKAS; Appendix G), includes items such as, "I am aware some research indicates that minority clients are more likely to be diagnosed with neuropsychological impairment than are majority clients." Although no standardized MC training guidelines exist in neuropsychology, researchers have provided recommendations (Rivera Mindt et al., 2010; Van Gorp et al., 2000).

\section{Recommendations}

For example, the APA (2003) ethical standards stated that psychologists should choose valid and reliable assessments based on the population of interest. Researchers recommended selecting measures that are translated appropriately with adequate norms (Diaz-Santos \& Hough, 2016; Puente et al., 2015). Furthermore, Byrd (2018), Manly (2018), and Rivera Mindt (2018) advocated for clearer guidelines about how to effectively assess REMs, given the limited norms and test translations available, while Puente et al. (2013) cautioned that, "simply warning the reader that the report may have inappropriate conclusions due to lack of understanding of the 
context of the individual is tantamount to simply shifting the responsibility of that issue from the author to the reader" (p. 235). Solely increasing awareness of cultural variables is insufficient in developing competencies necessary to assess cognitive ability (Puente et al., 2013).

Recommendations also included expanding brief guidelines about providing services to REMs and focusing training in multicultural topics (Diaz-Santos \& Hill, 2016; Echemendia et al., 1997; Elbulok-Characape, Rabin, Spadaccini, \& Barr, 2014; Pedraza \& Mungas, 2008; Puente et al., 2015; Van Gorp et al., 2000).

Training. As neuropsychology has grown during the past several decades, training standards evolved. Prior to the 1970s training was not well documented, and it was not until 1980 that the Division of Clinical Neuropsychology (Division 40) of the APA was formed (Bodin et al., 2015). Several professional organizations, such as the International Neuropsychology Society (INS) progressed training guidelines further, and the Houston Conference in 1997 provided a competency-based model across levels of training (Bodin et al., 2015). Although Houston Conference Guidelines (1997) underscored the importance of multiculturalism, this focus was aspirational in nature with limited integration in training (Bodin et al., 2015; Hannay, 1998; Van Gorp et al., 2000). A need to further develop multicultural training standards in neuropsychology remains (Horton, 2008; Manly, 2018; Puente \& PerezGarcia, 2000; River Mindt, 2018).

For example, Elbulok-Charcape et al. (2014) surveyed 512 neuropsychologists and concluded one third of respondents indicated no previous training to work with REMs. This is supported by data presented by Hui (2012) where $39 \%$ of 36 neuropsychology postdoctoral programs made no mention of multicultural terms in online program descriptions. These findings raise concern that multicultural training is not emphasized in neuropsychology. 
Echemendia et al. (1997) also observed trends indicating a lack of multicultural training in neuropsychology. Researchers surveyed 911 neuropsychologists, and over $80 \%$ of the sample felt either somewhat competent or not at all competent to provide neuropsychological assessments to Hispanic individuals. This finding raises the potential for invalid assessment practices and misdiagnosis of cognitive-based disorders (Echemendia et al., 1997). Although Echemendia et al. (1997) provided one of the only studies assessing competence providing neuropsychological assessments to REMs; a single-item self-report scale measured competence, which poses limitations to the study design. Future directions include expanding focus to trainees in neuropsychology and using valid/reliable measures.

To date, there are no standardized multicultural competencies in neuropsychology. In the wake of what Bodin et al. (2015) called a "competency movement," training in neuropsychology did not progress in parallel with MC trends (p. 103). Examining variables that contribute to MC in neuropsychological trainees may elucidate challenges, strengths, and future directions in assuring quality of care to those seeking neuropsychological services. Researchers have proposed such guidelines, based on the MC definition by Sue et al. (1982), that outlines the awareness, knowledge, and skills necessary to provide services to diverse groups.

Researchers applied this model to neuropsychology. For example, Diaz-Santos and Hough (2016) defined "know the other," as attaining knowledge about different cultures and worldviews; "know yourself," as self-awareness about race and social realities; and "know the assessment" as the skills necessary to choose appropriate assessments (p.12). Additionally, Rivera Mindt et al. (2010) outlined: knowledge of worldviews and how sociopolitical variables affect assessment; awareness of values and attitudes that influence neuropsychological services; and, skills to appropriately assess REMs. For the purposes of the current study, the MC 
definition by Sue et al. (1992) was applied to a sample of neuropsychological trainees.

Additional variables helped moved MC to the forefront in health service psychology.

\section{Health Disparities and Diversification}

Over the past four decades, the increased focus on multicultural topics brought information to light about cultural variables that influence the delivery of psychological services. This data influenced social justice advocacy and movements to increase MC (Brickman, Cabo, \& Manly, 2006; Cabral \& Smith, 2011; Fastenau, Evan, Johnson, \& Bond, 2002; Hill et al., 2013; O’Bryant et al., 2004; Ponterotto \& Casas, 1987). Sociocultural theorists laid the groundwork for what later became MC, which grew out of additional factors such as the racial diversification of the United States and increased attention to healthcare disparities, necessitating changes in the mental health care system (Atkinson \& Israel, 2003; Gelso \& Fretz, 2014; Shultz \& Shultz, 2012; Sue, Zane, Hall, \& Berger, 2009).

Health disparities are differences between groups related to health outcomes, and Smedley, Stith, and Nelson (2003) explained that race and ethnicity significantly correlate to quality of healthcare. Especially given the diversification of the United States and those seeking psychological services, healthcare disparities are important to address. For example, the U.S. population identifies as $12.6 \%$ Black or African American, $16.3 \%$ as Hispanic, $4.8 \%$ as Asian alone, $.9 \%$ as American Indian or Alaska Native, . $2 \%$ as Native Hawaiian and Other Pacific Islander alone, 6.2\% Other Race alone, and 2.9\% as Two or More Races (U.S. Census Bureau, 2011a). Although individuals who identify as Caucasian represent the majority $72 \%$ of the population, the U.S. Census Bureau projects this will not be the case in 2050 (2011b).

Despite more than a quarter of psychologists serving REMs in their caseloads, most psychologists and trainees identify as White (Michalski \& Jacobsen, 2009; Cope et al., 2016; 
Johnson \& Williams, 2015). More specifically, Cope et al. (2016) concluded that although REM trainees in APA-accredited doctoral programs is on the rise, a majority $70 \%$ of students identify as White. Likewise, Elbulok-Charcape et al. (2014) reported 91\% of participants identified as White in a sample of 512 licensed neuropsychologists. This parallels data from the current study, where $82 \%$ of participants did not identify as persons of color. The number of participants that identified as persons of color did not support the statistical analysis chosen for the current study such that results reflect the effects of demographics, racial identity development phases, and multicultural training on the MC of White neuropsychological trainees. In response to diversification and the healthcare disparities mentioned, revisions occurred in the APA training, ethical, and professional standards (Bray, 2009; Sue et al., 2009).

\section{Training, Ethical, and Professional Standards}

Professional psychology governing bodies such as the APA and the National Institute of Mental Health (NIMH) designate MC as a national priority. For example, the APA revised training standards to reflect changes in the U.S. population, while the NIMH increased supported research focused on REM populations (Atkinson \& Israel, 2003; Korman, 1974; Sue et al., 2009; Van Gorp et al., 2000). The movement to competency-based training models complemented increased attention to multicultural research and training (Fastenau et al., 2002; Rubin et al., 2007; Sue et al., 2009).

For example, the APA first published the Guidelines on Multicultural Education, Training, Research, Practice and Organizational Change for Psychologists in 2003, based on the Sue et al. (1982) multicultural counseling competencies--revised by Sue et al. (1992); Sue et al. (1998); and Sue (2001). These guidelines were revised in 2017 due to "significant growth in research and theory regarding multicultural contexts" (APA, 2017, p. 6). Multiculturalism should 
be incorporated into multiple facets of practice, including assessment, where practitioners are encouraged to understand "the limitations and lack of potential applicability" of assessments (APA, 2017, p., 38). Psychologists have a responsibility to consider how cultural variables influence the psychological presentation of the person being assessed (APA, 2003; Puente et al., 2013).

These policy changes represent the progression of psychology as an applied science (Cole, 1997; Hill et al., 2013). Advancements in neuropsychology occurred independent of the other developments in psychology related to MC (Van Gorp et al., 2000). According to Epstein and Hundert (2002) and Sue and Sue (2016), MC is developmental, dynamic, and arranged across three domains (i.e., knowledge, awareness, and skills).

\section{Multicultural Competence Framework}

The extent to which one develops multicultural knowledge, awareness, and skills necessary to work with diverse groups broadly defines MC (Sue et al.,1992; Sue et al., 1998; Sue, 2001). More specifically, Sue et al. (1992) defined multicultural knowledge as the information clinicians know about the group with which they are working. For example, Judd (2018) underscored that neuropsychologists should know how psychological concepts might be perceived across cultures. Understanding the influence of race on the manifestation of psychological disorders is cultivated by understanding different worldviews (Sue et al., 1992). Multicultural awareness refers to awareness of self and others, as well as beliefs, attitudes, biases, and values (Bernard \& Goodyear, 2014). Clinicians should strive to be sensitive to personal biases and values systems. For example, the MCKAS (Appendix G) was used to measure perceived MC in the current study, and includes items such as, "I am aware of the value assumptions inherent in traditional assessment and understand how these assumptions may 
conflict with values of culturally diverse clients." Multicultural skills define the ability of the provider to use "culturally appropriate interventions and strategies when working with different groups" (Sue \& Sue, 2016, p. 59). This includes using culturally appropriate techniques (Sue et al., 1992).

\section{Measuring Multicultural Competence}

Although data can be collected via clients' perspectives, and/or third-party observers, much of the literature relies on self-report methodology. Self-report MC measures include: the Cross-Cultural Counseling Inventory-Revised (CCCI-R; LeFromboise, Coleman, \& Hernandez, 1991), the Multicultural Awareness/Knowledge/Skill Survey (MAKASS; D’Andrea et al., 1991); the Multicultural Competence Student Affairs-Preliminary 2 Scale (MCSA-P2; Pope \& Mueller, 2000); the Multicultural Counseling Inventory (MCI; Sodowsky, Taffe, Gutkin, \& Wise, 1994); the Multicultural Counseling Self-Efficacy Scale- Racial Diversity Form (MCSE-RD; Sheu \& Lent, 2007); the Multicultural Mental Health Awareness Scale (MMHAS; Khawaja, Gomez, \& Turner, 2009), the Multicultural Counseling Awareness Scale (MCAS; Ponterotto et al., 1996), and the MCKAS (Ponterotto et al., 2002). Overall high scores on these measures indicated higher levels of perceived MC.

The MCKAS is based on the multicultural counseling competence model brought forth by Sue et al. (1982) and was chosen for the purposes of the current study. Significant findings in the empirical literature (e.g., Chao, 2013; Constantine, 2002; Neville et al., 2006; Penn \& Post, 2014) support using the MCKAS to measure perceived MC. Kutayli (2004) adapted the MCKAS, after receiving permission from the author to do so, to be relevant to neuropsychologists. Chapter three outlines additional information about the adapted MCKAS and the other measurements that were used in the current study. 


\section{Variables Linked to Multicultural Competence}

Several variables, alone or in various combination have been shown to contribute to perceived MC, however data related to factors that contribute to MC in neuropsychological trainees is still developing. Thus, previously identified predictors of MC (i.e., demographics, racial identity development phases, and multicultural training) in health service psychology more broadly will be outlined. Much of the MC literature focuses on self-report data, and due to concerns with self-report methodology, social desirability scales are recommended to control for socially desirable responding (Pope-Davis \& Dings, 1995; Sodowsky et al., 1998).

Demographics. The available research suggests demographics contribute to perceived MC. For example, trainees further along in training report higher MC (Barden \& Green, 2014). More specifically, Barden and Greene (2014) surveyed 118 counselor education students and concluded that participants enrolled in graduate school for a longer time reported higher MC, as measured by the MMHAS. Furthermore, Johnson and Williams (2015) determined that age was a statistically significant variable related to the Awareness Subscale of the MCI in a sample of 487 White doctoral students in clinical, counseling, and school psychology programs.

Racial identity development phases. Previous research suggests that racial identity development predicts perceived MC (e.g., Chao \& Nath, 2011; Constantine. 2002; Johnson \& Williams, 2015; Middelton et al., 200; Ottavi et al., 1994). According to Middleton, ErgunerTekinalp, Williams, Stadler, and Dow (2011), "the racial identity of the individual is not mutually exclusive from one becoming a culturally competent mental health practitioner" (p. 203). Helms and Piper (1994), explained that racial identity is a developmental process occurring in fluid schemas. Each of the schemas in the order presented represents an emergence of a more advanced racial identity development (Ladany et al., 1997). 
White racial identity development consists of two phases (Helms, 1990). Phase I represents less advanced schemas of racial identity development, and includes Contact, Disintegration, and Reintegration. Phase II represents more advanced schemas of racial identity development, and includes Pseudo-Independence, Immersion/Emersion, and Autonomy. Contact refers to beliefs such as colorblindness and lack of consciousness regarding White privilege (Helms \& Carter, 2002). Disintegration refers to realizing the advantages of being White. Reintegration describes feelings of White superiority and rationalizing racism (Helms \& Carter, 1990a, 1990b, 2002). Pseudo-Independence refers to intellectualizing the implications of race and trying to help people of color reach equality. Immersion/Emersion refers to understanding race relations and accepting responsibility for racism. The final status, Autonomy, embodies a non-racist identity (Bernard \& Goodyear, 2014; Helms \& Carter, 1990a, 1990b, 2002).

Johnson and Williams (2015) surveyed 487 White doctoral students in clinical, counseling, and school psychology, and results indicated that racial identity development added statistically significant variance on the perceived MC measure, the MCI. Scores on the WRIAS accounted for $12 \%$ of the variance in scores on the Awareness Subscale, $11 \%$ of the variance in scores on the Knowledge Subscale, and 7\% of the variance on the Skills Subscale. Likewise, Middelton et al. (2005) surveyed 412 European American counselors and clinical and counseling psychologists, and results indicated that less advanced racial identity development (as measured by the WRIAS), was negatively correlated with the MCI Skills Subscale. Similarly, more advanced racial identity development (as measured by the WRIAS) was positively correlated with the MCI Skills Subscale (Middelton et al. 2005).

Moreover, Chao and Nath (2011) surveyed 313 college counselors, and results indicated that racial identity development (as measured by the WRIAS) statistically significantly mediated 
the relationship between multicultural training and perceived MC (as measured by the MCKAS). Chao (2013) and Johnson and Williams (2015) recommended training programs promote racial identity development, and future researchers investigate racial identity and MC. Literature is still developing in neuropsychology with respect to racial identity development and MC. Furthermore, limited studies in neuropsychology investigate multicultural training.

Multicultural training. Empirical data demonstrates that multicultural training is statistically significantly correlated with perceived MC (e.g., Castillo, Brossart, Reyes, Conoley, \& Phoummarath, 2007; Chao, Meifen, Good, \& Flores, 2011; Chao, 2013; Constantine, 2002; D’Andrea et al., 1991; Echemendia et al., 1997; Johnson \& Williams, 2015; Lee \& Khawaja, 2013; Neville et al., 1996). For example, Sodowsky et al. (1998) surveyed 176 university counseling center staff, and multicultural training (e.g., multicultural coursework, research, and workshops) accounted for $20 \%$ of the variance on the perceived MC measure, the MCI.

Likewise, Johnson and Williams (2015) examined multicultural training and MC in a sample of 487 White doctoral students in clinical, counseling, and school psychology programs. Multicultural training questions included program type, months of practicum experience, and percentage of coursework devoted to multiculturalism. Results indicated that multicultural training accounted for $20 \%$ of the variance on the MCI (Johnson \& Williams, 2015). Furthermore, Lee and Khawaja (2013) investigated multicultural training and perceived MC in a sample of 127 postgraduate clinical psychology students from Australia. Researchers concluded that multicultural training (i.e., therapy, supervision, and education hours) accounted for $20 \%$ of the variance on the Knowledge Subscale of the MMHAS, with therapy and supervision uniquely contributing to the variance. Multicultural training also accounted for $11 \%$ of the variance in the 
MMHAS Skill Subscale, with therapy uniquely contributing to the variance (Lee \& Khawaja, 2013).

Moreover, Ottavi et al. (1994) surveyed 128 White counseling graduate students and operationalized multicultural training as number of clinical practica, multicultural coursework and workshops, hours of clinical experience with people of color, and hours spent in supervision on multicultural issues (Ottavi et al., 1994). Results indicated that multicultural training accounted for $19 \%$ of the variance on the perceived MC measure, the MCI (Ottavi et al., 1994). Similarly, Mueller and Pope (2001) defined multicultural training as education and supervision related to multicultural topics. In a sample of 534 White student affairs practitioners, results indicated that multicultural training accounted for $29 \%$ of the variance in scores on the perceived MC measure, the MCSA-P2 (Mueller \& Pope, 2001). Additional researchers concluded that clinical experience (including supervision) accounted for $97 \%$ of the variance in the MCI Awareness Subscale (Dickson \& Jepson, 2007).

Kutayli (2004) examined multicultural training and MC in a sample of 70 neuropsychologists from the APA Division of Clinical Neuropsychology (Division 40). Variables included academic education such as multicultural research and workshops, clinical experience such as supervision, and non-academic education such as diversity of participants' family and friends. Academic education and non-academic education accounted for $34 \%$ of the variance in perceived MC, as measured by the MCKAS. Kutayli (2004) concluded that the small sample size contributed to low statistical power, and recommended future researchers follow up this data with a larger sample.

Lastly, Echemendia et al. (1997) surveyed 3,604 neuropsychologists and concluded that clinical experience with Hispanic clients accounted for $33 \%$ of the variance in perceived 
competence in working with Hispanic clients. Multicultural training was operationalized as clinical experience, supervision, and workshops. Furthermore, Echemendia et al. (2004) examined test selection as a function of perceived competence working with Hispanic clients in a sample of 475 neuropsychologists and concluded that self-reported competence did not impact test selection. Neuropsychologists may inaccurately report MC, and/or believe "that cultural and linguistic factors are not salient issues" (Echemendia et al., 2004, p. 10). Researchers used a single-item scale to assess competence which poses limitations to the study design (Echemendia et al. 1997; Echemendia et al., 2004). Future directions include investigating MC in a sample of neuropsychological trainees, with a reliable and valid scale to measure MC.

The purpose of the current study is to investigate the influence of the variables previously outlined: age, training level, racial identity development phases, and multicultural training on MC in neuropsychological trainees. The goal of advancing the profession of psychology, and specifically the subspecialty of neuropsychology, includes examining MC in up and coming professionals. One way to accomplish this is to build on the research that has been conducted regarding MC, applied to a sample of neuropsychological trainees.

\section{Limitations of Previous Research}

Hill et al. (2013) concluded that multiculturalism has been the focus of empirical research in psychology over the past four decades. Investigating cultural influences on cognition is essential for the science of neuropsychology to grow in parallel with diversification of the United States, yet the integration of MC in neuropsychology is more recent (Arganovich \& Puente, 2007; Rivera Mindt et al., 2010; Van Gorp et al., 2000; Wajman et al., 2015). As developments in neuropsychology training grow, $\mathrm{MC}$ is fundamental for progress as well. The future of $\mathrm{MC}$ in psychology and in the discipline of neuropsychology has potential. 
There is consensus that $\mathrm{MC}$ is essential for ethical practice in psychology, yet there is a lack of MC reported by neuropsychologists. Training programs are required to focus training in multicultural topics; yet it is unclear whether neuropsychology training programs have formally addressed issues to help foster MC (Rivera Mindt et al., 2010). Although researchers encouraged the development and implementation of multicultural training standards, it remains to be investigated what contributes to MC in neuropsychological trainees (Rivera Mindt, 2018, Manly, 2018). For advancements to continue in professional psychology, researching MC is important, including factors that may contribute to $\mathrm{MC}$ in up and coming neuropsychologists. Research focused on how to develop competent health service providers has the potential to advance service efficacy in psychology and improve people's lives. 


\section{CHAPTER THREE: METHODS}

The purpose of this study is to address the relationship between perceived MC in neuropsychological trainees and their demographics, as well as their racial identity development, and multicultural training. After controlling for social desirability (as measured by the MarlowCrowne Social Desirability Scale-Short Form; MCSDS-SF) the following questions were addressed in this study:

\section{Research Questions}

1. Does age predict perceived MC (as measured by an adapted version of the Multicultural Knowledge and Awareness Scale [MCKAS]; Kutalyi, 2004; Ponterotto et al., 2002)?

2. Does training level (e.g., graduate, internship, post doctorate) predict perceived MC (as measured by the MCKAS)?

3. Do racial identity development phases (as measured by the White Racial Identity Scale [WRIAS]; Helms \& Carter, 1990) predict perceived MC (as measured by the MCKAS)?

4. Does multicultural training (number of multicultural research projects and workshops and time designated to multicultural diversity themes in coursework and supervision) predict perceived MC (as measured by the MCKAS)?

5. Overall, do models comprised of age, training level, WRIAS phases, and multicultural training (number of multicultural research projects and workshops and time designated to multicultural/diversity themes in coursework and supervision) have a statistically significant effect on perceived MC (as measured by the MCKAS)?

\section{Procedure}

A quantitative descriptive research design was used, and data were collected via a selfreport questionnaire made up of the demographic questionnaire (Appendix E), the MCSDS-SF 
(Appendix F), the adapted MCKAS (Appendix G), and the PRIAS (Appendix H) or the WRIAS (Appendix I). The survey was administered electronically via Qualtrics.com. Prior to recruitment and data collection, a pilot study was performed to determine length of time for survey completion. The pilot study group included one neuropsychology intern, two postdoctoral trainees in neuropsychology, and two neuropsychologists at West Virginia University (WVU). The average time of completion from the pilot study group was $20 \mathrm{~min}$, ranging from 17 to 26 $\min$.

Recruitment. Upon receiving approval from the WVU Institutional Review Board (Appendix A), convenience sampling was used, and study participants were recruited from among neuropsychological trainees in APA or CPA-accredited doctoral programs, or internships, or APA or AACN accredited postdoctoral programs. This researcher contacted program and internship training directors and requested that they forward an electronic study announcement to potential participants (Appendix B). A reminder email was sent to training directors four weeks after the initial request (Appendix C). The approved study announcement was also forwarded to the memberships of neuropsychology trainee organization and colleagues, who forwarded it to additional organizations and trainees.

Data collection. The study announcement included a link to an anonymous online survey hosted by Qualtrics.com. No identifying information was collected, responses were confidential, and response data was securely stored on Qualtrics.com. Trainees who met study inclusion criteria and chose to participate clicked the survey link and were directed to the study's informed consent (Appendix D). Potential participants were informed that participation was voluntary, confidential, and anonymous; that there was no penalty for not participating; and, that they could withdraw from the study at any time. Participants indicated consent by clicking "yes" to the 
informed consent prior to accessing survey items. Potential participants were notified that individuals who completed the survey could enter their email addresses on a separate page to access a 5 \$ Starbucks gift certificate as compensation for their time. Participants were informed that their email addresses collected for the purposes related to the gift certificate and would not be associated with survey responses.

After completing the informed consent page, participants were directed to the survey comprised of a demographic questionnaire (Appendix E), the MCSDS-SF (Appendix F), the adapted MCKAS (Appendix G), and the PRIAS (Appendix H) or the WRIAS (Appendix I). Participants who identified as persons of color were directed to the PRIAS and participants who identified as White were directed to the WRIAS. Dooley (2001) found that item order can influence responses and that administering measures randomly avoids this problem. Therefore, survey items were administered in a counterbalanced order. The final page of the survey included a debriefing about the purposes of the study, as well as relevant resources (Appendix J).

\section{Participants}

Participants were recruited as outlined in the procedures section. Participants were trainees completing neuropsychology specialization in: APA or Canadian Psychological Association (CPA)-accredited psychology graduate programs; or internship programs; or APA or Association of Postdoctoral Programs in Clinical Neuropsychology (APPCN) accredited postdoctoral programs. Of note, the CPA and APA, through its Commission on Accreditation (CoA), agree that CPA standards are equivalent to APA standards (First Street Accord, 2017). Additionally, APPCN member programs adhere to the APA Division of Clinical Neuropsychology/Houston Guidelines with emphasis on certification through the American Board of Professional Psychology/American Board of Clinical Neuropsychology (Hannay, 
1998). Inclusion criteria for participants also included being over 18 years of age and status in one of the training programs referenced above. Convenience sampling is commonly used in counseling psychology research and was applied in the current study (Heppner, Kivlighan, \& Wampold, 1999). The selection/recruitment procedures included recruiting neuropsychological trainees in APA or CPA-accredited doctoral programs, or internships, or APA or APPCN postdoctoral programs. Participant eligibility was determined by self-report and included trainees completing specialization in neuropsychology in APA or CPA-accredited doctoral programs, or internship programs, or APA or APPCN postdoctoral programs.

Sample size. An apriori power analysis was conducted using G*Power, version 3.1.9 to determine the number of participants needed for the study (Buchner, Erdfelder, Faul, \& Lang, 2012). In psychological research, a commonly accepted power criterion is .8, and, as such, this value was chosen for the current study (Cohen, 1988). To achieve the desired medium effect size of .15 , a power of .8 , and probability level of .05 , a minimum sample size of 107 participants was required for HMRA with 6 predictor variables (Cohen, 1988; Faul, Erdfelder, Buchner, \& Lang, 2007). A total of 97 participants were included in the current study.

\section{Demographics}

A total of 157 surveys were started, and $126(80.3 \%)$ were completed. Reflecting interest in the effects of demographics, racial identity development, and multicultural training on the MC of neuropsychological trainees of color, recruitment procedures did not exclude potential participants based on race or ethnicity. However, of the completed 126 surveys, most participants $(82.3 \%)$ did not identify as persons of color, which was insufficient to support the statistical analyses identified for the study design. This is representative of the underrepresentation of REMs providers in neuropsychology and psychology and highlights the importance of MC given 
the underrepresentation of REM providers (Cope et al., 2016; Rivera Mindt, 2010). Furthermore, because White racial identity development (as assessed by the WRIAS) and racial identity development of persons of color (as assessed by the PRIAS) are distinct constructs, WRIAS and PRIAS scores could not be combined to comprise a single outcome variable. Therefore, results reflect the effects of age, training level, racial identity development phases, and multicultural training on the MC of 97 White neuropsychological trainees.

Of the 97 included participants, $25(25.8 \%)$ identified as male and $71(73.2 \%)$ identified as female. Ages ranged from 22 to 44 years $(M=29.5, S D=3.3)$. Most participants $(73.2 \%)$ did not indicate proficiency in languages other than English, did not identify with being the target of discrimination related to their social identity (92.8\%), did not identify as persons with a disability (96.9\%), did not identify as sexual orientation minorities (92.8\%), and did not identify as religious orientation minorities $(77.3 \%)$. Most participants indicated that the racial/ethnic diversity of their community of origin was mostly White $(52.6 \%)$ and that they had visited or lived in countries different from their country of origin (82.5\%). Most participants were postdoctoral trainees $(48.5 \%)$ and were receiving or had received training in clinical psychology (92.8\%). The mean number of REM clients served in the past month was $1.59(S D=.45)$.

The mean number of completed multicultural research projects was $1.15(S D=1.75)$ and completed multicultural workshops was $3.98(S D=4.73)$. On average, participants reported $14 \%$ of time designated to multicultural/diversity themes in supervision $(S D=.10)$, and $15 \%$ of time designated to multicultural/diversity themes in coursework $(S D=.11)$. Complete data on participants are recorded in Table 1. 
Table 1. Participant Demographics and Multicultural Training

\begin{tabular}{|c|c|c|c|c|}
\hline Variable & $M$ & $(S D)$ & $n$ & $(\%)$ \\
\hline \multicolumn{5}{|l|}{ Identify as person of color } \\
\hline Yes & & & 21 & $(17.7)$ \\
\hline No & & & 97 & $(82.3)$ \\
\hline Age & 29.5 & (3.3) & & \\
\hline Missing & & & 0 & - \\
\hline \multicolumn{5}{|l|}{ Gender } \\
\hline Male & & & 25 & $(25.8)$ \\
\hline Female & & & 71 & $(73.2)$ \\
\hline Missing & & & 1 & (1.0) \\
\hline \multicolumn{5}{|l|}{ Languages other than English } \\
\hline Yes & & & 26 & $(26.8)$ \\
\hline No & & & 71 & (73.2) \\
\hline Missing & & & 0 & - \\
\hline \multicolumn{5}{|l|}{ Discrimination } \\
\hline Target of discrimination & & & 6 & $(6.2)$ \\
\hline Not target of discrimination & & & 90 & (92.8) \\
\hline Missing & & & 1 & (1.0) \\
\hline \multicolumn{5}{|l|}{ Disability } \\
\hline Person with a Disability & & & 2 & (2.1) \\
\hline Not Person with a Disability & & & 94 & (96.9) \\
\hline Missing & & & 1 & $(1.0)$ \\
\hline \multicolumn{5}{|l|}{ Sexual Orientation } \\
\hline Sexual Orientation Minority & & & 6 & (6.2) \\
\hline Not Sexual Orientation Minority & & & 90 & $(92.8)$ \\
\hline Missing & & & 1 & $(1.0)$ \\
\hline \multicolumn{5}{|l|}{ Religious Minority } \\
\hline Religious Minority & & & 21 & (21.7) \\
\hline Not a Religious Minority & & & 75 & (77.3) \\
\hline Missing & & & 1 & $(1.0)$ \\
\hline \multicolumn{5}{|l|}{ Training Level } \\
\hline Graduate & & & 20 & (20.6) \\
\hline Internship & & & 30 & (30.9) \\
\hline Postdoctoral & & & 47 & $(48.5)$ \\
\hline Missing & & & 0 & - \\
\hline \multicolumn{5}{|l|}{ Field } \\
\hline Clinical & & & 90 & $(92.8)$ \\
\hline Counseling & & & 3 & (3.1) \\
\hline School & & & 3 & (3.1) \\
\hline Other & & & 1 & $(1.0)$ \\
\hline Missing & & & 0 & - \\
\hline
\end{tabular}


Table 1. Participant Demographics and Multicultural Training

\begin{tabular}{lcccc}
\hline Variable & $M$ & $(S D)$ & $n$ & $(\%)$ \\
\hline Racial/ethnic Composition of Community of Origin & & & & \\
Mostly people of color & & & 3 & $(3.1)$ \\
50-50 & & 10 & $(10.3)$ \\
Mostly White & & 51 & $(52.6)$ \\
$\quad$ Nearly all White & & 33 & $(34.0)$ \\
$\quad$ Missing & & 0 & - \\
Visited/Lived in Countries Different from Country Origin & & & \\
$\quad$ Yes & & & 80 & 82.5 \\
$\quad$ No & & & 17 & 17.5 \\
$\quad$ Missing & 1.59 & $(.45)$ & & - \\
REM clients in the past month & & & 2 & 2.1 \\
$\quad$ Missing & 1.15 & $(1.75)$ & & \\
Multicultural training activities & & & 0 & - \\
Number of Multicultural Research Projects & 3.98 & $(4.73)$ & & \\
$\quad$ Missing & & & 0 & - \\
Number of Multicultural Workshops & .14 & $(.10)$ & & \\
$\quad \begin{array}{l}\text { Missing } \\
\text { Time Multicultural themes in Supervision } \\
\quad \text { Missing }\end{array}$ & .15 & $(.11)$ & & - \\
Time Multicultural themes in Coursework & & & 0 & - \\
$\quad$ Missing & & &
\end{tabular}

Note. $(n=97)$

\section{Measures}

\section{The Marlow Crowne Social Desirability Scale Short Form (MCSDS-SF; Crowne \&}

Marlowe, 1960; Reynolds, 1982). The MCSDS-SF (Appendix F) is a 13-item scale in a true/false format and measures the extent to which social desirability influences participant responses. The MCSDS-SF includes items such as, "I am always courteous, even to people who are disagreeable." Eight items on the MCSDS-SF were reversed scored, and individual responses were totaled to produce a composite score. Higher scores indicated higher tendency towards socially desirable responding. Reynolds (1982) reported that Cronbach's alpha coefficients, as an indicator of internal consistently reliability, ranged from .70 to .80. Concurrent validity involves correlations between the measurement of interest and a previously established measure (Salkind, 2010). Reported concurrent validity between the MCSDS-SF and the standard version was .80 to 
.90, and between the MCSDS-SF and the Edwards Social Desirability Scale (Edwards, 1957) was .37 (Reynolds, 1982).

Demographics questionnaire. The specific demographics that were tested as predictors in the HMRA model were age and training level (i.e., graduate, internship, post doctorate). The demographic questionnaire (Appendix E) included 16 questions drawn from Johnson and Williams (2015), Kutalyi (2004); Lee and Khwaja (2013), and Sigeti (2013). Current level of training was assessed according to a Likert scale, $1=$ graduate, $2=$ internship, and $3=$ postdoctoral. For gender, participants were asked to select as male, female, or nonconforming. Participants were asked to indicate if they had experienced discrimination. Racial/ethnic diversity of community of origin item was assessed according to a Likert scale, $1=$ Nearly all POC, 2 = Mostly POC, $3=50-50,4=$ Mostly White, $5=$ Nearly all White. Participants were asked to indicate their proficiency in languages other than English and visitation/residence in countries other than country of origin. Participants were asked to indicate how many REM clients served in the past month, according to a Likert scale, 1 ( 0 clients) to 4 ( 5 or more clients).

Multicultural training was a key variable analyzed in the current study. Participants were asked to indicate the number of multicultural research projects and number of multicultural workshops completed. Participants were asked to indicate the proportion of their coursework dedicated to multicultural/diversity themes and proportion of their supervision dedicated to multicultural/diversity themes. The four demographic questionnaire items concerning multicultural training experiences were used to code a single, standardized multicultural training experience variable (Song, Lin, Ward, \& Fine, 2013). The data related to multicultural training was standardized by calculating z-scores for applicable demographic variables. Once standardized on the same metric, these variables were used to calculate a unitary multicultural 
training variable. The standardized multicultural training variable included questions related to: number of multicultural research projects completed; the number of multicultural workshops completed; the percentage of participants' graduate level coursework related to multicultural issues and diversity themes; and, the percentage of clinical supervision time spent discussing multicultural issues.

White Racial Identity Attitudes Scale (WRIAS; Helms \& Carter, 1990). The WRIAS (Appendix I) is a 60-item measure that was used to examine Helms's (1990) developmental model of racial identity development for participants who did not identify as persons of color. On a Likert scale ranging from 1 (strongly disagree) to 5 (strongly agree), higher scores indicated affiliation with Phase I (less advanced racial identity development) or Phase II (more advanced racial identity development). Phase I includes the schemas contact, disintegration, and reintegration. Individuals in this phase have not fully processed how privilege contributes to racism. Phase II includes the schemas pseudo-independence, immersion/emersion, and autonomy. Individuals in this phase have developed a non-racist positive identity and are committed to positive behaviors about race as well as fighting oppression. To maintain consistency with Helms (1990) as well as previous studies (e.g., Buckhard et al., 1999; Johnson \& Williams, 2015; Ottavi et al., 1994; Tokar \& Swanson, 1991) scores were calculated by adding the point values of the responses and not by mean item response. Previous studies illustrated that the Cronbach alpha coefficients for the schemas used to calculate the phases range from .31 to .82 , and do not reflect coefficients as high as the phases, which range from .67 to .78 (Miklitsch, 2005). Similarly, the Cronbach alpha coefficients for the schemas in the current study range from .40 to .80 , while the phases range from .64 to .73 . 
Validity is supported by expected relationships with other instruments. For example, Alexander (1992) surveyed 177 undergraduate students, and reported that less advanced racial identity (as measured by the WRIAS) was negatively correlated $(p<.01)$ with scores on the Rosenberg Self-Esteem Scale (RSES; Rosenberg, 1995), and more advanced racial identity (as measured by the WRIAS) was positively correlated $(p<.01)$ with RSES scores.

\section{The Multicultural Counseling Knowledge and Awareness Scale (MCKAS;}

Ponterotto, 1997; Ponterotto et al., 2002). An adapted version of the MCKAS (Appendix G) was used to examine perceived MC. Kutalyi (2004) adapted the MCKAS to be applicable to neuropsychology in that the original scale was developed for use with counselors and clinicians. In the adapted MCKAS, words such as counselor changed to neuropsychologist, for example. The MCKAS is a 32-item self-report scale comprised of two factors, Knowledge (20 items) and Awareness (12 items). Participants rated their level of agreement based on a Likert scale ranging from 1 (not at all true) to 7 (totally true). The Knowledge items are positively scored, while the Awareness items are reverse scored. Higher scores indicated higher levels of MC. Cronbach's alpha coefficients, as a measure of internal consistency reliability, was reported as ranging from .77 to .91 (Kutayli, 2004). These values are consistent with the original MCKAS.

For example, Cronbach's alpha coefficients for the original MCKAS was reported as ranging from .75 to .93 , and 10-month test retest reliability was reported as ranging from .70 to .73 (Ponterotto \& Potere, 2003). Convergent validity is supported by expected relationships with other measures, such as the MAKSS (D’Andrea, Daniels, \& Heck, 1991; Ponterotto et al., 2002). The MCKAS has statistically significant correlations in the expected direction with measures of racial identity, and Constantine (2002) observed that Phase I WRIAS scores was positively 
correlated with MCKAS scores $(p<.001)$, and Phase II WRIAS scores was negatively correlated with MCKAS scores $(p<.001)$.

\section{Initial Analysis}

In the initial analysis, the psychometric properties of each instrument were computed to determine the reliability. Descriptive and reliability statistics included means, standard deviations, and Cronbach's alpha reliability coefficients for the MCSDS-SF, the Phase I and Phase II WRIAS, and the adapted MCKAS. Results are presented in Table 2.

Table 2. Descriptive and Reliability Statistics for Study Measures

\begin{tabular}{llccccc}
\hline Construct & Measure & $\begin{array}{c}\text { Number } \\
\text { of Items }\end{array}$ & $\begin{array}{c}\text { Response } \\
\text { Range }\end{array}$ & Mean & (SD) & $\begin{array}{c}\text { Cronbach's } \\
\alpha\end{array}$ \\
\hline Social Desirability & MCSDS-SF & 13 & $0-1$ & .40 & .20 & .63 \\
\hline Racial Identity & WRIAS & 60 & $1-5$ & - & - & - \\
& Phase I & 30 & $1-5$ & 6.33 & .81 & .73 \\
& Phase II & 30 & $1-5$ & 10.16 & .82 & .64 \\
\hline Multicultural Competence & MCKAS & 32 & $1-5$ & - & - & - \\
& Total & 32 & $1-7$ & 5.32 & .58 & .87 \\
& Awareness & 12 & $1-7$ & 6.03 & .58 & .76 \\
& Knowledge & 20 & $1-7$ & 4.90 & .78 & .89 \\
\hline
\end{tabular}

Note. $(n=97)$ MCSDS-SF = Marlow Crowne Desirability Scale Short Form (Crowne \& Marlowe, 1960; Reynolds, 1982); WRIAS= White Racial Identity Attitudes Scale (Helms \& Carter, 1990); MCKAS= Multicultural Counseling Knowledge and Awareness Scale (MCKAS; Ponterotto et al., 2002).

\section{Research Design}

A quantitative descriptive, cross-sectional, survey design was used to investigate the degree to which each of the predictor variables age, training level, racial identity development, and multicultural training contribute to the outcome variable, perceived MC. Self-report data from neuropsychological trainees at the doctoral, internship, and postdoctoral levels were used. Participants were not assigned to specific manipulations or conditions in the study. Individual scores were compared, and a between-subjects design was used. Hierarchical multiple regression modeling was used to determine the relationships between MC among neuropsychological trainees, and age, training level, racial identity development, and multicultural training. 


\section{Hypotheses}

After controlling for social desirability (as measured by the MCSDS-SF) the following hypotheses were addressed in this study:

Hypothesis 1: Age will account for additional statistically significant variance in participant scores on the MCKAS. This was tested with HMRA, with MCKAS scores serving as the outcome variable and age as the predictor variable.

Hypothesis 2: Training level will account for additional statistically significant variance in participant scores on the MCKAS. This was tested with HMRA, with MCKAS scores serving as the outcome variable and training level as the predictor variable.

Hypothesis 3: Participant scores on the WRIAS would account for statistically significant variance in scores on the MCKAS. This was tested with HMRA, with MCKAS scores serving as the outcome variable and scores on the WRIAS as the predictor variable.

Hypothesis 4: Multicultural training (number of multicultural research projects and workshops completed, and time designated to multicultural diversity themes in supervision and coursework) would account for statistically significant variance in scores on the MCKAS. This was tested with HMRA, with MCKAS scores serving as the outcome variable and multicultural training as the predictor variable.

Hypothesis 5: Overall, models comprised of age, training level, WRIAS Phases, and multicultural training (number of multicultural research projects and workshops and time designated to multicultural/diversity themes in coursework and supervision) will have a statistically significant effect on MCKAS scores. This was tested with HMRA, with MCKAS serving as the outcome and variable, and age, training level, WRIAS phases, and multicultural training as the predictor variables. 


\section{CHAPTER FOUR: RESULTS}

In this research study, the associations of age, training level, racial identity development, and multicultural training (number of multicultural research projects and workshops completed, and time designated to multicultural diversity themes in supervision and coursework) on multicultural competence (MC) were examined. The primary goal was to determine the extent to which age, training level, racial identity development, and multicultural training predicted perceived MC among neuropsychological trainees. This researcher used hierarchical multiple regression analysis (HMRA) to calculate the variance accounted for by age, training level, racial identity development, and multicultural training on perceived MC. This chapter describes the results of the preliminary analysis and screening of the data, descriptive statistics for each measure, as well as the results of the statistical analysis for each hypothesis. The following research questions were addressed:

\section{Hypotheses}

After controlling for social desirability (as measured by the MCSDS-SF) the following hypotheses were addressed in this study:

Hypothesis 1: Age will account for additional statistically significant variance in participant scores on the MCKAS. This was tested with HMRA, with MCKAS scores serving as the outcome variable and age as the predictor variable.

Hypothesis 2: Training level will account for additional statistically significant variance in participant scores on the MCKAS. This was tested with HMRA, with MCKAS scores serving as the outcome variable and training level as the predictor variable. 
Hypothesis 3: Participant scores on the WRIAS will account for statistically significant variance in scores on the MCKAS. This was tested with HMRA, with MCKAS scores serving as the outcome variable and scores on the WRIAS as the predictor variable.

Hypothesis 4: Multicultural training (number of multicultural research projects and workshops completed, and time designated to multicultural diversity themes in supervision and coursework) will account for statistically significant variance in scores on the MCKAS. This was tested with HMRA, with MCKAS scores serving as the outcome variable and multicultural training as the predictor variable.

Hypothesis 5: Overall, models comprised of age, training level, WRIAS Phase I and II scores, and multicultural training (number of multicultural research projects and workshops and time designated to multicultural/diversity themes in coursework and supervision) will have a statistically significant effect on MCKAS scores. This was tested with HMRA, with MCKAS serving as the outcome and variable, and age, training level, WRIAS phases, and multicultural training as the predictor variables.

\section{Entry, Screening, Coding, and Transformation}

A total of 157 participants started the survey, and of the completed 126 surveys, most participants $(82.3 \%)$ did not identify as persons of color. This was insufficient to support the statistical analyses identified for the study design. Furthermore, because White racial identity development (as assessed by the WRIAS) and racial identity development of persons of color (as assessed by the PRIAS) are distinct constructs, WRIAS and PRIAS scores could not be combined to comprise a single outcome variable. As such, results reflect the effects of age, training level, racial identity development phases, and multicultural training on the MC of 97 White neuropsychological trainees. 
Assumptions were checked prior to running the analysis with SPSS version 25. Homoscedasticity, normality of residuals, and outliers were assessed via inspection of scatter plots and histograms as well as analyzing the mean, median, and mode of each scale. A scatterplot revealed approximately normal distribution and linearity of the data. Skewness, linearity, and kurtosis were assessed by visual review of histograms and skewness and kurtosis statistics. The assumption of independence of observation was met according to the DurbinWatson statistic (Field, 2013). Data were assessed for missing values and outliers, and response patterns were examined for consistency. To screen for outliers, the distance between different points in the distribution were analyzed via Mahanlanobis distance (Kirk, 2008). Little's Missing Completely at Random test (Little, 1986) was performed to test the assumption that the missing data was at random and there was no recognizable pattern by which the data were missing. Missing values were addressed via expectation maximization, a method common to counseling psychology research to estimate parameters and missing scores (Schlomer, Bauman, \& Card, 2010). Gender was dummy coded as a categorical variable $(0=$ male, $1=$ female $)$. Scale scores were computed with mean item responses.

The data related to multicultural training was standardized by calculating z-scores for applicable demographic variables. Once standardized on the same metric, these variables were used to calculate a unitary multicultural training variable (Song, Lin, Ward, \& Fine, 2013). The standardized multicultural training variable included questions related to: number of multicultural research projects completed; the number of multicultural workshops completed; the percentage of participants' graduate level coursework related to multicultural issues and diversity themes; and, the percentage of clinical supervision time spent discussing multicultural issues. 


\section{Correlation Analysis}

Age was statistically significantly and positively correlated with training level $(r=.38, p$ $\leq .01)$, and number of multicultural workshops completed $(r=.30, \leq p .01)$. Training level (i.e., graduate, internship, post doctorate) was statistically significantly and negatively correlated to Phase I WRIAS scores $(r=-.22, p \leq .05)$. Training level was statistically significantly and positively correlated with Phase II WRIAS scores $(\mathrm{r}=.20, p \leq .05)$, and multicultural workshops $(r=.23, p \leq .05)$. Phase I WRIAS scores was statistically significantly and negatively correlated to Phase II WRIAS scores $(r=-.25, p \leq .05)$, and time dedicated to multicultural/diversity themes in coursework $(r=-.22, p \leq .05)$. Number of multicultural workshops completed was statistically significantly and positively correlated to time dedicated to multicultural/diversity themes in supervision $(r=.35, p \leq .01)$. Time dedicated to multicultural/diversity themes in coursework was statistically significantly and positively correlated to time dedicated to multicultural/diversity themes in supervision $(r=.62, p \leq .01)$. Multicultural training was statistically significantly and positively correlated to WRIAS Phase II scores $(r=.24, p \leq .05)$, number of multicultural research projects completed $(r=.50, p \leq .01)$, number of multicultural workshops completed ( $r=.59, p \leq .01)$, time dedicated to multicultural/diversity themes in coursework $(r=.72, p \leq .01)$, and time dedicated to multicultural/diversity themes in supervision $(r=.81, p \leq .01)$. The bivariate correlation results are displayed in Table 3 .

\section{Investigated Variables Associated with the Outcome Variable}

Correlation analyses were performed to uncover the extent to which age, training level, racial identity development, and multicultural training were associated with the outcome variable, perceived MC (MCKAS scores). Social desirability was not correlated with perceived MC. Scores on the Total MCKAS statistically significantly and positively correlated with the 
MCKAS Knowledge Subscale $(r=.94, p \leq .01)$ and the MCKAS Awareness Subscale $(r=.60, p$ $\leq .01)$. The MCKAS Awareness Subscale statistically significantly and positively correlated with the MCKAS Knowledge Subscale $(r=.28, p \leq .01)$. Correlations between perceived MC and the predictor variables selected for testing in the HMRA ranged from low to medium $(r=.23, p \leq$ .05 to $r=.47, p \leq .01)$ and were consistent with hypotheses.

Demographics. Correlations between perceived MC and demographics were for the most part, low-ranging from $(r=.23, p \leq .05$, to $r=.26, p \leq .01)$. Age was statistically significantly and positively correlated with Total MCKAS $(r=.23, p \leq .01)$. Current level of training (i.e., graduate, internship, or post doctorate) was statistically significantly and positively correlated with the Total MCKAS $(r=.25, p \leq .04)$, and the MCKAS Awareness subscale $(r=.26, p \leq .01)$. Gender was not statistically significantly correlated to the outcome variable (MCKAS scores). 
Table 3. Correlations, Means, and Standard Deviations for Investigated Variables

\begin{tabular}{|c|c|c|c|c|c|c|c|c|c|c|c|c|c|c|c|}
\hline \multicolumn{16}{|c|}{ Variable } \\
\hline & & 1 & 2 & 3 & 4 & 5 & 6 & 7 & 8 & 9 & 10 & 11 & 12 & 13 & 14 \\
\hline 1 & SD & 1 & & & & & & & & & & & & & \\
\hline 2 & Gender & .00 & 1 & & & & & & & & & & & & \\
\hline 3 & Age & -.01 & -.01 & 1 & & & & & & & & & & & \\
\hline 4 & Level & -.08 & -.01 & $.38 * *$ & 1 & & & & & & & & & & \\
\hline 5 & Phase 1 & -.03 & -.02 & -.17 & $-.22 *$ & 1 & & & & & & & & & \\
\hline 6 & Phase 2 & -.06 & -.02 & .05 & $.20 *$ & $-.25 *$ & 1 & & & & & & & & \\
\hline 7 & Resear & -.09 & -.02 & .02 & .09 & .01 & .14 & 1 & & & & & & & \\
\hline 8 & Work & .11 & .12 & $.30 * *$ & $.23 *$ & -.02 & .15 & .06 & 1 & & & & & & \\
\hline 9 & Course & .14 & .14 & -.11 & -.03 & $-.22 *$ & .15 & .11 & .15 & 1 & & & & & \\
\hline 10 & Sup & .15 & .15 & .12 & .11 & -.20 & .19 & .14 & $.35 * *$ & $.62 * *$ & 1 & & & & \\
\hline 11 & $\mathrm{MT}$ & .12 & .12 & .12 & .16 & -.16 & $.24 *$ & $.50 * *$ & $.59 * *$ & $.72 * *$ & $.81 * *$ & 1 & & & \\
\hline 12 & MCA & -.06 & -.01 & .19 & $.26 * *$ & $-.47 * *$ & .12 & .02 & .07 & .11 & .17 & .14 & 1 & & \\
\hline 13 & MCK & .01 & .01 & .19 & .18 & $-.37 * *$ & $.47 * *$ & .19 & $.30 * *$ & $.32 * *$ & $.43 * *$ & $.47 * *$ & $.28 * *$ & 1 & \\
\hline 14 & MCT & -.01 & -.01 & $.23 *$ & $.25 *$ & $-.47 * *$ & $.44 * *$ & .16 & $.27 * *$ & $.30 * *$ & $.42 * *$ & $.44 * *$ & $.60 * *$ & $.94 * *$ & 1 \\
\hline \multicolumn{2}{|c|}{ Mean } & .41 & .26 & 29.48 & 2.28 & 6.33 & 10.25 & 1.15 & 3.98 & .15 & .14 & .00 & 6.04 & 4.9 & 5.33 \\
\hline \multicolumn{2}{|c|}{$S D$} & .20 & .44 & 3.28 & .79 & .81 & .82 & 1.75 & 4.73 & .11 & .20 & .65 & .58 & .78 & .59 \\
\hline
\end{tabular}

Note. $(n=97){ }^{*} p \leq .05 ;{ }^{* *} p \leq .01 . \mathrm{SD}=$ social desirability as measured by the MCSDS; Age= Age; Level= training level (i.e., graduate, internship, post doctorate); Phase 1= WRIAS Phase I less advanced racial identity development; Phase 2= WRIAS Phase II more advanced racial identity development; Resear= number of multicultural research projects; Work= number of multicultural workshops; Course $=$ time designated to multicultural/diversity

themes in coursework; Sup= time designated to multicultural/diversity themes in supervision; MT = Multicultural Training; MCA= MCKAS Awareness Subscale; MCK= MCKAS Knowledge Subscale; MCT= Total MCKAS. 
Racial identity development. Statistically significant correlations between perceived MC and racial identity development were, for the most part, low to medium — ranging from $(r=-$ $.37, p \leq .01$ to $r=.47, p \leq .01$ ). Less advanced racial identity development (Phase I WRIAS scores) were statistically significantly and negatively correlated with the Total MCKAS $(r=-.47$, $p \leq .01)$, the MCKAS Knowledge Subscale $(r=-.37, p \leq .01)$, and the MCKAS Awareness Subscale $(r=-.47, p \leq .01)$. More advanced racial identity development (Phase II WRIAS scores) were positively correlated with the Total MCKAS $(r=.44, p \leq .01)$, and the MCKAS Knowledge Subscale $(r=.47, \mathrm{p} \leq 01)$.

Multicultural training. Statistically significant bivariate correlations between perceived $\mathrm{MC}$ and multicultural training were, for the most part low to medium — ranging from $(r=.27, p \leq$ .01 to $r=.43, p \leq .01)$. Number of multicultural research projects completed was not statistically significantly correlated to perceived MC. Number of multicultural workshops completed was statistically significantly and positively correlated with Total MCKAS $(r=.27, p \leq .01)$, and the MCKAS Knowledge Subscale $(r=.30, p \leq .01)$. Time designated to diversity/multicultural themes in coursework was statistically significantly and positively correlated with Total MCKAS $(r=.30, p \leq .01)$, and the MCKAS Knowledge Subscale $(r=.32, p \leq .01)$. Time designated to diversity/multicultural themes in supervision was statistically significantly and positively correlated with Total MCKAS $(r=.42, p \leq .01)$, and the MCKAS Knowledge Subscale $(r=.43$, $p \leq .01)$. The four demographic questionnaire items concerning multicultural training experiences were used to code a single, standardized multicultural training experience variable (the number of multicultural research projects completed, the number of workshops focused on multicultural topics completed, the percentage of participants' graduate level coursework related to multicultural issues and diversity themes, and the percentage of clinical supervision time spent 
discussing multicultural issues) (Song, et al., 2013). Multicultural training was statistically significantly and positively correlated with Total MCKAS $(r=.44, p \leq .01)$ and the MCKAS Knowledge Subscale $(r=.47, p \leq .01)$.

\section{Hierarchical Multiple Regression Analysis}

Hierarchical multiple regression analysis was used to test hypothesized relationships and to assess the variance in the outcome variable (perceived MC) that was accounted for each predictor set $\left(R^{2}, \Delta R^{2}\right)$. HMRA is a flexible approach to test hypotheses related to theory. The order of each predictor variable set is determined a priori. This type of regression assesses the predictive power of each set of variables, and the unique contribution of each individual predictor variable to the variance in the outcome variable (Hoyt, Imel, \& Chan, 2008). For the current study, existing empirical findings, study research questions and hypotheses, and data related to the bivariate correlations of relationships among predictor variables and the outcome variable determined model specification (Hoyt et al., 2008). I

In reflecting on existing literature (e.g., Johnson \& Williams, 2015; Pope-Davis \& Dings, 1995; Sodowsky et al., 1998), it became apparent that the first order of predictors should be social desirability. Demographics have been shown to account for varying portions of the variance in self-reported MC (e.g., Chao, 2013; Middleton et al., 2005; Sigeti, 2013). As such, age was chosen as the second variable set and training level as the third. The literature on racial identity development and MC (e.g., Johnson \& Williams, 2015; Ottavi et al., 1994), guided the justification of the fourth set of predictors comprised entirely of racial identity phases (Phase I and Phase II WRIAS scores). Previous findings suggested that multicultural training is correlated to perceived MC (e.g., Chao, 2013; Lee \& Kawaja, 2013), and the fifth step of the HMRA was comprised of multicultural training. Data relating to multicultural training (the number of 
multicultural research projects completed, the number of workshops focused on multicultural topics completed, the percentage of participants' graduate level coursework related to multicultural issues and diversity themes, and the percentage of clinical supervision time spent discussing multicultural issues) was used to code a multicultural training variable.

Five blocks of variables were entered into the model and statistical significance was assessed for each predictor variable to interpret the unique contributions to the variance in the outcome variable. The HMRA was conducted according to a priori specifications (alpha $=.05$ ):

- In step one, scores on the MCSDS-SF were entered, which measured social desirability.

- In step two age was entered. As the second variable block, the extent to which age contributed to the variance above and beyond the variance accounted for by social desirability was examined.

- In step three, training level (i.e., graduate, internship, post doctorate) was entered. As the third variable block, the extent to which training level contributed to the variance above and beyond the variance accounted for by social desirability was examined.

- In step four, Phase I WRIAS scores (less advanced racial identity development) and Phase II WRIAS scores (more advanced racial identity development) was entered. As the third variable block, the extent to which racial identity development phases contributed to the variance above and beyond the variance accounted for by social desirability, age, and training level was examined.

- In step five, multicultural training was entered. As the fourth variable block, the extent to which multicultural training contributes to variance above and beyond the variance accounted for by social desirability, age, training level, and racial identity development phases was examined. 
The HMRA was used to calculate an estimate of variance in MC that could be attributed to the five sets of predictive variables, and the unique contributions of each of the individual predictive variables. Results from the HMRA, including the values for change in $R^{2}\left(\Delta R^{2}\right), F$ $(\Delta F)$, regression coefficients $(B)$, standard errors $(S E$ B $)$, standardized coefficients $(\beta)$ at each step are presented in Tables 4-4.2. Perceived MC was measured as total scores on the MCKAS, but also as the Knowledge and Awareness subscales. As such, the HMRA was performed three times, for Total MC, Multicultural Knowledge, and Multicultural Awareness. The first step was comprised entirely of social desirability (measured by the MCSDS-SF) and did not account for statistically significant variance in perceived MC, as measured by Total MCKAS $R^{2}=.00, F(1$, $96)=.02, p=.90$, the MCKAS Knowledge Subscale $R^{2}=.00, F(1,96)=.01, p=.92$, and the MCKAS Awareness Subscale $R^{2}=.00, F(1,96)=.37, p=.54$. See Tables 4-6 for full details of the HMRA model.

Age. In the second step, age was entered into the equation. Taken together, age and social desirability did not account for additional statistically significant variance in perceived Total MC, $R^{2}=.05, \Delta R^{2}=.05, F(2,94)=2.60, p=.08$. However, age accounted for $5 \%$ of additional statistically significant variance $\Delta R^{2}=.05, p \leq .05$. Likewise, the standard partial regression coefficient for age, $\beta=.23 t=2.28, p \leq .05$, indicated that, after controlling for social desirability, age was a unique contributor to variance in Total MC, with each standard deviation increase of age predicting an increase of .23 standard deviations on Total MC.

In the Multicultural Knowledge model, taken together, social desirability and age did not account for additional statistically significant variance, $R^{2}=.04, \Delta R^{2}=.04, F(2,94)=1.83, p=$ .17 , and the addition of age did not statistically significantly improve prediction $\Delta R^{2}=.04, p=$ .06. The standard partial regression coefficient for age, $\beta=.19, t=1.91, p=.06$, indicated that 
age was not a unique contributor to variance. In the Multicultural Awareness model social desirability and age did not account for additional statistically significant variance, $R^{2}=.04, \Delta R^{2}$ $=.04, F(2,94)=1.88, p=.16$, and age did not statistically significantly improve prediction $\Delta R^{2}$ $=.04, p=.07$. The standard partial regression coefficient for age, $\beta=.19, t=1.84, p=.07$, indicated that age was not a unique contributor to variance in perceived Multicultural Awareness.

Training level. In the third step, training level was entered into the equation. Taken together, social desirability, age, and training level accounted for $8 \%$ of the variance in Total MC scores, $R^{2}=.08, \Delta R^{2}=.03, F(3,93)=2.79, p \leq .05$. However, the addition of training level did not statistically significantly improve prediction $\Delta R^{2}=.03, p=.08$, and the standard partial regression coefficient for training level, $\beta=.19, t=1.75, p=.08$, indicated that training level was not a unique contributor to variance in Total MC.

In the Multicultural Knowledge model, taken together, social desirability, age, and training level did not account for additional statistically significant variance, $R^{2}=.05, \Delta R^{2}=.01$, $F(3,93)=1.69, p=.17$. Similarly, training level did not statistically significantly improve prediction $\Delta R^{2}=.01, p=.24$ and the standard partial regression coefficient for training level, $\beta=$ $.13, t=1.19, p=.24$, indicated that training level was not a unique contributor to variance in perceived Multicultural Knowledge.

In the Multicultural Awareness Model, taken together, social desirability, age, and training level accounted for $8 \%$ of the variance, $R^{2}=.08, \Delta R^{2}=.04, F(3,93)=2.68, p \leq .05$ and training level accounted for $4 \%$ of additional statistically significant variance $\Delta R^{2}=.04, p \leq .05$. The standard partial regression coefficient for training level, $\beta=.22, t=2.04, p \leq .05$, indicated that after controlling for social desirability and age, training level was a unique contributor to 
variance in Multicultural Awareness, with each standard deviation increase of age predicting an increase of .22 standard deviations on Multicultural Awareness.

Racial identity development. In the fourth step, racial identity development phases (Phase I and Phase II WRIAS scores) were entered into the equation as a set. In the Total MC model, taken together, social desirability, age, training level, and racial identity development accounted for $34 \%$ of variance in Total MC scores, $R^{2}=.34, \Delta R^{2}=.26, F(5,91)=9.29, p \leq .01$. Similarly, racial identity development phases accounted for $26 \%$ of additional statistically significant variance in Total MC $\Delta R^{2}=.26, p \leq .01$. The standard partial regression coefficient for Phase I racial identity, $\beta=-.36, t=-4.01, p \leq .01$, indicated that after controlling for the effects of social desirability, age, and training level, Phase I racial identity development was a unique contributor to variance in Total MC, with each standard deviation decrease on Phase I scores predicting a decrease of .36 standard deviations on Total MC. The standard partial regression coefficient for Phase II racial identity, $\beta=.30, t=3.30, p \leq .01$, indicated that after controlling for the effects of social desirability, age, and training level, Phase II WRIAS scores was a unique contributor to variance in perceived $\mathrm{MC}$, with each standard deviation increase on Phase II WRIAS scores predicting an increase of .30 standard deviations on perceived Total MC. 
Table 4. Hierarchical Multiple Regression Analysis for Prediction of Perceived Multicultural Competence Total MCKAS

\begin{tabular}{|c|c|c|c|c|c|c|c|c|c|c|c|c|c|c|c|c|c|}
\hline \multirow[b]{2}{*}{ Variable } & \multirow[b]{2}{*}{$R^{2}$} & \multirow[b]{2}{*}{$\Delta R^{2}$} & \multicolumn{3}{|c|}{$\begin{array}{l}\text { At Entry Into } \\
\text { Model }\end{array}$} & \multicolumn{3}{|c|}{$\begin{array}{c}\text { Step } \\
2\end{array}$} & \multicolumn{3}{|c|}{$\begin{array}{l}\text { Step } \\
3\end{array}$} & \multicolumn{3}{|c|}{$\begin{array}{c}\text { Step } \\
4\end{array}$} & \multicolumn{3}{|c|}{$\begin{array}{l}\text { Final } \\
\text { Model }\end{array}$} \\
\hline & & & $B$ & $\begin{array}{c}S E \\
B \\
\end{array}$ & $\beta$ & $B$ & $\begin{array}{c}S E \\
B \\
\end{array}$ & $\beta$ & $B$ & $\begin{array}{c}S E \\
B \\
\end{array}$ & $\beta$ & $B$ & $S E B$ & $\beta$ & $B$ & $\begin{array}{c}S E \\
B \\
\end{array}$ & $\beta$ \\
\hline Step 1 & .00 & .00 & & & & & & & & & & & & & & & \\
\hline $\begin{array}{l}\text { SD } \\
\text { Step } 2\end{array}$ & .05 & $.05 *$ & -.04 & .30 & -.01 & -.03 & .30 & -.01 & .01 & .30 & .00 & .02 & .25 & .01 & -.12 & .24 & -.04 \\
\hline Age & & & -- & -- & -- & .04 & .02 & $.23 *$ & .03 & .02 & .16 & .03 & .01 & .14 & .02 & .02 & .11 \\
\hline $\begin{array}{l}\text { Step } 3 \\
\text { TL }\end{array}$ & $.08 *$ & .03 & -- & -- & -- & -- & -- & -- & .14 & .08 & .19 & .05 & .07 & .07 & .03 & .07 & .04 \\
\hline $\begin{array}{l}\text { Step } 4 \\
\text { Phase I }\end{array}$ & $.34 *$ & $.26 * *$ & -- & -- & -- & -- & -- & -- & -- & -- & -- & -.03 & .01 & $-.36 * *$ & -.03 & 01 & $-35 * *$ \\
\hline $\begin{array}{l}\text { Phase II } \\
\text { Step } 5\end{array}$ & $.44 *$ & $.10 * *$ & -- & -- & -- & -- & -- & -- & -- & -- & -- & .02 & .01 & $.30 * *$ & .02 & .01 & $.23 * *$ \\
\hline MT & & & -- & -- & -- & -- & -- & -- & -- & -- & -- & -- & -- & -- & .20 & .05 & $.34 * *$ \\
\hline
\end{tabular}


Table 5. Hierarchical Multiple Regression Analysis for Prediction of Perceived Multicultural Competence Knowledge MCKAS

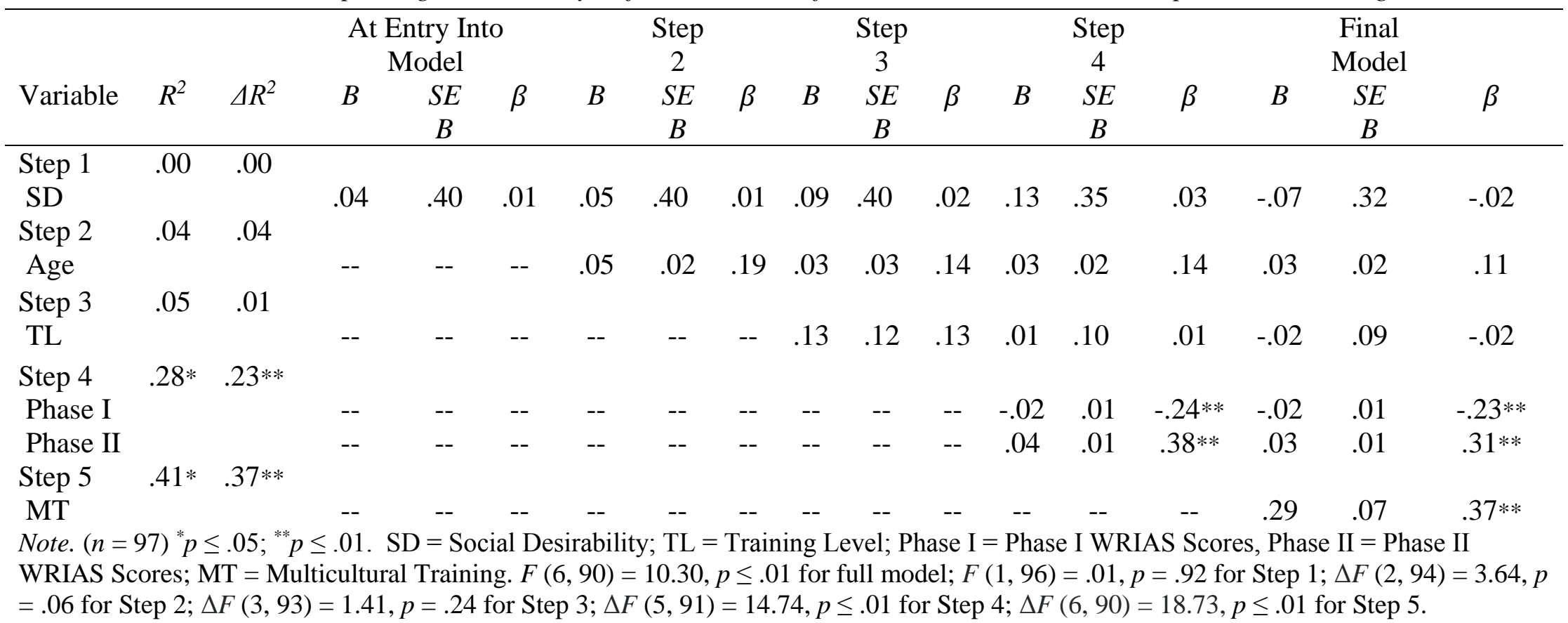


Table 6. Hierarchical Multiple Regression Analysis for Prediction of Perceived Multicultural Competence Awareness MCKAS

\begin{tabular}{|c|c|c|c|c|c|c|c|c|c|c|c|c|c|c|c|c|c|}
\hline \multirow[b]{3}{*}{ Variable } & \multirow[b]{3}{*}{$R^{2}$} & \multirow[b]{3}{*}{$\Delta R^{2}$} & \multirow{2}{*}{\multicolumn{3}{|c|}{$\begin{array}{l}\text { At Entry Into } \\
\text { Model }\end{array}$}} & \multirow{2}{*}{\multicolumn{3}{|c|}{$\begin{array}{l}\text { Step } \\
2\end{array}$}} & \multirow{2}{*}{\multicolumn{3}{|c|}{$\begin{array}{l}\text { Step } \\
3\end{array}$}} & \multirow{2}{*}{\multicolumn{3}{|c|}{$\begin{array}{l}\text { Step } \\
4\end{array}$}} & \multirow{2}{*}{\multicolumn{3}{|c|}{$\begin{array}{l}\text { Final } \\
\text { Model }\end{array}$}} \\
\hline & & & & & & & & & & & & & & & & & \\
\hline & & & $B$ & $\begin{array}{c}S E \\
B\end{array}$ & $\beta$ & $B$ & $\begin{array}{c}S E \\
B\end{array}$ & $\beta$ & $B$ & $\begin{array}{c}S E \\
B\end{array}$ & $\beta$ & $B$ & $\begin{array}{c}S E \\
B\end{array}$ & $\beta$ & $B$ & $\begin{array}{c}S E \\
B\end{array}$ & $\beta$ \\
\hline Step 1 & .00 & .00 & & & & & & & & & & & & & & & \\
\hline $\mathrm{SD}$ & & & -.18 & .30 & -.06 & -.18 & .30 & -.06 & -.13 & .29 & -.04 & -.18 & .27 & -.06 & -.21 & .27 & -.07 \\
\hline Step 2 & .04 & .04 & & & & & & & & & & & & & & & \\
\hline Age & & & -- & -- & -- & .03 & .02 & .19 & .02 & .02 & .10 & .01 & .02 & .07 & .01 & .02 & .06 \\
\hline Step 3 & $.08 *$ & $.04 *$ & & & & & & & & & & & & & & & \\
\hline $\mathrm{TL}$ & & & -- & -- & -- & -- & -- & -- & .16 & .08 & $.22 *$ & .12 & .07 & .16 & .11 & .08 & .15 \\
\hline Step 4 & $.26^{* *}$ & $.18^{* *}$ & & & & & & & & & & & & & & & \\
\hline Phase I & & & -- & -- & -- & -- & -- & -- & -- & -- & -- & -.03 & .01 & $-.44 * *$ & -.03 & .01 & $-.43 * *$ \\
\hline Phase II & & & -- & -- & -- & -- & -- & -- & -- & -- & -- & -.01 & .01 & .06 & -.01 & .01 & -.07 \\
\hline Step 5 & $.26 *$ & .01 & & & & & & & & & & & & & & & \\
\hline MT & & & -- & -- & -- & -- & -- & -- & -- & -- & -- & -- & -- & -- & .05 & .06 & .08 \\
\hline
\end{tabular}


In the Multicultural Knowledge model, taken together, social desirability, age, training level, and racial identity development accounted for $28 \%$ of variance, $R^{2}=.28, \Delta R^{2}=.23, F(5$, $91)=7.21, p \leq .01$. Likewise, racial identity development phases accounted for $23 \%$ of additional statistically significant variance $\Delta R^{2}=.23, p \leq .01$. The standard partial regression coefficient for Phase I racial identity $\beta=-.24, t=-2.57, p \leq .05$, indicated that after controlling for social desirability, age, and training level, Phase I racial identity development was a unique contributor of variance in Multicultural Knowledge, with each standard deviation decrease on Phase I scores predicting a decrease of .24 standard deviations on Multicultural Knowledge. The standard partial regression coefficient for Phase II racial identity, $\beta=.38, t=4.05, p \leq .01$, indicated that after controlling for social desirability, age, and training level, Phase II racial identity development was a unique contributor to variance in Multicultural Knowledge, with each standard deviation increase on Phase II score predicting an increase of .38 standard deviations on perceived Multicultural Knowledge.

In the Multicultural Awareness Model, taken together, social desirability, age, training level, and racial identity development accounted for $26 \%$ of variance, $R^{2}=.26, \Delta R^{2}=.18, F(5$, $91)=6.30, p \leq .0$. Likewise, racial identity development phases accounted for $18 \%$ of additional statistically significant variance $\Delta R^{2}=.23, p \leq .01$. The standard partial regression coefficient for Phase I racial identity development, $\beta=-.44, t=-4.63, p \leq .01$, indicated that after controlling for social desirability, age, and training level, Phase I racial identity development was a unique contributor to variance in Multicultural Awareness with each standard deviation decrease on Phase I scores predicting a decrease of .44 standard deviations on perceived Multicultural Awareness. The standard partial regression coefficient for Phase II racial identity development, $\beta$ 
$=-.06, t=-.58, p=.10$, indicated that Phase II racial identity development was not a unique contributor to variance in perceived Multicultural Awareness.

Multicultural training. In the fourth step, multicultural training was entered into the equation. In the Total MC model, taken together, social desirability, age, training level, racial identity development, and multicultural training accounted for $44 \%$ of variance in Total MC scores $R^{2}=.44, \Delta R^{2}=.10, F(6,90)=11.82, p \leq .05$. Likewise, multicultural training accounted for $10 \%$ of additional statistically significant variance $\Delta R^{2}=.10, p \leq .01$. This is a small effect size, and indicates that controlling for other factors, multicultural training $(\beta=.34)$ was a statistically significant predictor of Total MC in neuropsychological trainees (Cohen, 1992). The standard partial regression coefficient for multicultural training, $\beta=.34, t=4.07, p \leq .01$, indicated that after controlling for social desirability, age, training level, and racial identity development phases, multicultural training was a unique contributor to variance in Total MC, with each standard deviation increase in multicultural training scores predicting an increase of .34 standard deviations on perceived Total MC.

In the Multicultural Knowledge model, taken together, social desirability, age, training level, racial identity development, and multicultural training accounted for $41 \%$ of variance $R^{2}=$ $.41, \Delta R^{2}=.12, F(6,90)=10.30, p \leq .05$. Likewise, multicultural training accounted for $37 \%$ of additional statistically significant variance $\Delta R^{2}=.37, p \leq .01$. This is a medium effect size, and indicates that controlling for other factors, multicultural training $(\beta=.37)$ was a statistically significant predictor of perceived Multicultural Knowledge in neuropsychological trainees (Cohen, 1992). The standard partial regression coefficient for multicultural training, $\beta=.37, t=$ $4.33, p \leq .01$, indicated that after controlling for social desirability, age, training level, and racial identity development, multicultural training was a unique contributor to variance in Multicultural 
Knowledge, with each standard deviation increase in multicultural training scores predicting an increase of .37 standard deviations on perceived Multicultural Knowledge.

In the Multicultural Awareness Model, taken together, social desirability, age, training level, racial identity development, and multicultural training accounted for $26 \%$ of variance $R^{2}=$ $.26, \Delta R^{2}=.01, F(6,90)=5.34, p \leq .05$. However, the addition of multicultural training did not statistically significantly improve prediction $\Delta R^{2}=.01, p=.42$, and the standard partial regression coefficient for multicultural training, $\beta=.08, t=.82, p=.42$, indicated that multicultural training was not a unique contributor to variance in perceived Multicultural Awareness.

Overall, Total MC, Multicultural Knowledge, and Multicultural Awareness models comprised of age, training level, WRIAS Phase I and II scores, and multicultural training (number of multicultural research projects and workshops and time designated to multicultural/diversity themes in coursework and supervision) had a statistically significant effect on MCKAS scores.

\section{Summary}

This chapter outlined the results of the preliminary analysis and screening of the data, descriptive statistics, and results of the statistical analysis for each hypothesis. The primary purpose of this study was to uncover the extent to which age, training level, racial identity development, and multicultural training predicted perceived $\mathrm{MC}$ among neuropsychological trainees. Results from the bivariate correlation analysis revealed that age was positively and statistically significantly correlated with perceived Total MC, and training level was positively and statistically significantly correlated with perceived Total MC, and Multicultural Awareness. Multicultural training was positively and statistically significantly correlated with perceived 
Total MC and Multicultural Knowledge. Less advanced racial identity development was statistically significantly correlated with lower levels of perceived MC and more advanced racial identity development was statistically significantly correlated to higher levels of perceived MC.

Findings from the primary analysis (HMRA) indicated after controlling for social desirability, age, training level, and racial identity development phases, multicultural training was a statistically significant predictor of Total MC and Multicultural Knowledge. Overall, findings indicated that models comprised of social desirability, age, training level, racial identity development, and multicultural training had a statistically significant effect on MCKAS in Total MC, Multicultural Knowledge, and Multicultural Awareness. 


\section{CHAPTER FIVE: DISCUSSION}

The primary purpose of this study was to investigate the extent to which age, training level, racial identity development phases, and multicultural training predict perceived multicultural competence (MC) in neuropsychological trainees. Although the United States and those seeking psychological and neuropsychological services continues to diversify, REM trainees and practitioners remain underrepresented (Cope et al., 2016; Rivera Mindt, 2010). This discrepancy highlights the importance of competencies working with diverse groups, and previous literature illustrates that MC is necessary to provide psychological services to diverse groups (Fuertes \& Brobst, 2002; Johnson \& Williams, 2015; Middleton et al., 2005; Sue et al., 1992).

Understanding what contributes to MC among up and coming practitioners is helpful to inform training standards and application of such standards for those working with trainees. This is especially true given that up to $25 \%$ of psychology and neuropsychology caseloads are made up of REMs; while most psychologists, graduate students in psychology, and neuropsychologists identify as White (Cope et al., 2016; Echemendia et al., 1997; Elbulok-Charcape et al., 2014; Johnson \& Williams, 2015; Michalski \& Jacobsen, 2009). Likewise, 82\% of participants in the current study did not identify as persons of color. The number of participants that identified as persons of color did not support the statistical analysis chosen for the current study such that results reflect the effects of age, training level, racial identity development phases, and multicultural training on the MC of White neuropsychological trainees.

Hierarchical multiple regression analysis (HMRA) was used to determine if age, training level, racial identity development phases, and multicultural training (number of multicultural research projects and workshops, and time designated to multicultural/diversity themes in 
coursework and supervision) statistically significantly predicted perceived MC in a sample of neuropsychological trainees. The purpose of this chapter is to review the hypotheses that were tested, summarize general findings, review specific findings, discuss the implications, and describe the strengths and limitations of the study. Suggestions for future research are offered.

\section{Hypotheses}

This study's hypotheses focused on the relationships of the several predictor variables to the outcome variable, perceived MC. After controlling for social desirability (as measured by the MCSDS-SF), the following hypotheses were addressed:

Hypothesis 1: Age will account for additional statistically significant variance in participant scores on the MCKAS. This was tested with HMRA, with MCKAS scores serving as the outcome variable and age as the predictor variable.

Hypothesis 2: Training level will account for additional statistically significant variance in participant scores on the MCKAS. This was tested with HMRA, with MCKAS scores serving as the outcome variable and training level as the predictor variable.

Hypothesis 3: Participant scores on the WRIAS will account for statistically significant variance in scores on the MCKAS. This was tested with HMRA, with MCKAS scores serving as the outcome variable and scores on the WRIAS as the predictor variable.

Hypothesis 4: Multicultural training (number of multicultural research projects and workshops completed, and time designated to multicultural diversity themes in supervision and coursework) will account for statistically significant variance in scores on the MCKAS. This was tested with HMRA, with MCKAS scores serving as the outcome variable and multicultural training as the predictor variable. 
Hypothesis 5: Overall, models comprised of age, training level, racial identity phases, and multicultural training (number of multicultural research projects and workshops and time designated to multicultural/diversity themes in coursework and supervision) will have a statistically significant effect on MCKAS scores. This was tested with HMRA, with MCKAS serving as the outcome and variable, and age, training level, WRIAS phases, and multicultural training as the predictor variables.

Findings from the primary analysis (HMRA) indicated that after controlling for social desirability, age, training level, and racial identity development phases, multicultural training was a statistically significant predictor of perceived Total MC and Multicultural Knowledge. Although multicultural training did not add statistically significant variance to Multicultural Awareness, overall the Multicultural Awareness model was statistically significant. Thus, findings indicated that models comprised of social desirability, age, training level, racial identity development phases, and multicultural training accounted for statistically significant proportions of variance in Total MC, Multicultural Knowledge, and Multicultural Awareness.

Results from bivariate correlation analysis also generally supported these hypotheses and revealed statistically significant correlations between the outcome variable (perceived MC) and the predictor variables age, training level, racial identity development phases, and multicultural training. Several implications materialized, including that age was positively and statistically significantly correlated with Total MC, and training level was positively and statistically significantly correlated with Total MC and Multicultural Awareness. Multicultural training was positively and statistically significantly correlated with Total MC and Multicultural Knowledge. Less advanced racial identity development was statistically significantly correlated with lower 
levels of perceived MC and more advanced racial identity development was statistically significantly correlated to higher levels of perceived MC.

\section{Hypothesis 1: Age}

With respect to the first hypothesis, results are mixed. The three tested models (Total MC, Multicultural Knowledge, and Multicultural Awareness) indicated that after controlling for social desirability, the second variable block, comprised of age was statistically significant in the Total MC model, accounting for 5\% of variance in Total MC scores. As an individual variable, age was a unique statistically significant predictor in Total MC. However, age did not have a unique statistically significant relationship to Multicultural Knowledge or Multicultural Awareness. Positive bivariate correlations between age and total perceived $\mathrm{MC}(r=.23)$ parallel HMRA results as well as findings in the literature (e.g., Barden \& Greene, 2014; Chao, 2012; Johnson \& Williams; 2015), and highlight that MC is a process not independent from demographics such as age.

A potential explanation for the relationship between age and perceived $\mathrm{MC}$ is that $\mathrm{MC}$ may increase as individuals gain more life experiences. Age may not only correlate to more opportunities to engage in multicultural training, but also more opportunities for personal experiences that may impact MC development. With more life experiences, older participants may also have had time to experience other cultures and develop MC. Older participants also may have had more time for self-reflection, which additionally can impact perceived MC. Results from the current study support previous data that indicates age is important to consider within the MC framework (e.g., Barden \& Greene, 2014; Chao, 2012; Johnson \& Williams; 2015). Furthermore, results align with the theoretical foundations of MC. For example, Sue et al. (2009) highlighted that MC is a developmental process, one that is never achieved but rather, 
trainees continue to build their awareness, knowledge, and skills related to providing services to diverse groups over time. Future directions include further exploration of demographics variables like age and MC.

\section{Hypothesis 2: Training Level}

With respect to the second hypothesis, results are mixed. The three tested models (Total MC, Multicultural Knowledge, and Multicultural Awareness) indicated that after controlling for social desirability and age, the third variable block, comprised of training level was statistically significant in the Multicultural Awareness model, accounting for $4 \%$ of variance in scores. As an individual variable, training level was a unique statistically significant predictor in Multicultural Awareness. However, training level did not have a unique statistically significant relationship to Total MC or Multicultural Knowledge.

Lewis (2004) conceptualized an analogous finding and concluded that participants were better able to rate their level of Multicultural Awareness than their Multicultural Knowledge. Data from bivariate correlation analysis in the current study corroborate with this finding such that participants further along in training reported higher Total MC $(r=.25)$ and Multicultural Awareness $(r=.26)$, but not Multicultural Knowledge. Multicultural Knowledge refers to understanding different worldviews and diverse groups, whereas Multicultural Awareness refers to acknowledgement of biases and assumptions that may influence working with diverse groups (Ponterotto \& Potere, 2003). Researchers recommended cultivating Multicultural Knowledge outside of traditional training modalities, for example by attending cultural events in the community (Ridley, 2005).

Bivariate correlation results support this conclusion such that older participants $(r=.30)$ and those with higher levels of training $(r=.23)$ also reported having completed more 
multicultural workshops. A potential explanation for this finding is that with more advanced training comes requirements to attend continuing education courses, thus offering more opportunities to engage in multicultural workshops. Although a multicultural focus is still relatively new in neuropsychology, multiculturalism more broadly in psychology has been central for the past four decades (Hill et al., 2013; Rivera Mindt et al., 2010). As such, older participants and those further along in training may have had more exposure to multicultural training activities, and increased opportunities to attend multicultural workshops.

Results revealed that trainees with higher levels of training reported higher perceived Total MC $(r=.25)$ and Multicultural Awareness $(r=.26)$. Similarly, Barden and Greene (2014) observed a positive relationship between self-reported MC and time in graduate school in a sample of counseling trainees. Results from the current study support this data in that participants with higher levels of training reported higher perceived MC. Aside from achieving higher competencies across a range of areas as trainees progress through training, Barden and Green (2014) suggested self-efficacy as an additional potential explanation for the relationship between training level and MC. Participants with more training likely have had more clinical experiences, supervision, and coursework that not only impacts perceived MC but also selfefficacy providing services to diverse groups. Barden and Green (2014) explained that trainees with higher levels of training may perceive themselves as more multiculturally competent, as a function of increased confidence. Similarly, it is possible variables such as self-efficacy influenced the observed relationship in the current study between training level and MC. Thus, future directions include examining the effects of self-efficacy and MC in a sample of neuropsychological trainees.

\section{Hypothesis 3: Racial Identity}


With respect to the third hypothesis, results indicated that after controlling for social desirability, age, and training level, the third variable block, comprised of racial identity development phases was statistically significant in Total MC, accounting for $26 \%$ of variance in scores. Racial identity development phases were also statistically significant in the Multicultural Knowledge model, accounting for $23 \%$ of variance in scores, and statistically significant in the Multicultural Awareness model, accounting for $18 \%$ of variance in scores. As an individual variable, racial identity development was a unique statistically significant predictor in Total MC, Multicultural Knowledge, and Multicultural Awareness. Correlation analysis support these findings such that participants with higher WRIAS scores scored higher on the MCKAS, and those with lower WRIAS scores scored lower on the MCKAS. Results parallel the theoretical foundations of racial identity development and $\mathrm{MC}$, as well as prior research.

Notably, racial identity development is different from racial category or simply identifying as White; and involves "distinct belief, feelings, and behaviors related to understanding of the self as a racial being" (Johnson \& Williams, 2015, p. 441). Racial identity development refers to people examining their thoughts and feelings about their own race as well as the race of others. Furthermore, Middelton et al. (2005) described that individuals with less advanced racial identity development might be unaware of racism and of the privileges associated with being White. Results from the current study revealed that those who reported less advanced racial identity development also reported less MC. More specifically, the less advanced racial identity development (WRIAS Phase I), was a unique statistically significant predictor in Total MC, Multicultural Knowledge, and Multicultural Awareness. Results from the bivariate correlation analysis also indicated that the less advanced racial identity development phase was 
statistically significantly and negatively correlated with perceived Total MC $(r=-.47)$, Multicultural Knowledge $(r=-.37)$, and Multicultural Awareness $(r=-.47)$.

Likewise, more advanced racial identity development (WRIAS Phase II), was a unique statistically significant predictor in Total MC and Multicultural Knowledge. Results from the bivariate correlation analysis also revealed that more advanced racial identity development was statistically significantly and positively correlated with Total MC ( $r=.44)$ and Multicultural Knowledge $(r=.47)$, but not Multicultural Awareness. Torres-Rivera, Phan, Maddux, Wilbur, and Garett (2001) explained that Multicultural Awareness reflects the values and biases that impact working with diverse groups and is a difficult domain to cultivate in up and coming practitioners. Similarly, Pope, Reynolds, and Mueller (2004) concluded that developing Multicultural Awareness is an introspective process involving examination of values and assumptions. This process might be impacted, for example, by participating in cultural events and discussing varying cultural perspectives (Pope et al., 2004). Results from the current study highlight that developing MC is a dynamic process, and that racial identity development is important to consider within the MC framework (Chao, 2013; Johnson \& Williams, 2015; Ottavi et al., 1994; Pope et al., 2004).

\section{Hypothesis 4: Multicultural Training}

With respect to the fourth hypothesis, results from the three tested models indicated that after controlling for social desirability, age, training level, and racial identity development phases, the fourth variable block, comprised of multicultural training, was statistically significant in Total MC, accounting for $10 \%$ of variance in scores, and statistically significant in the Multicultural Knowledge model, accounting for $37 \%$ of variance in scores. As an individual variable, multicultural training was a unique statistically significant predictor in Total MC and 
Multicultural Knowledge. Although multicultural training did not account for an additional statistically significant variance in perceived Multicultural Awareness, the total model was statistically significant, indicating that overall, models comprised of social desirability, age, training level, racial identity development, and multicultural training accounted for statistically significant proportions of variance in Total MC, Multicultural Knowledge, and Multicultural Awareness. These findings generally align with previous literature (e.g., Constantine, 2002; Dickson \& Jepson, 2007; Kutayli, 2004; Johnson \& Williams, 2015; Lee \& Khawaja, 2013; Sodowsky et al., 1998), and highlight important dynamics between multicultural training and MC.

For example, the finding that multicultural training added the most variance to Multicultural Knowledge indicates that trainees may develop their knowledge about different worldviews and cultures through multicultural research projects and workshops, as well as discussions or content related to multicultural/diversity themes in coursework and supervision. This finding aligns with the theoretical foundations of MC, in that Multicultural Knowledge refers to information clinicians know about the group with which they are working. This information is perhaps more easily achievable through traditional multicultural training modalities, such as workshops, supervision, and coursework. For example, in these forums trainees likely have opportunities to learn about how psychological concepts might be perceived across cultures as well as the influence of race on the manifestation of psychological disorders (Sue et al., 1992).

Contrastingly, Multicultural Awareness refers to beliefs and attitudes about diverse individuals and involves an introspective and at times anxiety producing process. This construct reflects the values, assumptions, and biases of the practitioner, and involves personal 
development deemed difficult to teach in multicultural training forums. As such, multicultural training did not add statistically significant variance to Multicultural Awareness. This highlights that $\mathrm{MC}$ is not easily achievable through traditional training modalities across each of the domains. Likewise, results from the bivariate correlation analysis revealed that multicultural training was statistically significantly correlated with Total MC $(r=.44)$ and Multicultural Knowledge $(r=.47)$, but not Multicultural Awareness. Kim and Lyons (2011) explained that experiential training modalities can help build Multicultural Awareness. For example, games and role plays promote a safe place for trainees to explore their beliefs, assumptions, and biases, while learning from each other (Kim \& Lyons, 20011). Unlike Multicultural Knowledge, Multicultural Awareness involves a developmental process not explicitly tied to traditional multicultural training modalities. Therefore, researchers also recommended immersion activities outside of the classroom to cultivate Multicultural Awareness (Torres-Rivera et al., 2001). Although results highlight that cultivating MC, especially Multicultural Awareness is difficult to achieve through traditional raining modalities, results do indicate that training has the potential to positively influence racial identity development. More specifically, adding multicultural training to the model, the association of racial identity development phases was somewhat attenuated for Total MC as well as Multicultural Knowledge. Results from the bivariate correlation analysis also revealed that participants further along in training $(r=.20)$ and those with more multicultural training $(r=.24)$ reported more advanced racial identity development. These findings support previous research (e.g., Johnson \& Williams, 2015), and underscore that neuropsychological trainees further along in training and with more multicultural training may develop more advanced racial identity. This is encouraging in that training has the potential to positively influence racial identity development. Based on the results from the 
current study, it seems important for trainees to be encouraged to complete multicultural research projects and workshops, as well as training programs and clinical supervisors to focus content on multicultural topics. This suggestion is further supported by results indicating each of the models were statistically significant.

\section{Hypothesis 5: Overall Model}

The Total MC, Multicultural Knowledge, and Multicultural Awareness models comprised of social desirability, age, training level, racial identity development phases, and multicultural training were statistically significant. Results indicated that in addition to multicultural training, it is important to consider the effects of age, training level, and racial identity development. The implications for training based on these conclusions build on previous similar findings as well as recommendations where researchers conceptualized similar findings (e.g., Constantine, 2002; Dickson \& Jepson, 2007; Johnson \& Williams, 2015; Lee \& Khawaja, 2013; Sodowsky et al., 1998).

\section{Implications}

In general, the findings and results from correlational analysis and HMRA provided support for the proposed models. In most cases, the findings across analyses were consistent with the proposed relationships in which age, training level, racial identity development phases, and multicultural training were correlated with perceived MC. The results from this study also contribute to the existing recommendations emphasizing the importance of $\mathrm{MC}$ in neuropsychology. Collectively, results from correlation analyses and HMRA indicated that age, training level, racial identity development phases, and multicultural training were statistically significantly related to MC. Several applications are provided in this section based on these findings. 
Notably, results of the primary analysis (HMRA) indicated that racial identity development phases added statistically significant variance to each of the models (Total MC, Multicultural Knowledge, and Multicultural Awareness). Likewise, participants with more advanced racial identity development reported higher MC, and participants with less advanced racial identity development reported lower MC. Implications include that the racial identity development of trainees is not mutually exclusive from developing into competent and effective health service providers (Johnson \& Williams, 2015; Middleton, Erguner-Tekinalp, Williams, Stadler, and Dow, 2011; Ottavi et al., 1994). Up and coming neuropsychologists develop not only as clinicians, but also as individuals with their own thoughts and feelings about their race and the race of others. Therefore, developing curricula and training didactics across the graduate, internship, and post-doctoral levels in neuropsychology focused on racial identity and Multicultural Awareness is recommended. For example, Pope and Reynolds (1997) suggested trainees examine their own cultural backgrounds as well as experiences of racism and how this influences their interactions with individuals clinically and personally.

Implications include promoting racial identity development throughout training to support MC in up and coming neuropsychologists. This is based on results from the current study, as well as recommendations by Chao (2013) and Johnson and Williams (2015). Fostering a sophisticated understanding of racial identity throughout training is recommended. These recommendations are important to consider for teachers, training directors, and clinical supervisors in neuropsychology. Moreover, results indicated that participants with more multicultural training and those further along in training reported more advanced racial identity development. Neuropsychological trainees with more multicultural training and those further 
along in training may develop more advanced racial identity development. Therefore, it is recommended that training programs facilitate exploration of racial identity development.

This can be achieved by focusing course content on constructs such as oppression and privilege, and/or incorporating these topics in discussions and essay prompts (Middelton et al., 2005). Encouraging honest and open discussions about racial identity development in coursework and supervision is recommended. These recommendations align with results in the current study, in that time designated to multicultural/diversity themes in supervision was statistically significantly and positively correlated with perceived MC. Johnson and Williams (2015) suggested trainees discuss differing worldviews in process groups and/or other experiential learning forums focused on self-reflection, while Chao (2013) recommended training programs foster increased understanding of worldviews, biases, and cultural backgrounds. Training programs may want to incorporate, for example, work in diverse communities, in that Helms (1990) highlighted that experiential learning is important for racial identity development. Similarly, Torres-Rivera et al. (2001) recommended immersion activities outside of the classroom to increase multicultural awareness and Chao, Paiko, Zhang, and Zhao (2017) underscored the importance of civic engagement in training programs.

In sum, results supported multicultural training to help develop MC. Implications include continued advocacy for multicultural training in neuropsychology (Bryd, 2018; Judd, 2018; Manly, 2018; River Mindt, 2018). As a foundation, it is recommended that neuropsychology training programs continue to adhere to the Multicultural Guidelines: An Ecological Approach to Context, Identity, and Intersectionality (APA, 2017). The current study supports the formal application of multicultural competencies into training models, and continued evaluation of such competencies. 


\section{Strengths}

This study calls attention to MC in a sample of neuropsychological trainees. Multicultural topics in psychology have become increasingly visible in empirical research, while data in neuropsychology is developing in this regard (Hill et al., 2013; Manly, 2018; Wajman et al., 2015). In fact, neuropsychology has been called upon to increase focus on cultural variables. Recommendations included reforming multicultural training guidelines (e.g., Rivera Mindt et al., 2010; Van Gorp et al., 2000), and this study provides preliminary information related to training and MC in neuropsychology.

The proposed model was generally consistent with previous literature; however, previous studies investigated MC in samples of trainees more broadly in psychology, and were not focused to neuropsychological trainees, specifically (e.g., Johnson \& Williams, 2015; Lee \& Khawaja, 2013). The current study is an initial step to investigate MC in neuropsychological trainees. Findings underscore that multicultural training is correlated to $\mathrm{MC}$ and highlights the importance of racial identity development in developing MC. Professional psychology training is full of potential to help up and coming neuropsychologists develop MC, and results from the current study established a foundation for further research investigating variables that contribute to $\mathrm{MC}$ in neuropsychological trainees. As a jumping off point for empirical research, this study provides preliminary information about perceived MC in a sample of neuropsychological trainees.

The results from the current study demonstrated that age, training level, racial identity development, and multicultural training all correlate to perceived MC. This indicates that neuropsychological trainees that actively engage in personal and professional interactions related to building their multicultural awareness, knowledge, and skills, will ultimately continue to 
develop MC. Data from the current study also adds to the knowledge base about variables that improve competencies working with diverse groups. Continued research in these topics has the potential to improve service delivery and the lives of those we treat.

\section{Limitations and Future Directions}

The current study provided preliminary data about variables that contribute to perceived MC in a sample of neuropsychological trainees. These findings and implications should be considered within the context of several limitations. Firstly, the conclusions presented in this study are correlational in nature. Generalizations of causality based on the results are not recommended. Limitations related to instrumentation used in the current study include that the outcome variable (perceived MC) was measured by an adapted version of the MCKAS. After receiving permission from the author, Kutayli (2004) changed the language of the MCKAS to be applicable to neuropsychological assessment. The adapted version shares similar psychometric properties to the original MCKAS, however careful interpretations should be made in that this measure was not initially developed for use with neuropsychological trainees. Suggestions for future research include factor analysis of the MCKAS with a sample of neuropsychologists (Kutayli, 2004).

An additional limitation includes the poor internal reliability consistencies for the subscales of the WRIAS, which was used to measure racial identity development. These values are consistent with previous literature (e.g., Johnson \& Williams, 2015; Neville et al., 1996). Furthermore, Helms (1990; 1997) explained that the WRIAS measures a fluid construct with inherent nuances due to the developmental nature of the model. Johnson and Williams (2015) also described that the WRIAS is consistent with racial identity development theory, despite low reliabilities on some subscales. In the current study the subscales performed in the expected 
direction on correlation analyses, and the internal consistency of Phase I and Phase II were acceptable. Despite this, future directions include improving the psychometric properties of the WRIAS and providing explanations as to why the WRIAS phase scores prove to be reliable while the schema scores are less reliable.

Multi-modal research design. An additional limitation relevant in self-report surveys is response bias. To control for this limitation, the survey in the current study was anonymous, and the email addresses obtained were kept separate from survey responses. Despite the advantages of survey research design (e.g., cost effectives, and ease of data collection), disadvantages include response and sample bias. In fact, The multicultural guidelines: An ecological approach to context, identity, and intersectionality (APA, 2017) recommended investigating MC in multiple contexts. Similarly, using an internet survey limits participation to individuals with internet access. Future directions include outreach to different training programs where pencil and paper surveys are made available to trainees. Future directions additionally include examining client-clinician dynamics and/or other third-party observations to evaluate MC, as well as broadening the examination of MC to contexts other than self-report.

Researchers additionally may want to conduct qualitative analyses and target minority clinicians to interpret MC themes in a more ethnically and racially diverse sample. Qualitative research is a promising method to use for underrepresented populations in psychology research literature, to "give a voice to historically disenfranchised populations" (Levitt et al., 2018, p. 28). Furthermore, given the exploratory nature of examining MC in neuropsychological trainees, qualitative methods to develop this area of research is recommended. Implementing multimodal research designs as well as qualitative research methods can yield more in-depth data and conclusions relevant to the practice of providing neuropsychological services to diverse groups. 
Demographics. Results from the current study indicated that there was a statistically significant relationship between age and perceived MC. Additional demographics effects such as gender were also investigated with no differences observed. This parallels previous findings (e.g. Chao, 2012; Pope and Mueller, 2005). Contrastingly, Pope and Mueller (2005) observed differences based on female participants who identified as members of socially marginalized groups. Future research investigating the identification as a socially marginalized group based on gender in a larger sample of neuropsychological trainees is a notable future direction. To broaden the scope of future investigations, researchers may also want to focus recruitment to obtain a diverse sample regarding other social identities (e.g., sexual orientation, religious orientation, etc.). It is additionally recommended future researchers include an adequate number of participants in each of the demographic categories to better interpret group differences.

This is especially relevant given that the demographic composition of participants that identified as persons of color was limited in the current study. An apriori power analysis indicated that 107 participants were needed for this study to have a power of .8 and medium effect size of .15. A total of 157 surveys were started, and $126(80.3 \%)$ were completed and included in analysis. Reflecting interest in the effects of demographics, racial identity development, and multicultural training on the MC of neuropsychological trainees of color, recruitment procedures did not exclude potential participants based on race or ethnicity. However, of the completed 126 surveys, most participants (82.3\%) did not identity as persons of color which parallels previously reported demographic data in psychology and in neuropsychology (e.g., Cope et al., 2016; Echemendia et al., 1997; Elbulok-Charcape et al., 2014; Johnson \& Williams, 2015; Michalski \& Jacobsen, 2009). This highlights the 
underrepresentation of REM practitioners, for example, in a sample of 512 licensed neuropsychologists, 91\% of the sample identified as White (Elbulok-Charcape et al., 2014).

A such, the total number of participants in the current study was 97, which is a limitation in that just over $61 \%$ of the initial sample collected. Although I was interested in assessing between group differences and impact on racial identity development for participants that identified as persons of color, generalizations of findings from the current study to populations other than neuropsychological trainees that do not identify as persons of color are not recommended. Results should be interpreted with caution in that the study was underpowered, increasing the likelihood of a Type II error and not detecting an effect (Cohen, 1992). Future researchers may way to obtain a larger sample of neuropsychological trainees. This may increase the diversity of the sample, so that interpretations of group differences can be made.

Therefore, future researchers may want to reach out to ethnic minority psychological associations such as the Hispanic Neuropsychological Society and the APA Association of Black Psychologists to obtain a more racially and ethnically diverse sample of neuropsychological trainees. Furthermore, the sample in the current study may represent neuropsychological trainees with inherent interests in multicultural topics. Future researchers may want to use methods other than convenience sampling, and increase the likelihood of obtaining a range of participants with varying interests in $\mathrm{MC}$.

Racial identity. Results from the current study indicated that racial identity development phases are important to consider within the MC framework. This is also supported by data highlighting the importance of racial identity development in training (e.g., Chao, 2013; Johnson \& Williams, 2015). Thus, continued research focused on the implications of racial identity development on MC in samples of trainees is recommended. Current findings also suggested that 
neuropsychological trainees further along in training and with more multicultural training may develop more advanced racial identity. Similarly, Chao and Nath (2011) concluded that ethnic identity mediated the relationship between multicultural training and perceived MC, while Johnson and Williams (2015) recommended training programs promote racial identity development. Future researchers may want to investigate factors that contribute to racial identity development in neuropsychological trainees.

Multicultural training. Multicultural training practices are still developing in neuropsychology, and researchers highlighted the lack of multicultural guidelines available (Elbulok-Charcape et al., 2014). Findings from the current study indicated $15 \%$ of coursework and $14 \%$ of supervision was designated to multicultural themes, which is lower than data reported in samples other than neuropsychology trainees (e.g., Johnson \& Williams, 2015). Although previous researchers examined MC across clinical, counseling, and school psychology trainees (e.g., Johnson \& Williams, 2015), to the knowledge of the researcher, there are no data available comparing multicultural training in neuropsychology to other disciplines. As such, examining group differences across psychology disciplines, including variables such as time spent in coursework and supervision focused on multicultural topics warrants future investigation.

Moreover, continued emphasis on standardizing multicultural training in neuropsychology is recommended, as well as investigations measuring the impact of multicultural training on MC. Further defining and implementing multicultural training practices can help move culture in neuropsychology into focus and ensure a future of competent practitioners. Although the multicultural training questions used in the current study were based on previous research (e.g., Dicken \& Jepsen, 2007; Echemendia et al., 1997; Lee \& Khawaja, 
2013; Mueller \& Pope, 2001; Ottavi et al., 1994; Sodowsky et al., 1998), a standardized multicultural training measure would have been optimal. Previous dissertations (e.g., Sagun, 2014) developed multicultural training scales for the purposes of specific studies, however limited standardized multicultural training scales are available for research purposes. Future directions include standardizing multicultural training practices in neuropsychology and developing multicultural training measures in the form of a scale or questionnaire.

In addition, participants reported an average 0-2 REM clients served in the past month. Although this finding is difficult to interpret in relation to total caseload, this result does not align with data presented by the APA (Michalski \& Jacobsen, 2009) where 34,000 health service psychologists reported slightly over $25 \%$ of caseloads made up of REM clients. Similarly, Echemendia et al. (1997) surveyed 911 neuropsychologists in the United States and found 28\% of time was spent providing services to REM clients. In the current study, clinical caseload made up of REMs was assessed on a Likert scale, which made interpreting the proportion of REM clients relevant to entire caseload difficult. Future directions include measuring clinical training with REM clients as a proportion to total caseload.

Additional variables. Finally, age, training level, racial identity development phases, and multicultural training predicted under half of the variance in perceived MC. Lee and Khawaja (2013) concluded that MC is potentially "effected by several factors, more than what pedagogical forums can offer" (p. 215). The question remains as to what other variables contribute to perceived MC in neuropsychological trainees. Although the variables that were statistically significantly correlated to MC in the current study had not been tested in a sample of neuropsychological trainees, there are likely additional variables to discover as well. The hope is 
that this research is a springboard for future studies to continue to examine the development of $\mathrm{MC}$ in neuropsychology training.

\section{Conclusion}

The United States and those seeking psychological and neuropsychological services continues to diversify, however, providers in neuropsychology remain predominately White (Rivera Mindt et al., 2010; Wajman et al., 2015). This discrepancy highlights the importance of $\mathrm{MC}$ in neuropsychology, and previous researchers found that $\mathrm{MC}$ is necessary to provide psychological services to diverse groups (Fuertes \& Brobst, 2002; Johnson \& Williams, 2015; Sue et al., 1992). Factors have not yet been identified that help develop MC in neuropsychological trainees. The primary purpose of this study was to provide preliminary data, and evaluate the relationship between MC and age, training level, racial identity development, and multicultural training in a sample of neuropsychological trainees. More specifically, this study examined the extent to which age, training level, racial identity development phases, and multicultural training may contribute to perceived MC.

Following recruitment and data collection in Spring 2017, several implications materialized, including that age and training level were positively and statistically significantly correlated to perceived MC. Less advanced racial identity development was correlated to lower levels of perceived MC and more advanced racial identity development was correlated to higher levels of perceived MC. Additionally, multicultural training was statistically significantly and positively correlated to perceived MC. Results of the primary analysis (HMRA) indicated that after controlling for social desirability, age, training level, and racial identity development phases, multicultural training was a statistically significant predictor of perceived Total MC, and Multicultural Knowledge. Overall, findings indicated that models comprised of social 
desirability, age, training level, racial identity development phases, and multicultural training accounted for statistically significant proportions of variance in perceived Total MC, Multicultural Knowledge, and Multicultural Awareness. These findings highlighted the importance of age, training level, racial identity development, and multicultural training in neuropsychology.

As such, opportunities for neuropsychological trainees to complete multicultural research projects and workshops, as well as engage in material related to multicultural/diversity themes in coursework and supervision ought to be encouraged. These forums provide opportunities for trainees to become more aware, for example, about their own racial identity development and how this may influence service delivery in psychology. These forums provide opportunities for neuropsychological trainees to improve their skills for working with diverse groups. Trainees that take advantage of these opportunities and advocate for increased multicultural focus across training modalities will continue to move $\mathrm{MC}$ in neuropsychology from an infancy stage to foundational groundwork upon which to build.

Although multiculturalism has been acknowledged and embraced in recent years across disciplines in psychology, much remains to be accomplished. The hope is that the results from this study encourage additional research on these topics. Examining MC to improve service delivery in professional psychology has the potential to effect change at personal, professional, academic, institutional, and societal levels. 


\section{References}

Agranovich, A. V., \& Puente, P. E. (2007). Do Russian and American normal adults perform similarly on neuropsychological tests? Preliminary findings on the relationship between culture and test performance. Archives of Clinical Neuropsychology, 22(3), 273-282. doi:10.1016/j.acn.2007.01.003

Agranovich, A. V., Panter, A. T., Puente, A. E., \& Touradji, P. (2011). The culture of time in neuropsychological assessment: Exploring the effects of culture specific time attitudes on timed test performance in Russian and American samples. Journal of the International Neuropsychological Society, 17(4), 692-701. doi:10.1017/S1355617711000592

Alvarez, A. N. (1996). Asian American racial identity: An examination of world views and racial adjustment. (Doctoral dissertation). Retrieved from Proquest Dissertations \& Theses. (9707563).

Alvarez, A. N., \& Helms, J. E. (2001). Racial identity and reflected appraisals as influences on Asian Americans' racial adjustment. Cultural Diversity and Ethnic Minority Psychology, 7(3), 217-231. doi:10.1037//1099-9809.7.3.217

American Psychological Association. (2002). Ethical principles of psychologists and code of conduct. American Psychologist, 57(12), 1060-1073. doi:10.1037/0003-066X.57.12.1060

American Psychological Association. (2003). Guidelines on multicultural education, training, research, practice, and organizational change for psychologists. American Psychologist, 58(5), 377-402. doi:10.1037/0003-066X.58.5

American Psychological Association (2006). APA task force on the assessment of competence in professional psychology: Final report. Washington, D.C.: American Psychological Association. doi.org/10.1037/e583002010-001 
American Psychological Association. (2017). Multicultural guidelines: An ecological approach to context, identity, and intersectionality. doi:10.1037/e501962018-001

Atkinson, D. R., \& Israel, T. (2003). The future of multicultural counseling competence. In D. Pope-Davis, H. Coleman, W. Liu, \& R. Toporek (Eds.), Handbook of multicultural competence: In counseling \& psychology (pp. 591-606). Thousand Oaks, CA: Sage Publications.

Arredondo, P., \& Toporek, R. (2004). Multicultural counseling competencies = ethical practice. Journal of Mental Health Counseling, 26(1), 44-55.

doi:10.17744/mehc.26.1.hw2enjqve2p2tj6q

Artiola, F. L., Heaton, R. K., \& Hermosillo, D. (1998). Neuropsychological comparisons of Spanish-speaking participants from the U.S.-Mexico border region versus Spain. Journal of International Neuropsychological Society, 4(4), 363-379.

doi:10.1080/13803390490918282

Barden, S. M., \& Cashwell, C. S. (2013). Critical factors in cultural immersion: A synthesis of relevant literature. International Journal for the Advancement of Counseling, 35(4), 286297. doi:10.1007/s10447-013-9183-y

Barden, S. M., \& Greene, J. H. (2015). An investigation of multicultural counseling competence and multicultural counseling self-efficacy for counselors-in-training. International Journal for the Advancement of Counseling, 37(1), 41-53. doi:10.1007/s10447-0149224-1

Bidell, M. P. (2005). The Sexual Orientation Counselor Competency Scale: Assessing attitudes, 
skills, and knowledge of counselors working with lesbian, gay, and bisexual clients.

Counselor Education and Supervision, 44(4), 267-279. doi:10.1002/j.1556-

6978.2005.tb01755.x

Bidell, M. P. (2012). Examining school counseling students' multicultural and sexual orientation competencies through a cross-specialization comparison. Journal of Counseling \& Development, 90(2), 200-207. doi:10.1111/j.1556-6676.2012.00025

Block, C. J., Roberson, L., \& Neuger, D. (1995). White racial identity theory: A framework for understanding reactions toward interracial situations in organizations. Journal of Vocational Behavior, 46(1), 71-88. doi:10.1006/jvbe.1995.1005

Boake, C. (2008). Clinical neuropsychology. Professional Psychology: Research and Practice 39(2), 234-239. doi:10.1037/0735-7028.39.2.234

Bodin, D., Roper, B. L., O’Toole, K., \& Haines, M. E. (2015). Postdoctoral training in neuropsychology: A review of the history, trends, and current issues. Training and Education in Professional Psychology, 9(2), 99-104. doi:10.1037/tep0000057

Boone, K., Victor, T., Wen, J., Razani, J., \& Ponton, M. (2007). The association between neuropsychological scores and ethnicity, language, and acculturation variables in a large patient population. Archives of Clinical Neuropsychology, 22(3), 335-365. doi:10.1016/j.acn.2007.01.010

Bray, J. (2009). Vision for the future of psychology practice. Monitor on Psychology, 40(2), 5. doi:10.1037/e515462010-003

Brickman, A. M., Cabo, R., \& Manly, J. J. (2006). Ethical issues in cross-cultural neuropsychology. Applied Neuropsychology, 13(2), 91-100. doi:10.1207/s15324826an1302_4 
Brown, J. D. (1996). Testing in language programs. Upper Saddle River, NJ: Prentice Hall Regents.

Burkard, A. W., Juarez-Huffaker, M., \& Ajmere, K. (2003). White racial identity attitudes as a predictor of cross-cultural working alliances. Journal of Multicultural Counseling and Development, 31(4), 226-244. doi:10.1002/j.2161-1912.2003.tb00352.x

Buschke, H., \& Fuld, P. A. (1974). Evaluating storage, retention, and retrieval in disordered memory and learning. Neurology, 24(11), 1019-1025. doi:10.1212/WNL.24.11.1019

Byrd, D. (2018, February). Cross cultural neuropsychological research: Developments and forecasts. In A. Thames (Chair), Challenging the status quo: Future directions in cultural neuropsychology. Symposium conduced at the Annual Meeting of the International Neuropsychology Society, Washington, DC.

Byrd, D. A., \& Manly, J. J. (2005). Cultural considerations in the neurological assessment of older adults. In S. Bush, \& T. Martin (Eds.), Geriatric neuropsychology: Practice essentials (pp. 115-139). Philadelphia, PA: Taylor \& Francis.

Camilli, G., \& Shepard, L. A. (1994). Methods for identifying biased test items. Volume 4. Thousand Oaks, CA: Sage.

Castillo, L. G., Brossart, D. F., Reyes, C. J., Conoley, C. W., \& Phoummarath, M. J. (2007). The influence of multicultural training on perceived multicultural counseling competencies and implicit racial prejudice. Journal of Multicultural Counseling and Development, 35(4), 243-255. doi:10.1002/j.2161-1912.2007.tb00064.x

Carlson, M. H., Brack, C. J., Laygo, R., Cohen, R., \& Kirkscey, M. (1998). An exploratory study of multicultural competence of counselors in training: Support for experiential skills building. Clinical Supervisor, 17(2), 75-87. doi:10.1300/J001v17n02_04 
Carter, R. T. (1995). The influence of race and racial identity in psychotherapy. New York, NY: Wiley.

Carter, R. T., \& Helms, J. E. (1990). White racial identity attitudes and cultural values. In. E. Helms (Ed.), Black and White racial identity: Theory, research and practice (pp. 105118) Westport, CT: Greenwood Press.

Chao, R. C., Paiko, L., Zhang, Y. S., Zhao, C. (2017). Service-learning: A training method to enhance multicultural competence toward international students. Scholarship of Teaching and Learning in Psychology, 3(1), 28-42. doi:10.1037/st10000078

Chao, R. C., \& Nath, S. (2011). The role of ethnic identity, gender roles, and multicultural training in college counselors' multicultural counseling competence: A mediation model. Journal of College Counseling, 14(1), 50-64. doi:10.1002/j.2161-1882.2011.tb00063.x

Chao, R. C., Wei, M., Good, G. E., \& Flores, L. Y. (2011). Race, ethnicity, color-blind racial attitudes, and multicultural counseling competence: The moderating effects of multicultural counseling training. Journal of Counseling Psychology, 58(1), 72-82. doi:10.1037/a0022091

Chao, R. C. (2013). Race/ethnicity and multicultural competence among school counselors: Multicultural training, racial/ethnic identity, and color-blind racial attitudes. Journal of Counseling \& Development, 91(2), 140-151. doi:10.1002/j.1556-6676.2013.00082.x

Cohen, J. (1992). A power primer. Psychological Bulletin, 112(1), 155-159. doi:10.1037/0033-2909.112.1.155

Cohen, S., Kamarck, T., \& Mermelstein, R. (1983). A global measure of perceived stress. Journal of Health and Social Behavior, 24(4), 386-396. doi:10.2307/2136404 Cole, M. (1996). Cultural psychology: A once and future discipline. Cambridge, MA: Harvard 
University Press.

Coleman, M. N. (2006). Critical incidents in multicultural training: an examination of student experiences. Journal of Multicultural Counseling and Development, 34(3), 168. doi:10.1002/j.2161-1912.2006.tb00036.x

Conners, K. C. (2004). Conners continuous performance test (2nd ed.). Toronto, Canada: Multi Health Systems.

Constantine, M. G. (2002). Racism attitudes, White racial identity attitudes, and multicultural counseling competence in school counselor trainees. Counselor Education and Supervision, 41(3), 162-174. doi:10.1002/j.1556- 6978.2002.tb01281.x

Constantine, M. G., \& Ladany, N. (2000). Self-report multicultural counseling competence scales: Their relations to social desirability attitudes and multicultural case conceptualization ability. Journal of Counseling Psychology, 47(4), 155-164. doi:10.1037/0022-0167.47.2.155

Cope, C., Michalski, D. S., \& Fowler, G. A. (2016). Graduate study in psychology 2017: Summary report: Student demographics. doi:10.1037/e500852017-001

Crown, D. P., \& Marlowe, D. (1960). A new scale of social desirability independent of psychopathology. Journal of Consulting Psychology, 24(4), 349-354. doi: $10.1037 / \mathrm{h} 0047358$

Dana, R. H. (1996). Culturally competent assessment practice in the United States. Journal of Personality Assessment, 66(3), 472-487. doi:10.1207/s15327752jpa6603_2

D’Andrea, M., Daniels, J., \& Heck, R. (1991). Evaluating the impact of multicultural counseling training. Journal of Counseling and Development, 70(1), 143-150. doi:10.1002/j.15566676.1991.tb01576.x 
Darwin, C. (1859). Origin of the species. Mineola, NY: Dover Publication.

Davies, M., Strickland, T., \& Cao, M. (2014). Neuropsychological evaluation of culturally diverse populations. In F. Leong, L. Comas-Diaz, H. Nagayama, C. Gordon, V. Mcloyd, \& J. Trimble (Eds.), APA handbook of multicultural psychology, Vol 2: Applications and training (pp. 231-251). Washington, DC: American Psychological Association.

Díaz-Santos, M., \& Hough, S. (2016). Cultural competence guidelines for neuropsychology trainees and professional: Working with ethnically diverse individuals. In F. Ferraro (Ed.), Minority and cross-cultural aspects of neuropsychological assessment: Enduring and emerging trends. (2nd ed.) (pp.11-33). New York, NY: Taylor \& Francis.

Dickson, G. L., \& Jepsen, D. A. (2007). Multicultural training experiences as predictors of multicultural competencies: Students' perspectives. Counselor Education and Supervision, 47(2), 76-95. doi:10.1002/j.1556-6978.2007.tb00040.x

Dooley, D. (2001). Social research methods, $4^{\text {th }}$ edition. Upper Saddle River, NJ: Prentice-Hall.

Dotson, V. M., Kitner-Triolo, M., Evans, M. K., \& Zonderman, A. B. (2008). Literacy-based normative data for low socioeconomic status African Americans. The Clinical Neuropsychologist, 22(6), 1-29. doi:10.1080/13854040701679017

Echemendia, R. J. (2004). Cultural diversity and neuropsychology: An uneasy relationship in a time of change. Applied Neuropsychology, 11(1), 1-3. doi:10.1207/s15324826an1101_1

Echemendia, R. J., \& Harris, J. G. (2004). Neuropsychological test use with Hispanic/Latino populations in the United States: Part II of a national survey. Applied Neuropsychology, 11(1), 4-12. doi:10.1207/s15324826an1101_2

Echemendia, R., Harris, J. G., Congett, S. M., Diaz, M. L., \& Puente, A. E. (1997). Neuropsychological training and practices with Hispanics: A national survey. Clinical 
Neuropsychologist, 11(3), 229-243. doi:10.1080/13854049708400451

Edwards, A. R. (1957). The social desirability variable in personality assessment and research. New York, NY: Dryden.

Elbulok-Charcape, M. M., Rabin, L. A., Spadaccini, A. T., \& Barr, W. B. (2014). Trends in the neuropsychological assessment of ethnic/racial minorities: A survey of clinical neuropsychologists in the United States and Canada. Cultural Diversity and Ethnic Minority Psychology, 20(3), 353-361. doi:10.1037/a0035023

Epstein, R. M., \& Hundert, E. M. (2002). Defining and assessing professional competence. Journal of the American Medical Association, 287(2), 226-235. doi:10.1001/jama.287.2.226

Faul, F., Erdfelder, E., Lang, A. G., \& Buchner, A. (2007). G*Power 3: A flexible statistical power analysis program for the social, behavioral, and biomedical sciences. Behavior Research Methods, 39(2), 175-191. doi:10.3758/BF03193146

Falender, C. A., Cornish, J. A. E., Goodyear, R., Hatcher, R., Kaslow, N. J., \& Leventhal, G., \& ...Grus, C. (2004). Defining competencies in psychology supervision: A consensus statement. Journal of Clinical Psychology, 60(7), 771-786. doi:10.1002/jclp.20013

Fastenau, P. S., Evans, J. D., Johnson, K. E., \& Bond, G. R. (2002). Multicultural training in neuropsychology. In F. Ferraro (Ed.), Minority and cross-cultural aspects of neuropsychological assessment (pp. 345-373). New York, NY: Taylor \& Francis.

First Street Accord, (2017). Canadian psychological association and American psychological association Mutual Recognition. Retrieved from http://www.apa.org/ed/accreditation/signed-accord-cpa.pdf

Fischer, A. R., \& Moradi, B. (2001). Racial and ethnic identity: Recent developments and 
needed directions. In J. G. Ponterotto, J. M. Casas, L. A. Suzuki, \& C. M. Alexander (Eds.), Handbook of multicultural counseling. (2nd ed.) (pp. 341-370). Thousand Oaks, CA: Sage Publications.

Fong, M. L., \& Lease, S. H. (1997). Cross-cultural supervision: Issues for the White supervisor. In D. B. Pope-Davis, \& H. L. K. Coleman (Eds.), Multicultural counseling competencies: Assessment, education and training, and supervision (pp. 387-405). Thousand Oaks, CA: Sage Publications

Fowler, F. J. (2002). Survey research methods (3rd ed.). Thousand Oaks, CA: Sage Publications. Fukuyama, M. A. (1994). Critical incidents in multicultural counseling supervision: A phenomenological approach to supervision research. Counselor Education and Supervision, 34(2), 142-151. doi:10.1002/j.1556-6978.1994.tb00321.x

Galton, F. (1889). Natural inheritance. London, UK: Macmillan.

Gamst, G., \& Liang, C. T. H. (2013). A review and critique of multicultural competence measures: Toward a social justice oriented health service delivery model. In F. Paniagua, \& A. Yamada (Eds.), Handbook of multicultural mental health: Assessment and treatment of diverse populations. (2nd ed.) (pp. 547-569). Taramani, Chennai, India: Elsevier.

Gloria, A. M., Hird, J. S., \& Tao, K. W. (2008). Self-reported multicultural supervision competence of white predoctoral intern supervisors. Training and Education in Professional Psychology, 2(3), 129-136. doi:10.1037/1931-3918.2.3.129

Goddard, H. H. (1926). Feeble-mindedness. New York, NY: Macmillan Company. Gould, S. J. (1996). The mismeasure of man. New York, NY: W.W. Norton \& Company. Green, D., Radcliffe, A. M., Luebbe, A. M., \& Klonoff, E. A. (2009). Clinical psychology 
students' perceptions of diversity training: A study of exposure and satisfaction. Journal of Clinical Psychology, 65(10), 1056-1070. doi:10.1002/jclp.20605

Groth-Marnat, G. (2000). Neuropsychological assessment in clinical practice: A guide to test interpretation and integration. New York, NY: John Wiley \& Sons

Hall, C. (1997). Cultural malpractice: The growing obsolescence of psychology with the changing U.S. population. American Psychologist, 52(6), 642-651. doi:10.1037/0003 066X.52.6.642

Hannay, J. H. (1998). Proceedings from the Houston Conference on specialty education and training in clinical neuropsychology. Archives of Clinical Neuropsychology, 13(2), 157158. doi:10.1093/arclin/13.2.157

Helms, J. E. (1984). Toward a theoretical explanation of the effects of race on counseling: A Black and White model. Counseling Psychologist, 12(4), 153-165. doi:10.1177/0011000084124013

Helms, J. E. (1990). Black and White racial identity: Theory, research, and practice (1st ed.). New York, NY: Greenwood Press.

Helms, J. E. (1992). Why is there no study of cultural equivalence in standardized cognitive ability testing? American Psychologist, 47(9), 1083-1101. doi:10.1037/0003066X.47.9.1083

Helms, J. E. (1995). An update of Helms' White and People of Color racial identity models. In J. G. Ponterotto, J. M. Casas, L. A. Suzuki \& C. M. Alexander (Eds.), Handbook of Multicultural Counseling (pp. 181-198). Thousand Oaks, CA: Sage Publications.

Helms, J. E. (1995). Scoring key for the People of Color Racial Identity Attitude Scale (PRIAS). Unpublished Manuscript. 
Helms, J. E. (1996). Toward a methodology for measuring and assessing racial as distinguished from ethnic identity. In G. R. Sodowsky, \& J. Impara (Eds.), Multicultural assessment in counseling and clinical psychology (pp. 143-192). Lincoln, NE: Buros Institute of Mental Measurement.

Helms, J. E. (1999). Another meta-analysis of the White Racial Identity Attitude Scale's Cronbach alphas: Implications for validity. Measurement \& Evaluation in Counseling \& Development, 32(3), 122. Retrieved from https://psycnet.apa.org/record/1999-01872-001

Helms, J. E. (2002). A remedy for the Black-White test-score disparity. American Psychologist, 57(4), 303-304. doi:10.1037/0003-066X.57.4.303b

Helms, J. E. (2005). A review of White racial identity theory: The social implications of studying White racial identity in psychology. In C. Saths, \& K. Ratele (Eds.), Psychology serving humanity. New York, NY: Taylor \& Francis Group.

Helms, J. E. (2007). Some better practices for measuring racial and ethnic identity constructs. Journal of Counseling Psychology, 54(3), 235-246. doi:10.1037/0022-0167.54.3.235

Helms, J. E., \& Carter, R. T. (1990). Development of the White Racial Identity Scale. In J. E. Helms (Ed.), Black and White racial identity: Theory, research, and practice. Westport, CT: Greenwood.

Helms, J. E., \& Carter, R. T. (1991). Relationships of White and Black racial identity attitudes and demographic similarity to counselor preferences. Journal of Counseling Psychology, 38(4), 446-457. doi:10.1037/0022-0167.38.4.446

Helms, J. E., \& Carter, R. T. (2002). Scoring key for the White Racial Identity Attitude Scale (WRIAS). Unpublished Manuscript.

Helms, J. E., \& Piper, R. E. (1994). Implications of racial identity for vocational psychology. 
Journal of Vocational Behavior, 44(2), 124-128. doi:10.1006/jvbe.1994.1009

Henrich, J., Heine, S., \& Norenzayan, A. (2010). The weirdest people in the world? Behavioral and Brain Sciences, 33(2-3), 61-135. doi:10.1017/S0140525X0999152X

Heppner, P. P., Kivlighan, D. M., Jr., \& Wampold, B. E. (1999). Research design in counseling (2nd ed.). Belmont, CA: Wadsworth.

Heppner, M. J., \& O’Brien, K. M. (1994). Multicultural counselor training: students' perceptions of helpful and hindering events. Counselor Education and Supervision, 34(1), 4-18. doi:10.1002/j.1556-6978.1994.tb00306.x

Hill, N., Vereen, L., McNeal, D., \& Stotesbury, R. (2013). Multicultural awareness, knowledge, and skills among American counselor trainees: Group differences in self-perceived competence based on dispositional and programmatic variables. International Journal for the Advancement of Counseling, 35(4), 261-272. doi:10.1007/s10447-012-9181-5

Horton, A. M., (2008). Neuropsychological assessment in a multicultural context: Past, present, and future. In L. A. Suzuki, \& J. G. Ponterotto (Eds.), Handbook of multicultural assessment: Clinical, psychological, and educational applications. ( $3^{\text {rd }}$ ed.) (pp. 542564). San Francisco, CA: Jossey-Bass.

Hoyt, W. T., Imel, Z. E., \& Chan, F. (2008). Multiple regression and correlation techniques: Recent controversies and best practices. Rehabilitation Psychology, 53(3), 321-339. doi: $10.1037 / \mathrm{a} 0013021$

Hsiao-wen, L. (2004). Construct validity of the People of Color Racial Identity Attitude Scale. (Doctoral dissertation). Retrieved from Proquest Dissertations and Theses (3147181). Hui, A. Y. (2012). Cultural sensitivity training in clinical neuropsychology post-doctoral 
training programs: A website analysis. (Doctoral dissertation). Retrieved from Proquest Dissertations \& Theses (3578725).

Inman, A. G. (2006). South Asian women: Identities and conflicts. Cultural Diversity \& Ethnic Minority Psychology, 12(2), 306-319. doi:10.1037/1099-9809.12.2.306

Inman, A. G., Ladany, N, Constantine, M. G, \& Morano, C. K. (2001). Development and preliminary validation of the cultural values conflict scale for South Asian women. Journal of Counseling Psychology, 48(1), 17-27. doi:10.1037/0022-0167.48.1.17

Jackson, J. (2004) Racially stuffed shirts and other enemies of mankind: Horace Manna Bond's parody of segregationist psychology in the 1950s. In A. Winston (Ed.), Defining difference: Race and racism in the history of psychology (pp. 261-283). Washington, DC: American Psychological Association.

Jacobs, D. M., Sano, M., Albert, S., Schofield, P., \& Dooneief, G., Stern, Y. (1997). Crosscultural neuropsychological assessment: a comparison of randomly selected, demographically matched cohorts of English- and Spanish-speaking older adults. Journal of Clinical and Experimental Neuropsychology, 19(3), 331-339.

doi:10.1080/01688639708403862

Johnson, A., \& Williams, D. J. (2015). White racial identity, color-blind racial attitudes, and multicultural counseling competence. Cultural Diversity and Ethnic Minority Psychology, 21(3), 440-449. doi:10.1037/a0037533

Judd, T. (2018, February). Global neuropsychology priorities. In A. Thames (Chair), Challenging Challenging the status quo: Future directions in cultural neuropsychology. Symposium conduced at the Annual Meeting of the International Neuropsychology Society, Washington, DC. 
Judd, T., Capetillo, D., Carrion-Baralt, J., Marmol, L., San-Miguel-Montes, L., Navarrete, M., \& \& ...Valdes, J. (2009). Professional considerations for improving the neuropsychological evaluation of Hispanics: A National Academy of Neuropsychology education paper. Archives of Clinical Neuropsychology, 24(2), 127-135. doi:10.1093/arclin/acp016

Jurado, M., \& Pueyo, R. (2012). Doing and reporting a neuropsychological assessment. International Journal of Clinical and Health Psychology, 12(1), 123-141. doi: $10.1186 / \mathrm{s} 40337-015-0062-2$

Kaufman, A., \& Kaufman, N. (1983). Kaufman assessment battery for children. Circle Pines, MN: American Guidance Service.

Kavanagh, K., Absalom, K., Beil, J. W., \& Schliessmann, L. (1999). Connecting and becoming culturally competent: A Lakota example. Advances in Nursing Science, 21(3), 9-31. doi:10.1097/00012272-199903000-00005

Kim, B. S., Lyons, H. Z. (2011). Experiential activities and multicultural counseling competence training. Journal of Counseling and Development, 81(4), 400-408. doi:10.1002/j.1556-6678.2003.tb00266.x

Kirk, R. E. (2008). Statistics: An introduction. Belmont, CA: Thomas Higher Education.

Korman, M. (1974). National conference on levels and patterns of professional training in psychology: Major themes. American Psychologist, 29(6), 301-313. doi:10.1037/h0036469

Krieger, N., Smith, K., Naishadham, D., Hartman, C., \& Barbeau, E. M. (2005). Experiences of discrimination: Validity and reliability of a self-report measure for population health research on racism and health. Social Science and Medicine, 61(7), 1576-1596. doi:10.1016/j.socscimed.2005.03.006 
Kutayli, A. L. M., \& Program, C. P. (2004). Factors contributing to multicultural competence among practicing neuropsychologists. (Doctoral dissertation). Retrieved from Proquest Dissertations \& Theses. (3156727).

Ladany, N., Brittan-Powell, C. S., \& Pannu, R. K. (1997). The influence of supervisory racial identity interaction and racial matching on the supervisory working alliance and supervisee multicultural competence. Counselor Education and Supervision, 36(4), 284304. doi:10.1002/j.1556-6978.1997.tb00396.x

Ladany, N., Inman, A. G., Constantine, M. G., \& Hofheinz, E. W. (1997). Supervisee multicultural case conceptualization ability and self-reported multicultural competence as functions of supervisee racial identity and supervisor focus. Journal of Counseling Psychology, 44(3), 284-293. doi: 10.1037/0022-0167.44.3.284

Lee, A., \& Khawaja, N. G., (2013). Multicultural training experiences as predictors of psychology students' cultural competence. Australian Psychologist, 48(3), 209-216. doi:10.1111/j.1742-9544.2011.00063.x

Levitt, M., Bamberg, M., Creswell, J. W., Frost, D. M., Josselson, R., Suarez-Orozco, C. (2018). Journal article reporting standards for qualitative primary, qualitative meta-analytics, and mixed methods research in psychology: The APA Publications and Communications Board task force report. American Psychologist, 73 (1) 26-46. doi:10.1037/amp0000151

Lewis, D. E. (2004). The relationship between self-report and behavioral observation indices of multicultural counseling competence. (Doctoral dissertation). Retrieved from Proquest Dissertations \& Theses. (3134441).

Little, R. J. A. (1986). A test of missing completely at random for multivariate data with missing 
values. Journal of the American Statistical Association, 83(404) 1198-1202.

doi:10.2307/2290157

Liu, W. K., Sheu, H. B., \& Williams, K. (2004). Multicultural competency in research:

Examining the relationships among multicultural competencies, research training and self-efficacy, and the multicultural environment. Cultural Diversity and Ethnic Minority Psychology, 10(4), 324-339. doi:10.1037/1099-9809.10.4.324

Loo, R., \& Thorpe, K. (2000). Confirmatory factor analyses of the full and short versions of the Marlowe-Crowne Social Desirability scale. Journal of Social Psychology, 140(5), 628635. doi:10.1111/j.1559-1816.2004.tb01980.x

Luhtanen, R., \& Crocker, J. (1992). A collective self-esteem scale: Self-evaluation of one's social identity. Personality and Social Psychology Bulletin, 18(3), 302-318. doi:10.1177/0146167292183006

Luria, A. R. (1976). The cognitive development: Its cultural and social foundations. Cambridge, MA: Harvard University Press.

MacNeill, H., \& Wedding, D. (2007). Neuropsychology handbook. New York, NY: Springer.

Manly, J. J. (2005a). Advantages and disadvantages of separate norms for African Americans. The Clinical Neuropsychologist, 19(2), 270-275. doi:10.1080/13854040590945346

Manly, J. J. (2005b). Book review: Handbook of cross-cultural neuropsychology. Journal of Cross-Cultural Psychology, 36(2), 278. doi:10.1177/0022022104272906

Manly, J. J. (2006). Cultural issues. In D. K. Attix \& K. A. Welsh-Bohmer (Eds.), Geriatric neuropsychology: Assessment and intervention (pp.198-222). New York, NY: The Guilford Press.

Manly, J. J. (2008). Critical issues in cultural neuropsychology: Profit from diversity. 
Neuropsychology Review, 18(3), 179-183. doi:10.1007/s11065-008-9068-8

Manly, J. J., \& Echemendia, R. J. (2007). Race-specific norms: Using the model of hypertension to understand issues of race, culture, and education in neuropsychology. Archives of Clinical Neuropsychology, 22(3), 319-325. doi:10.1016/j.acn.2007.01.006

Manly, J. J., Byrd, D. A., Touradji, P., \& Stern, Y. (2004). Acculturation, reading level, and neuropsychological test performance among African American elders. Applied Neuropsychology, 11(1), 37-46. doi:10.1207/s15324826an1101_5

Manly, J. J., Jacobs, D. M., Touradji, P., Small, S. A., \& Stern, Y. (2002). Reading level attenuates differences in neuropsychological test performance between African American and White elders. Journal of the International Neuropsychological Society, 8(3), 341-348. doi:10.1017/S1355617702813157

Manly, J. J., Miller, S., Heaton, R., Byrd, D., Reilly, J., Velasquez, R., \& ...Grant, I. (1998). The effect of African American acculturation on neuropsychological test performance in HIV-positive individuals. Journal of the International Neuropsychology Society, 4(3), 291-302. Retrieved from http://web.a.ebscohost.com/ehost/detail/detail?

Manly, J. J. (2018, February). Advocacy in cultural neuropsychology. In A. Thames (Chair), Challenging the status quo: Future directions in cultural neuropsychology. Symposium conduced at the Annual Meeting of the International Neuropsychology Society, Washington, DC.

Marin, G., Gamba, R. J. (1996). A new measurement of acculturation for Hispanics: The Bidimensional Acculturation Scale for Hispanics (BAS). Hispanic Journal of Behavioral Sciences, 18(3), 297-316. doi:10.1177/07399863960183002

McDowell, T., Goessling, K., \& Melendez, T. (2012). Transformative learning through 
international immersion: Building multicultural competence in family therapy and counseling. Journal of Marital and Family Therapy, 38(2), 365-379. doi: 10.1111/j.17520606.2010.00209.x

Meyer, P., Penman-Aguilar, A., Campbell, V., Graffunder, C., O’Connor, A., \& Yoon, P. (2013). Conclusion and future directions: CDC health disparities and inequalities report United States. Morbidity and Mortality Weekly Report, 62(3), 184-186. Retrieved from https://www.cdc.gov/mmwr/preview/mmwrhtml/su6203a32.htm

Michalski, D. \& Jacobsen, T. (2009). 2008 APA survey of psychology health service providers: Preliminary results. doi: 10.1037/e587412010-001

Middleton, R. A., Erguner-Tekinalp, B., Williams, N., Stadler, H. A., \& Dow, J. E. (2011). Racial identity development and multicultural counseling competencies of White mental health practitioners. International Journal of Psychology and Psychological Therapy, 11(2), 201-218. Retrieved from https://www.ijpsy.com/volumen11/num2/293/racialidentity-development-and-multicultural-EN.pdf

Middleton R. A., Stadler H. A., Simpson C., Guo, Y. J., Brown, M. J., Crow, G., \& ...Lazarte, A. A. (2005). Mental health practitioners: the relationship between white racial identity attitudes and self-reported multicultural counseling competencies. Journal of Counseling Development, 83(4), 444-456. doi:10.1002/j.1556-6678.2005.tb00366.x

Miville, M. L., Koonce, D., Darlington, P., \& Whitlock, B. (2000). Exploring the relationships between racial/cultural identity and ego identity among African Americans and Mexican Americans. Journal of Multicultural Counseling \& Development, 28(4), 208-224. doi:10.1002/j.2161-1912.2000.tb00616.x

Mueller, J. A., \& Pope, R. L. (2001). The relationship between multicultural competence and 
white racial consciousness among student affairs practitioners. Journal of College Student Development, 42(2), 133-144. doi:10.2202/1949-6605.1285

Murphy-Shigematsu, S. (2010). Microaggressions by supervisors of color. Training and Education in Professional Psychology, 4(1), 16-18. doi:10.1037/a0017472

Neisser, U., Boodoo, G., Bouchard, J., Thomas, J., Boykin, A. W., Brody, N., \& ...Ceci, S. J. (1996). Intelligence: Knowns and unknowns. American Psychologist, 51(2), 77-101. doi:10.1037/0003-066X.51.2.77

Nell, V. (2000). Cross-cultural neuropsychological assessment: Theory and practice. Mahwah, NJ: Lawrence Erlbaum Associates, Inc.

Neville, H. A., Heppner, M. J., Louie, C. E., Thompson, C. E., Brooks, L., \& Baker, C. E. (1996). The impact of multicultural training on White racial identity attitudes and therapy competencies. Professional Psychology: Research and Practice, 27(1), 83-89. doi:10.1037/0735-7028.27.1.83

Neville, H., Spanierman, L., \& Doan, B. (2006). Exploring the association between color-blind racial ideology and multicultural counseling competencies. Cultural Diversity and Ethnic Minority Psychology, 12(2), 275-290. doi:10.1037/1099-9809.12.2.275

O’Bryant, S., O’Jile, J., \& McCaffrey, R. (2004). Reporting of demographic variables in neuropsychological research: Trends in the current literature. The Clinical Neuropsychologist, 18(2), 229-233. doi:10.1080/13854040490501439

Ottavi, T. M., Pope-Davis, D. B., \& Dings, J. (1994). Relationship between White racial identity attitudes and self-reported multicultural counseling competencies. Journal of Counseling Psychology, 41(2), 149 -154. doi:10.1037/0022-0167.41.2.149

Pedraza, O., \& Mungas, D. (2008). Measurement in cross-cultural neuropsychology. 
Neuropsychology Review, 18(3), 184-193. doi:10.1007/s11065-008-9067-9

Peterson, R. L., McHolland, J. D., Bent, R. J., David-Russell, E., Edwall, G. E., \& Polite, K., \& ...Stricker, G. (Eds.). (1992). The core curriculum in professional psychology.

Washington DC: American Psychological Association.

Perez-Arce, P., \& Puente, A. (1996). Neuropsychological assessment of ethnic-minorities: The case of assessing Hispanics living in North America. In R. J. Sbordone, \& C. J. Long (Eds.), Ecological validity of neuropsychological testing (pp. 283-300). Boca Raton, FL: St. Lucie Press.

Perinelli, E., \& Gremigni, P. (2016). Use of social desirability scales in clinical psychology: A systemic review. Journal of Clinical Psychology, 72(6), 534-551. doi:10.1002/jclp.22284

Perry, J. C., Vance, K. S., \& Helms, J. E. (2009). Using the people of color racial identity attitude scale among Asian American college students: An exploratory factor analysis. American Journal of Orthopsychiatry, 79(2), 252-260. doi:10.1037/a0016147

Phay, A., Gainer, C., \& Goldstein, G. (1986). Clinical interviewing of the patient and history in neuropsychological assessment. In T. Incagnoli, G. Goldstein, \& C. J. Golden (Eds.), Clinical application of neuropsychological batteries (pp. 45-73). New York, NY: Plenum Press.

Phinney, J. (1992). The multigroup ethnic identity measure: A new scale for use with adolescents and youth adults from diverse groups. Journal of Adolescent Research, 7(2), 156-17. doi:10.1177/074355489272003

Ponterotto, J. G., Gretchen, D., Utsey, S. O., Rieger, B. P., \& Austin, R. (2002). A revision of the Multicultural Counseling Awareness Scale. Journal of Multicultural Counseling \& Development, 30(3), 153-180. doi:10.1002/j.2161-1912.2002.tb00489.x 
Ponterotto, J. G., \& Potere, J. C. (2003). The multicultural counseling knowledge and awareness scale: Validity, reliability and user guidelines. In D. B. Pope-Davis, H. L. K. Coleman, W. M. Liu, \& R. L. Toporek (Eds.), Handbook of multicultural competencies in counseling \& psychology (pp. 137-153). Thousand Oaks, CA: Sage Publications.

Ponterotto J. G., Rieger, B. T., Barrett, A., Harris, G., Sparks, R. \& Sanchez, C. M., \& Magids, D. M. (1996). Development and initial validation of the multicultural counseling awareness scale. In G. R. Sodowsky, \& J. C. Impara (Eds.), Multicultural assessment in counseling and clinical psychology (pp. 247-282). Lincoln, NE: Buros Institute of Mental Measurements.

Ponterotto, J. G., Rieger, B. T., Barrett, A., \& Sparks, R. (1994). Assessing multicultural counseling competence: A review of instrumentation. Journal of Counseling \& Development, 72(3), 316-322. doi:10.1002/j.1556-6676.1994.tb00941.x

Ponterotto, J. G., Sanchez, C. M., \& Magids, D. M. (1991, August). Initial development and validation of the Multicultural Counseling Awareness Scale. Poster presented at the annual meeting of the American Psychological Association, San Francisco, CA.

Pope, R. L., \& Mueller, J. A. (2000). Development and initial validation of the Multicultural Competence in Student Affairs-Preliminary 2 Scale. Journal of College Student Development, 41(6), 599-608. doi:10.1.1.707.9765

Pope-Davis, D. B., \& Ottavi, T. M. (1994). Examining the association between self-reported multicultural counseling competencies and demographics variables among counselors. Journal of Counseling \& Development, 72(6), 651-654. doi:10.1002/j.15566676.1994.tb01697.x

Pope-Davis, D. B., \& Ottavi, T. M. (1994). The relationship between racism and racial identity 
among White Americans: A replication and extension. Journal of Counseling \& Development, 72(3), 293-297. doi:10.1002/j.1556-6676.1994.tb00937.x

Pope-Davis, D. B., Reynolds, A. L., Dings, J. G., \& Nielson, D. (1995) Examining multicultural counseling competencies of graduate students in psychology. Professional Psychology: Research and Practice, 26(3), 322-329. doi:10.1037/0735-7028.26.3.322

Pope-Davis, D. B., Reynolds, A. L., Dings, J. G., \& Ottavi, T. M. (1994). Multicultural competencies of doctoral interns at university counseling centers: An exploratory investigation. Professional Psychology: Research and Practice, 25(4), 466-470. doi:10.1037/0735-7028.25.4.466

Puente, A. E., \& Ardila, A. (2000). Neuropsychological assessment of Hispanics. In E. FletcherJanzen, T. L. Strickland, \& C. R. Reynolds (Eds.), Handbook of cross-cultural neuropsychology (pp. 87-104). New York, NY: Plenum Publishers

Puente, A. E., \& Agranovich, A. V. (2002). Are neuropsychological tests measuring cultural knowledge? A review of V. Nell cultural neuropsychological assessment: Theory and practice. Applied Neuropsychology, 9, 121-124. doi:10.1027//02698803.15.2.128

Puente, A. E., \& Agranovich, A. V. (2004). The cultural in cross-cultural neuropsychology. In G. Goldstein, S. Beers, \& M. Hersen (Eds.), Comprehensive Handbook of Psychological Assessment (pp. 321-333). Hoboken, New Jersey: John Wiley \& Sons.

Puente, A. E., \& Marcotte, A. (2000). A history of Division 40 (Clinical Neuropsychology). In D. Dewsbury (Ed.), Unification through division: Histories of the division of the American Psychological Association. (Vol V.) (pp.137-160). Washington, DC: American Psychological Association. 
Puente, A. E., \& Perez-Garcia M. P. (2000). Psychological assessment of ethnic minorities. In G. Goldstein, \& M. Hersen (Eds.), Handbook of psychological assessment (pp. 527-551). Boston, MA: Allyn \& Bacon.

Puente, A. E., Perez-Garcia, M., Lopez, R., Hidalgo-Ruzzante, N., \& Fasfous, A. (2013). Neuropsychological assessment of culturally and educationally dissimilar individuals. In F. Paniagua, \& A. Yamada (Eds.), Handbook of multicultural mental health: Assessment and treatment of diverse populations. ( $2^{\text {nd }}$ ed.) (pp. 225-241). San Diego, CA: Academic Press.

Puente, A. E., Ojeda, C., Zink, D., \& Portiollo Reyes, V. (2015). Neuropsychological testing of Spanish speakers. In K. Geisinger (Ed.), Psychological testing of Hispanics: Clinical cultural and intellectual issues. (2 $2^{\text {nd }}$ ed.) (pp. 135-152). Washington, DC: American Psychological Association.

Ramirez, M., Ford, M. E., Stewart, A. L., \& Teresi, J. A. (2005). Measurement issues in health disparities research. Health Services Research, 40(5), 1640-1657. doi:10.1111/j.14756773.2005.00450.x

Ready, R., \& Veague, H. (2014). Training in psychological assessment: Current practices of clinical psychology programs. Professional Psychology: Research and Practice, 45(4), 278-282. doi:10.1037/a0037439

Reynolds, W. M. (1982). Development of reliable and valid short forms of the marlowe-crowne social desirability scale. Journal of Clinical Psychology, 38(1), 119-125. doi:10.1002/1097-4679(198201)38:1119

Rivera Mindt, M. (2018, February). Integration of cultural and linguistic competency into neuropsychology training. In A. Thames (Chair), Challenging the status quo: Future 
directions in cultural neuropsychology. Symposium conduced at the Annual Meeting of the International Neuropsychology Society, Washington, DC.

Rivera Mindt, M., Byrd, D., Saez, P., \& Manly, J. (2010). Increasing culturally competent neuropsychological services for ethnic minority populations: A call to action. The Clinical Neuropsychologist, 24(3), 429-453. doi:10.1080/13854040903058960

Roth, R., Koven, N., \& Pendergrass, J. (2007). An Introduction to structural and functional neuroimaging. In H. MacNeill, \& D. Wedding (Eds.), Neuropsychology handbook. New York, NY: Springer

Rubin, N. J., Bebeau, M., Leigh, I. W., Lichtenberg, J. W., Nelson, P. D., Portnoy, S., \& Kaslow, N. J. (2007). Competency movement within psychology: An historical perspective. Professional Psychology: Research and Practice, 38(5), 452-462. doi:10.1037/0735$7028 \cdot 38.5 .452$

Sagun, J. N. (2014). Psychologists' multicultural training on racial/ethnic minority issues and multicultural competency. (Doctoral dissertation). Retrieved from Proquest Dissertations $\&$ Theses. (3624657).

Salkind, N. (2010). Encyclopedia of research design. Thousand Oaks, CA: Sage Publications. doi: $10.4135 / 9781412961288$

Sue, D. W., \& Sue, D. (2016). Counseling the culturally diverse. ( $7^{\text {th }}$ Edition). Hoboken, NJ: Wiley \& Sons Inc.

Sanchez, D., \& Germine, H. (2016). Ethnic group differences in racial identity attitudes, perceived discrimination and mental health outcomes in African American, Black Caribbean and Latino Caribbean college students. International Journal of Culture and Mental Health, 9(1), 31-43. doi:10.1080/17542863.2015.1081955 
Sashidharan, T., Pawlow, L. a, \& Pettibone, J. C. (2012). An examination of racial bias in the Beck Depression Inventory-II. Cultural Diversity \& Ethnic Minority Psychology, 18(2), 203-9. doi:10.1037/a0027689.

Schlomer, G. L., Bauman, S., \& Card, N. A. (2010). Best practices for missing data management in counseling psychology. Journal of Counseling Psychology, 57(1), 1-10. doi:10.1037/a0018082

Sellers, R. M., Smith, M. A., Shelton, J. N., Rowley, S. A. J., \& Chavous, T. M. (1998). Multidimensional model of racial identity: A reconceptualization of African American racial identity. Personality and Social Psychology Review, 2(1), 18-39. doi:10.1207/s15327957pspr0201_2

Sheu, H. B., \& Lent, R. W. (2007). Development and initial validation of the multicultural counseling self-efficacy scale- racial diversity form. Psychotherapy: Theory, Research, Practice, Training, 44(1), 30-45. doi:10.1037/0033-3204.44.1.30

Sigeti, R. J. (2013). Multicultural competence in medical education: Exploring the extent that racial identity, multicultural education, and multicultural experiences are associated with levels of multicultural competence among third year medical students. (Doctoral dissertation). Retrieved from Proquest Dissertations \& Theses. (3598755).

Smedley, B. D, Stith, A. Y., \& Nelson, A. R. (2003). Unequal treatment: Confronting racial and ethnic disparities in health care. Washington, DC: National Academies Press.

Sodowsky, G. R., Kuo-Jackson, P. Y., Richardson, M. F., \& Corey, A. T. (1998). Correlates of self-reported multicultural competencies: Counselor multicultural social desirability, race, social inadequacy, locus of control racial ideology, and multicultural training. Journal of Counseling Psychology, 45(3), 256-264. doi:10.1037/0022-0167.45.3.256 
Sperry, R. W. (1961). Cerebral organization and behavior: The split brain behaves in many respects like two separate brains, providing new research possibilities. Science, 133(3466), 1749-1757. doi:133.3466.1749

Sperry, R. W. (1965). Mind, brain, and humanist values. In J. R. Platt (Ed.), New views of the nature of man (pp. 71-92). Chicago: University of Chicago Press.

Sue, D. W., Bernier, Y., Durran, A., Feinberg, L., Pedersen, P. B., Smith, E. J., \& Vasquez-Nuttal, E. (1982). Position paper: Cross-cultural counseling competencies. The Counseling Psychologist, 10(2), 45-52. doi:10.1177/0011000082102008

Sue, D. W., Arredondo, P., \& McDavis, R. J. (1992). Multicultural competencies/standards: A call to the profession. Journal of Counseling \& Development, 70(4), 477-486. doi:10.1002/j.1556-6676.1992.tb01642.x

Sue, S. (1998). In search of cultural competence in psychotherapy and counseling. American Psychologist, 53(4), 440-448. doi:10.1037/0003-066X.53.4.440

Sue, D. W. (2001). Multidimensional facets of cultural competence. The Counseling Psychologist, 29(6), 790-821. doi:10.1177/0011000001296002

Sue, D. W., Capodilupo, C. M., Torino, G. C., Bucceri, J. M., Holder, A. M., \& Nadal, K. L. (2007). Racial microaggressions in everyday life: Implications for clinical practice. American Psychologist, 62(4), 271-286. doi:10.1037/0003-066X.62.4.271

Sue, S., Zane, N., Hall, G., \& Berger, L. (2009). The case for cultural competency in psychotherapeutic interventions. Annual Review for Psychology, 60, 525-548. doi:10.1146/annurev.psych.60.110707.163651

Sue, D. W., \& Sue, D. (2016). Counseling the culturally diverse. ( $7^{\text {th }}$ Edition). Hoboken, NJ: Wiley \& Sons Inc. 
Swanson, J. L., Tokar, D. M., \& Davis, L. E. (1994). Content and construct validity of the White Racial Identity Attitude Scale. Journal of Vocational Behavior, 44(2), 198-217. doi:10.1006/jvbe.1994.1014

Thompson, C. E., Carter, R. T. (2012). Racial identity theory: Applications to individual, group, and organizational interventions. Mahwah, NJ: Lawrence Erlbaum Associates

Toia, A., Herron, W. G., Primavera, L. H., \& Javier, R. A. (1997). Ethnic diversification in clinical psychology graduate training. Cultural Diversity and Mental Health, 3(3), 193206. doi:10.1037/1099-9809.3.3.193

Tokar, D. M., \& Swanson, J. L. (1991). An investigation of the validity of Helms's (1984) model of White racial identity development. Journal of Counseling Psychology, 38(3), 296-301. doi:10.1037/0022-0167.38.3.296

Torres-Rivera, E., Phan, L. T., Maddux, C., Wilbur, M. P., \& Garett, M. T. (2001). Process versus content: Integrating personal awareness and counseling skills to meet the multicultural challenge of the twenty-first century. Counselor Education and Supervision, 41, 28-40. doi: 10.1002/j.1556-6978.2001.tb01266.x

Tuckman, B. W. (1999). Conducting educational research (5th ed.). Fort Worth TX: Harcourt Brace College Publishers.

Tuokko, H. A., Chou, P. H. B., Bowden, S. C., Simartd, M., Ska, B., \& Crossley, M. (2009). Partial measurement equivalence of French and English versions of the Canadian study of health and aging neuropsychological battery. Journal of International Neuropsychological Society, 15(3), 416-425. doi:10.1017/S1355617709090602

Umaña-Taylor, A. J., Yazedjian, A., \& Bamaca-Gomez, M. (2004). Developing the ethnic identity scale using Eriksonian and social identity perspectives. Identity, 4(1), 9-38. 
doi:10.1207/S1532706XID0401_2

U.S. Census Bureau. (2011a). Population distribution and change: 2000 to 2010. Retrieved from http://2010.census.gov/2010 census/

U.S. Census Bureau. (2011b). Table 6. Resident population by sex, race, and Hispanic-origin status: 2000 to 2009. Washington, DC: U.S. Census Bureau. Retrieved from http://www.census.gov/compendia/statab/2011/tables/11s0006.pdf

Van Gorp, W. G., Myers, H. F., \& Drake, E. B. (2000). Neuropsychology training: Ethnocultural considerations in the context of general competency training. In E. Fletcher-Janzen, T. L. Strickland, \& C. R. Reynolds (Eds.), Handbook of cross-cultural neuropsychology (pp. 19-27). New York, NY: Kluwer Academic/Plenum Publishers.

Vereen, L. G., Hill, N. R., \& McNeal, D. T. (2008). Perceptions of multicultural counseling competency: Integration of the curricular and the practical. Journal of Mental Health Counseling, 30(3), 226-236. doi:10.17744/mehc.30.3.g34u122m16q64g44

Vygotsky, L. (1978). Mind in society. Cambridge, MA: Harvard University Press.

Wajman, J., Bertolucci, P., Mansur, L., \& Gauthier, S. (2015). Culture as a variable in neuroscience and clinical neuropsychology. Dementia and Neuropsychology, 9(3), 203218. doi:10.1590/1980-57642015DN93000002

Welsh, K. A., Fillenbaum, G., Wilkinson, W., Heyman, A., Mohs, R. C., Stern, Y., \& ...Beekly, D. (1995). Neuropsychological test performance in African-American and white patients with Alzheimer's disease. Neurology, 45(2), 2207-2211. doi:10.1212/WNL.45.12.2207

Wong, M., Strickland, T., Fletcher-Janzen, E., Ardila, A. \& Reynolds, C. (2000). Theoretical and practical issues in the neuropsychological assessment and treatment of culturally 
dissimilar patients. In E. Fletcher-Janzen, T. Strickland, \& C. Reynolds (Eds.), Handbook of cross-cultural neuropsychology (pp. 3-19). New York, NY: Kluwer Academic/Plenum Publishers 


\title{
APPENDICES
}

\section{APPENDIX A: IRB Approval}

\section{W. WestVurginiaUniversity. \\ Office of Research Integrity and Compliance \\ aA6 ChesNut aldeg nono mongantown, wV 26506}

\section{Acknowledgement Letter Exempt Initial Protocol Review}

\author{
Action Date $\quad 08 / 09 / 2017$ \\ To John Blake \\ From WVU Office of Research Integrity and Compliance \\ Approval Date $\quad 07 / 13 / 2017$ \\ Expiration Date $\quad 07 / 12 / 2020$ \\ Subject \\ Acknowledgement Letter Exempt Initial Protocol Review \\ Protocol Number 1704558085A001 \\ Title \\ Predictors of perceived multicultural competence in neuropsychology trainees
}

The above-referenced study was reviewed by the West Virginia University Institutional Review Board IRB and was granted exemption in accordance with 45 CFR 46.101 .

- Amendment Wording: I am adding to the requirements for participation and participant eligibility to increase participant enrollment. I would like to also include individuals who are students enrolled in Canadian Psychological Association (CPA) accredited programs within a neuropsychology track, as well as individuals who are trainees in neuropsychological postdoctoral programs that are members of the Association of Postdoctoral Programs in Clinical Neuropsychology (APPCN). I list the eligibility requirements on Cover Letter 1 and Cover Letter 2, so I will edit to reflect additions. The accreditation standards of the CPA and APPCN are widely accepted and similar to the accreditation standards of the American Psychological Association (APA).

Documents reviewed and/or approved as part of this submission:

CoverLetter1.docx: 2017-07-28-04:00

CoverLetter2.docx: 2017-07-28-04:00

ResearchSurvey.docx: 2017-06-28-04:00

Issues Addressed by SMR correspondence.docx: 2017-06-28-04:00

Debrief, Resources, Counseling List.docx: 2017-06-28-04:00 
Documents for use in this study have been acknowledged and are available in the WVUkc system in the Notes and Attachments section of your protocol.

The Office of Research Integrity and Compliance is here to provide assistance to you from the initial submission of an IRB protocol and all subsequent activity. Please feel free to contact us by phone at 304.293 .7073 with any question you may have. Thank you.

WVU Office of Research Integrity and Compliance

Date:08/09/2017

Signed:

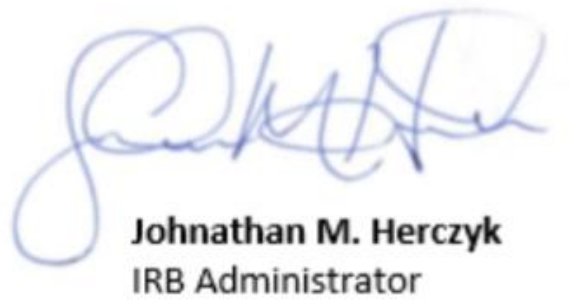




\section{APPENDIX B: Introductory Email}

Dear Training Director,

WVUIRB APPROVAL \# 1704558085

My name is Hannah Greenbaum, and I am a Counseling Psychology doctoral candidate at West Virginia University. In conjunction with my advisors, Christine Schimmel, Ed.D. and John Blake, Ph.D. I am writing you to let you know about our research study regarding trainee experiences and multicultural competence in neuropsychology.

This is a request for you to forward this link to the trainees in your APA or CPA-accredited clinical psychology graduate program within the neuropsychology track; or APA-accredited or CPA-accredited neuropsychology internship program; or APA or American Association of Postdoctoral Programs in Clinical Neuropsychology (APPCN) accredited neuropsychology postdoctoral program so that we could have representation from your program in this study.

The criteria for participation in this study are as follows:

1. Clinical psychology doctoral student within a neuropsychology track at an APAaccredited or CPA-accredited program; an intern at an APA-accredited or CPAaccredited program within a neuropsychology track; or a neuropsychology postdoctoral trainee at an APA-accredited or APPCN member program.

2. 18 years of age or older.

This study has been approved by the West Virginia University Institutional Review Board (WVU IRB). All participants will be monetarily compensated with a $5 \$$ gift certificate to Starbucks upon completion of the 20-minute survey. All responses will be confidential If you have questions please contact me at: hkgreenbaum@mix.wvu.edu.

Thank you for your assistance in our participant recruitment! 


\section{APPENDIX C: Email Reminder}

WVUIRB APPROVAL \# 1704558085

Dear Training Director,

My name is Hannah Greenbaum, and I am a Counseling Psychology doctoral candidate at West Virginia University. Approximately four weeks ago, I wrote requesting you to forward this link to the trainees in your APA or CPA-accredited clinical psychology graduate program within the neuropsychology track; or APA-accredited or CPA-accredited neuropsychology internship program; or APA or American Association of Postdoctoral Programs in Clinical Neuropsychology (APPCN) accredited neuropsychology postdoctoral program so that we could have representation from your program in this study.

The purpose of this study is to explore areas that are related to multicultural competence in neuropsychological trainees, and more specifically how neuropsychological trainees develop multicultural competence.

The criteria for participation in this study are as follows:

1. Clinical psychology doctoral student within a neuropsychology track at an APAaccredited or CPA-accredited program; an intern at an APA-accredited or CPAaccredited program within a neuropsychology track; or a neuropsychology postdoctoral trainee at an APA-accredited or APPCN member program.

2. 18 years of age or older.

This study has been approved by the West Virginia University Institutional Review Board (WVU IRB). All participants will be monetarily compensated with a $5 \$$ gift certificate to Starbucks upon completion of the 20-minute survey. All responses will be confidential. If you have questions please contact me at: $\underline{\text { hkgreenbaum@mix.wvu.edu. }}$

I appreciate that your time is limited, thank you for assistance in our participant recruitment! 


\section{APPENDIX D: Informed Consent}

Study Title: Neuropsychology training: Predictors of perceived MC Investigators: Christine Schimmel, Ed.D.

John Blake, Ph.D.

Hannah Greenbaum, M.A.

WVU IRB \#: 1704558085

Please read this consent document carefully before deciding to participate in this study.

\section{Introduction}

Hannah Greenbaum, M.A. is conducting this study in fulfillment of the requirements for the degree of Doctor of Philosophy in Counseling Psychology in the Department of Counseling, Rehabilitation Counseling, and Counseling Psychology at West Virginia University. The purpose of this study is to explore areas that are related to MC in neuropsychological trainees, and more specifically how neuropsychological trainees develop MC. Hannah Greenbaum, M.A., Christine Schimmel, Ed.D., and John Blake, Ph.D. seek to recruit approximately 200 neuropsychological trainees in completion of this study.

\section{Criteria for Participation:}

1. Clinical psychology doctoral student within a neuropsychology track at an APAaccredited or CPA-accredited program; an intern at an APA-accredited or CPAaccredited program within a neuropsychology track; or a neuropsychology postdoctoral trainee at an APA-accredited or American Association of Postdoctoral Programs in Clinical Neuropsychology (APPCN) member program.

2. 18 years of age or older.

\section{Time required:}

If you choose to participate, you will be asked to complete an online research survey that will take approximately $\mathbf{2 0}$ minutes and provide valuable information about $\mathrm{MC}$ in neuropsychological training.

\section{Risks and Benefits:}

By participating in this study, you will add to the growing research on professional development and $\mathrm{MC}$ in the field of neuropsychology. There are no anticipated risks to participating in this study.

\section{Compensation:}

Five-dollar electronic gift certificate to Starbucks.

\section{Confidentiality:}

No identifying information will be linked to survey data. You will be asked to enter your email address at the end of the survey if you would like to be compensated with $5 \$$ gift certificate to Starbucks. Data will be safely stored on a secure website. There is minimal risk that security of any online data may be breached, but since the online host uses several layers of encryption and 
firewalls and your data will be removed from the server soon after you complete the study, it is highly unlikely that a security breach of the online data will result in any adverse consequence. (See Qualtrics's privacy statement for more details: http://www.qualtrics.com/privacystatement/).

Voluntary participation:

Your participation in this study is completely voluntary. There is no penalty for not participating.

Right to withdraw from the study:

You have the right to withdraw from the study at any time without consequence. Furthermore, you do not have to answer any question in the survey that you do not wish to answer. All survey completers will be directed to an opportunity to receive $5 \$$ electronic gift certificate to Starbucks.

Whom to contact if you have questions about the study:

Hannah Greenbaum, M.A.

hkgreenbaum@mix.wvu.edu

Christine Schimmel, Ed.D

Chris.Schimmel@mail.wvu.edu

John Blake, Ph.D.

jpblake@mail.wvu.edu

Whom to contact about your rights as a research participant in the study:

West Virginia University Office of Research Integrity and Compliance, 886 Chestnut Ridge

Road, PO Box 6845 Morgantown, WV 26506-6845; (304) 293-7073 | Fax: (304) 293-309

\section{Agreement:}

Please select one of the following options:

1. If you have read these statements, understand them, and consent to participate, please click on the "next" button below to begin the survey.

2. If you have read these statements, understand them, and do not want to be in this study, checking this box will take you out of the survey. 


\section{APPENDIX E: Demographic Questions}

1. What is your current age?

2. With what gender do you identify?
( ) Female
() Male
( ) Transitioning Female to Male (TF2M)
( ) Transitioning Male to Female (TM2F)
( ) Custom:

3. Do you speak any languages in addition to English?

( ) Yes

( ) No

If Yes, please specify:

4. Do you identify as a person of color?

( ) Yes

( ) No

5. How do you primarily identify yourself racially or ethnically?
( ) African American/Black
( ) Arab/Arab American
( ) Asian American/Asian Pacific Islander
( ) European American/Caucasian
( ) Hispanic/Latino(a)/Hispanic American
( ) International/Immigrant
( ) Middle Eastern/Middle Eastern American
( ) Native American/American Indian
( ) Biracial/Multiracial (please describe)
( ) Custom

6. Are you a member of any of the following groups that you believe is or has been the target of discrimination? (Check ALL that apply)
( ) Gender Minority
( ) Persons with a Disability
( ) Sexual Minority
( ) Religious Minority
( ) Custom
( ) None of the above

7. Describe the racial/ethnic composition of the community you grew up: 

( ) Nearly all people of color
( ) Mostly people of color
( ) $50-50$
( ) Mostly White
( ) Nearly all White

8. Have you ever visited or lived in any countries that are different from your country of origin?

( ) Yes

( ) No

If Yes, how many:

9. In what level of training are you currently?
( ) Graduate (doctoral)
( ) Internship
( ) Postdoctoral

10. Indicate in which of the following field of psychology you will receive/received your doctoral degree?
( ) Clinical
( ) Counseling
( ) School
( ) Custom

11. Indicate the number of multicultural research projects (e.g., poster presentations, papers, etc.) you have contributed to/completed.

12. Indicate the number of multicultural workshops focused in multiculturalism that you have participated/completed from the start of your graduate level training to present.

13. Indicate the overall percentage of time graduate level coursework was/is related to multicultural issues/diversity themes.

14. Indicate the overall percentage of time in clinical supervision was/is spent discussing to multicultural issues/diversity themes. 
15. Indicate the overall number of clients in your current clinical caseload within the past month that identify as:

(1) 0 clients (2) 1-2 clients (3) 3-4 clients (4) 5 or more clients
( ) African American/Black
() Arab/Arab American
( ) Asian American/Asian Pacific Islander
( ) European/Caucasian
( ) Hispanic/Latino(a)/Hispanic American
( ) International/Immigrant
( ) Middle Eastern/Middle Eastern American
( ) Native American/American Indian
( ) Biracial (please describe)

16. Rank (1-8 or 1-9) where you have learned THE MOST about racial/ethnic groups different from your own?
( ) Personal interactions outside of training and/or clinical work
( ) Clinical experience/practica
( ) Discussions in clinical supervision
( ) Community outreach/advocacy
( ) Popular media (TV, movies, magazines, etc.)
( ) Professional conferences/workshops
( ) Research focused in multiculturalism
( ) Graduate school coursework
( ) Custom

17. Indicate how much your multicultural knowledge, skills, and awareness changed from the start of your graduate training to present.
() Substantial
() Some
( ) Slightly
( ) None at all 


\section{APPENDIX F: Marlow-Crowne Social Desirability Scale Short Form Copyrighted by Crowne \& Marlowe, 1960; Reynolds, 1982}

Listed below are a number of statements concerning personal attitudes and traits. Rate each item and decide whether the statement is true or false as it pertains to you.

Read each item and decide

1. It is sometimes hard for me to go on with my work if I am not encouraged.

( ) True ( ) False

2. I sometimes feel resentful when I don't get my way.

( ) True ( ) False

3. On a few occasions, I have given up doing something because I thought too little of my ability.

( ) True ( ) False

4. There have been times when I felt like rebelling against people in authority even though I knew they were right.

( ) True ( ) False

5. No matter who I'm talking to, I'm always a good listener.

( ) True ( ) False

6. There have been occasions when I took advantage of someone.

( ) True ( ) False

7. I'm always willing to admit it when I make a mistake.

( ) True ( ) False

8. I sometimes try to get even rather than forgive and forget.

( ) True ( ) False

9. I am always courteous, even to people who are disagreeable.

( ) True ( ) False

10. I have never been irked when people expressed ideas very different from my own.

( ) True ( ) False

11. There have been times when I was quite jealous of the good fortune of others.

( ) True ( ) False

12. I am sometimes irritated by people who ask favors of me.

( ) True ( ) False

13. I have never deliberately said something that hurt someone's feelings.

( ) True ( ) False 
APPENDIX G: Multicultural Counseling Knowledge and Awareness Scale (MCKAS) Copyrighted by Joseph G. Ponterotto, 1997 (Altered with permission by Kutayli, 2004)

\begin{tabular}{|c|c|c|c|c|c|c|c|c|}
\hline \multicolumn{2}{|r|}{$\begin{array}{l}\text { Instructions: Using the following scale, rate } \\
\text { the truth of each item as it applies to you. }\end{array}$} & $\begin{array}{l}\text { Not at all } \\
\text { true }\end{array}$ & & & $\begin{array}{l}\text { Somewhat } \\
\text { True }\end{array}$ & & & $\begin{array}{l}\text { Totally } \\
\text { True }\end{array}$ \\
\hline \multicolumn{2}{|c|}{ Item } & 1 & 2 & 3 & 4 & 5 & 6 & 7 \\
\hline 1 & $\begin{array}{l}\text { I believe all clients should maintain } \\
\text { direct eye contact during interviews. }\end{array}$ & & & & & & & \\
\hline 2 & $\begin{array}{l}\text { I check up on my minority/cultural } \\
\text { assessment skills by monitoring my } \\
\text { functioning- via consultation, } \\
\text { supervision, and continuing education. }\end{array}$ & & & & & & & \\
\hline 3 & $\begin{array}{l}\text { I am aware some research indicates that } \\
\text { minority clients receive "less preferred" } \\
\text { forms of assessment than majority } \\
\text { clients. }\end{array}$ & & & & & & & \\
\hline 4 & $\begin{array}{l}\text { I think that clients who do not discuss } \\
\text { intimate aspects of their lives are being } \\
\text { resistant and defensive. }\end{array}$ & & & & & & & \\
\hline 5 & $\begin{array}{l}\text { I am aware of certain assessment skills, } \\
\text { techniques, or approaches that are more } \\
\text { likely to transcend culture and be } \\
\text { effective with any clients. }\end{array}$ & & & & & & & \\
\hline 6 & $\begin{array}{l}\text { I am familiar with the "culturally } \\
\text { deficient" and "culturally deprived" } \\
\text { depictions of minority mental health and } \\
\text { understand how these labels serve to } \\
\text { foster and perpetuate discrimination. }\end{array}$ & & & & & & & \\
\hline 7 & $\begin{array}{l}\text { I feel all the recent attention directed } \\
\text { towards multicultural issues in } \\
\text { psychology is overdone and not really } \\
\text { warranted. }\end{array}$ & & & & & & & \\
\hline 8 & $\begin{array}{l}\text { I am aware of individual differences that } \\
\text { exist among members within a particular } \\
\text { ethnic group based on values, beliefs, and } \\
\text { level of acculturation. }\end{array}$ & & & & & & & \\
\hline
\end{tabular}




\begin{tabular}{|c|c|c|c|c|c|c|c|c|}
\hline 9 & $\begin{array}{l}\text { I am aware some research indicates that } \\
\text { minority clients are more likely to be } \\
\text { diagnosed with neuropsychological } \\
\text { impairment than are majority clients. }\end{array}$ & & & & & & & \\
\hline 10 & $\begin{array}{l}\text { I think that clients should perceive the } \\
\text { nuclear family as the ideal social unit. }\end{array}$ & & & & & & & \\
\hline & $\begin{array}{l}\text { Instructions: Using the following scale, } \\
\text { rate the truth of each item as it applies to } \\
\text { you. }\end{array}$ & $\begin{array}{l}\text { Not at all } \\
\text { true }\end{array}$ & & & $\begin{array}{l}\text { Somewhat } \\
\text { True }\end{array}$ & & & $\begin{array}{l}\text { Totally } \\
\text { True }\end{array}$ \\
\hline & Item & 1 & 2 & 3 & 4 & 5 & 6 & 7 \\
\hline 11 & $\begin{array}{l}\text { I think that being highly competitive and } \\
\text { achievement oriented are traits that all } \\
\text { clients should work towards. }\end{array}$ & & & & & & & \\
\hline 12 & $\begin{array}{l}\text { I am aware of the differential } \\
\text { interpretations of nonverbal } \\
\text { communication (e.g., personal space, eye } \\
\text { contact, handshakes) within various } \\
\text { racial/ethnic groups. }\end{array}$ & & & & & & & \\
\hline 13 & $\begin{array}{l}\text { I understand the impact and operations of } \\
\text { oppression and the racist concepts that } \\
\text { have permeated the mental health } \\
\text { professions. }\end{array}$ & & & & & & & \\
\hline 14 & $\begin{array}{l}\text { I realize that psychologist-client } \\
\text { incongruities in problem } \\
\text { conceptualization and goals for } \\
\text { assessment may reduce psychologist } \\
\text { credibility. }\end{array}$ & & & & & & & \\
\hline 15 & $\begin{array}{l}\text { I am aware that some racial/ethnic } \\
\text { minorities see the profession of } \\
\text { psychology functioning to maintain and } \\
\text { promote the status and power of the } \\
\text { White Establishment. }\end{array}$ & & & & & & & \\
\hline 16 & $\begin{array}{l}\text { I am knowledgeable of acculturation } \\
\text { models for various ethnic minority } \\
\text { groups. }\end{array}$ & & & & & & & \\
\hline
\end{tabular}




\begin{tabular}{|c|c|c|c|c|c|c|c|c|}
\hline 17 & $\begin{array}{l}\text { I have an understanding of the role } \\
\text { culture and racism play in the } \\
\text { development of identity and worldviews } \\
\text { among minority groups. }\end{array}$ & & & & & & & \\
\hline 18 & $\begin{array}{l}\text { I believe that it is important to emphasize } \\
\text { objective and rational thinking in } \\
\text { minority clients. }\end{array}$ & & & & & & & \\
\hline 19 & $\begin{array}{l}\text { I am aware of culture-specific, that is } \\
\text { culturally indigenous, models of } \\
\text { rehabilitation for various racial/ethnic } \\
\text { groups. }\end{array}$ & & & & & & & \\
\hline 20 & $\begin{array}{l}\text { I believe that my clients should view a } \\
\text { patriarchal structure as the ideal. }\end{array}$ & & & & & & & \\
\hline 21 & $\begin{array}{l}\text { I am aware of both the initial barriers and } \\
\text { benefits related to the cross-cultural } \\
\text { professional relationship. }\end{array}$ & & & & & & & \\
\hline & $\begin{array}{l}\text { Instructions: Using the following scale, } \\
\text { rate the truth of each item as it applies to } \\
\text { you. }\end{array}$ & $\begin{array}{l}\text { Not at all } \\
\text { true }\end{array}$ & & & $\begin{array}{l}\text { Somewhat } \\
\text { True }\end{array}$ & & & $\begin{array}{l}\text { Totally } \\
\text { True }\end{array}$ \\
\hline & Item & 1 & 2 & 3 & 4 & 5 & 6 & 7 \\
\hline 22 & $\begin{array}{l}\text { I am comfortable with differences that } \\
\text { exist between me and my clients in terms } \\
\text { of race and beliefs. }\end{array}$ & & & & & & & \\
\hline 23 & $\begin{array}{l}\text { I am aware of institutional barriers which } \\
\text { may inhibit minorities from using } \\
\text { neuropsychological services. }\end{array}$ & & & & & & & \\
\hline 24 & $\begin{array}{l}\text { I think that my clients should exhibit } \\
\text { some degree of psychological } \\
\text { mindedness and sophistication. }\end{array}$ & & & & & & & \\
\hline 25 & $\begin{array}{l}\text { I believe that minority clients will benefit } \\
\text { most from assessment with a majority } \\
\text { who endorses White middle class values } \\
\text { and norms. }\end{array}$ & & & & & & & \\
\hline 26 & $\begin{array}{l}\text { I am aware that being born a White } \\
\text { person in this society carries with it } \\
\text { certain advantages. }\end{array}$ & & & & & & & \\
\hline
\end{tabular}




\begin{tabular}{|c|c|c|c|c|c|c|c|c|}
\hline 27 & $\begin{array}{l}\text { I am aware of the value assumptions } \\
\text { inherent in traditional assessment and } \\
\text { understand how these assumptions may } \\
\text { conflict with values of culturally diverse } \\
\text { clients. }\end{array}$ & & & & & & & \\
\hline 28 & $\begin{array}{l}\text { I am aware that some minorities see the } \\
\text { assessment process as contrary to their } \\
\text { own life experiences and inappropriate or } \\
\text { insufficient to their needs. }\end{array}$ & & & & & & & \\
\hline 29 & $\begin{array}{l}\text { I am aware that being born a minority in } \\
\text { this society brings with it certain } \\
\text { challenges that White people do not have } \\
\text { to face. }\end{array}$ & & & & & & & \\
\hline 30 & $\begin{array}{l}\text { I believe that all clients must view } \\
\text { themselves as their number one } \\
\text { responsibility. }\end{array}$ & & & & & & & \\
\hline 31 & $\begin{array}{l}\text { I am sensitive to circumstances (personal } \\
\text { biases, language dominance, stage of } \\
\text { ethnic identity development) which may } \\
\text { dictate referral of the minority client to a } \\
\text { member of his/her own racial/ethnic } \\
\text { group. }\end{array}$ & & & & & & & \\
\hline & $\begin{array}{l}\text { Instructions: Using the following scale, } \\
\text { rate the truth of each item as it applies to } \\
\text { you. }\end{array}$ & $\begin{array}{l}\text { Not at all } \\
\text { true }\end{array}$ & & & $\begin{array}{l}\text { Somewhat } \\
\text { True }\end{array}$ & & & $\begin{array}{l}\text { Totally } \\
\text { True }\end{array}$ \\
\hline & Item & 1 & 2 & 3 & 4 & 5 & 6 & 7 \\
\hline 32 & $\begin{array}{l}\text { I am aware that some minorities believe } \\
\text { psychologists lead minority students into } \\
\text { non-academic programs regardless of } \\
\text { student potential, preferences, or } \\
\text { ambitions. }\end{array}$ & & & & & & & \\
\hline
\end{tabular}




\section{APPENDIX H: People of Color Racial Identity Attitudes Scale (PRIAS)}

To obtain a copy of the PRIAS, contact: Janet E. Helms, Ph.D. Institute for the Study and Promotion of Race and Culture Department of Counseling Psychology Campion 318 Boston College Chestnut Hill, MA 02467 Telephone: 617-552-2482, ext. 1 Fax: 617-552-1981 Email: isprc@bc.edu 


\section{APPENDIX I: White Racial Identity Attitudes Scale (WRIAS)}

To obtain a copy of the WRIAS, contact: Janet E. Helms, Ph.D. Institute for the Study and Promotion of Race and Culture Department of Counseling Psychology Campion 318 Boston College Chestnut Hill, MA 02467 Telephone: 617-552-2482, ext. 1 Fax: 617-552-1981 Email: isprc@bc.edu 


\section{APPENDIX J: Debrief and Resources}

Thank you for your time completing this research survey. The purpose of this study was to assess the relationship between perceived multicultural competence among current neuropsychological trainees at the doctoral, internship, and postdoctoral levels and

This survey included questions that may be considered uncomfortable or difficult, particularly related to feelings and cognitions individuals have about their own race and the race of others. If you would like support around these topics the researcher suggests you consult resources on the American Psychological Association (APA) website. For example, the psychology help center includes links to resources nationwide.

Furthermore, the APA website includes resources and information about topics related to multicultural competence on division websites, such as: the Society of Counseling Psychology; the Society for the Psychology of Women; the Society for the Psychological Study of Lesbian, Gay, Bisexual and Transgender issues; the Society for the Psychology Study of Culture, Ethnicity, and Race; and the Society for the Psychological Study of Men and Masculinity. The Hispanic Neuropsychological Society is an additional resource for Spanish speaking and nonSpanish speaking trainees, psychologists, and the general public.

Lastly, if you experienced discomfort completing this research survey and/or have questions please contact the principle investigator.

Hannah Greenbaum, M.A.

hkgreenbaum@mix.wvu.edu 


\section{Curriculum Vitae}

\section{EDUCATION}

Doctor of Philosophy in Counseling Psychology

Expected 2019

West Virginia University (WVU), Morgantown, WV

Dissertation Title: Predictors of perceived multicultural

competence in neuropsychological trainees

Proposal Approved: 04/17/17

Master of Arts in Counseling

2012-2014

Santa Clara University (SCU), Santa Clara, CA

Bachelor of Arts in Psychology

University of California, Santa Cruz (UCSC), Santa Cruz, CA

2007-2014

\section{CLINICAL EXPERIENCE}

Predoctoral Intern in Pediatric Psychology: CHOC Children's Hospital of Orange County, Orange County, CA; August 2018-present

- Major rotation in neuropsychology and pulmonary.

- Minor and specialty rotations in neuropsychology, emergency department, psychopharmacology, and consultation and liaison.

Neuropsychology Extern: Children's National Health System, Division of Neuropsychology, Washington, DC; June 2017-present

- Performed neuropsychological evaluations to children and adolescents as part of a multidisciplinary team. Wrote integrated neuropsychological reports.

Supervisor: Jacqueline Sanz, PhD, ABPP-CN \& Leigh Sepeta, PhD

Psychology Practicum Student: WVU School of Medicine, Department of Behavioral Medicine and Psychiatry, Morgantown, WV; May 2016-May 2017

- Maintained a caseload of 6-8 children.

- Facilitated inpatient stress-management groups using progressive muscle relaxation and guided imagery techniques.

- Co-facilitated cognitive behavioral groups in the Comprehensive Opioid Addiction Treatment clinic.

Supervisor: Jennifer Ludrosky, $\mathrm{PhD}$

Neuropsychology Practicum Student: Allegheny General Hospital, Department of Psychiatry, Pittsburgh, PA; May 2015-July 2016

- Administered, scored, and interpreted outpatient neuropsychological assessments.

- Integrated data to formulate diagnoses and write neuropsychological reports.

Supervisor: Michael Franzen, PhD.

Counseling Practicum Student: Stanford University School of Medicine, Department of Child and Adolescent Psychiatry, Palo Alto, CA; August 2013-August 2014

- Provided pivotal response treatment (PRT) to children with autism spectrum disorder (ASD) as part of randomized control trial.

Supervisors: Antonio Hardan, MD, \& Grace Gengoux, PhD. 
Relief Residential Counselor: The Bill Wilson Center, Santa Clara, CA; December 2012-June 2013

- Provided therapeutic support to children and adolescents.

Instructor: The Bay School, Santa Cruz, CA; July 2011-June 2014

- Implemented applied behavior analysis (ABA), participated in Individualized Education Plan (IEP) meetings, transferred skills to caregivers

Supervisor: Andrea Gold, $\mathrm{PhD}$

\section{TEACHING EXPERIENCE}

Presenter: WVU School of Medicine, Department of Behavioral Medicine and Psychiatry, Psychology Section Didactic, Morgantown WV; January 2017

- Presented research and taught faculty, trainees, students, and residents about findings of survey research examining West Virginia licensed psychologists' training and practice.

Presenter: WVU School of Medicine, Department of Behavioral Medicine and Psychiatry, Neuropsychology Case Conference, Morgantown WV; February 2017

- Presented research and taught faculty, trainees, students, and residents about findings of survey research examining multicultural competence in neuropsychology.

Classroom Aide: Pacific Elementary School, Davenport, CA; September 2010-June 2011

- Assisted children 1 on 1 with special needs and transferred skills to caregivers.

Supervisor: William Rosse, $\mathrm{PhD}$

Writing Tutor: UCSC, Santa Cruz, CA; December 2007-June 2011

- Tutored undergraduate students in individual and group formats.

\section{RESEARCH EXPERIENCE}

Intern: American Psychological Association (APA), Department of Publications and Databases, Style Office, Washington, DC; May 2017- August 2018

- Contributed to research-reporting standards and refined APA Style products

Research Assistant: WVU School of Medicine, Department of Behavioral Medicine and Psychiatry, Morgantown, WV; March 2016-May 2017

- Investigated neurological and neuropsychological clinical factors distinguishing attention deficit hyperactivity disorder and post-traumatic stress disorder.

Supervisors: Stacie Leffard, $\mathrm{PhD}, \mathrm{ABPP}, \&$ Jennifer Ludrosky, $\mathrm{PhD}$

Graduate Assistant: WVU College of Education and Human Services, Office of the Dean, Morgantown, WV; May 2015-May 2017

- Wrote and edited manuscripts focused in educational psychology.

- Assisted faculty projects (e.g., data collection and analysis).

Supervisor: Cecil Smith, PhD

Research Assistant: WVU Blanchette Rockefeller Neurosciences Institute, Morgantown, WV; November 2014-November 2016

- Analyzed resting state connectivity MRI (rs-fcMRI).

- Administered neuropsychological assessment battery to children (ages 5-12).

Supervisors: Paola Pergami, MD, PhD, \& Marc Haut, PhD, ABPP-CN 
Research Assistant: WVU Blanchette Rockefeller Neurosciences Institute, Department of Neurobiology and Anatomy, Morgantown, WV; January 2015-September 2016

- Biomedical research study funded by the NIH investigating sensory processing and integration in adults with ASD. Administered neuropsychological assessment battery to adults (ages 18-28).

Supervisor: James Lewis, $\mathrm{PhD}$

Graduate Assistant: WVU Department of Counseling, Rehabilitation Counseling, and Counseling Psychology, Morgantown, WV; August 2014-May 2015

- Co-authored a manuscript investigating employment outcomes for people with spinal cord injury.

- Co-authored a book-chapter on multiculturalism and social justice.

Supervisors: John Blake, PhD, \& Jennifer Taylor, PhD

Research Assistant: Palo Alto Medical Foundation, Department of Veteran Affairs, Poly

Trauma Transitional Rehabilitation Program, Palo Alto, CA; March 2014-August 2014.

- Observed and assisted neuropsychological assessment administration.

- Scored neuropsychological assessment data.

Supervisors: Carey Pawlowski, PhD, ABPP-CN, Maya Yutsis, PhD, ABPP-CN

Research Assistant \& Coordinator: Stanford University, Psychophysiology Laboratory, Palo Alto, CA; December 2012-August 2014

- Collected and analyzed data on emotion regulation in children with ASD.

- Co-conducted fMRI sessions.

Supervisors: James Gross, PhD, Andrea Samson, PhD, \& Antonio Hardan, MD

Research Assistant, Youth Participatory Action Research: UCSC, Department of

Psychology, Santa Cruz, CA; September 2009-June 2011.

- Co-led meetings in the community with middle school-aged youth and collected data through ethnographic field note writing and observations.

Supervisor: Regina Langhout, $\mathrm{PhD}$

\section{BOOK CHAPTERS}

Shaw, J., Catania, B., Greenbaum, H., \& Taylor, J. (2016). Infusing multiculturalism and social justice from college to community. In M. Hickey (Ed.), Service learning in higher education (pp. 189-196). New York: NY: Peter Lang Publishing.

\section{JOURNAL PUBLICATIONS}

Greenbaum, H., Goodsir, H., Smith, C., \& Robinson, D. (2018). Female participation as topproducing authors, editors, and editorial board members in educational psychology journals from 2009-2016. Educational Psychology Review. https://doiorg.www.libproxy.wvu.edu/10.1007/s10648-018-9452-8.

Greenbaum, H. (2017). Silence and social justice. The National Psychologist, 26, 17.

Blake, J., Brooks, J., \& Greenbaum, H., Chan, F. (2016). Attachment and employment outcomes for people with spinal cord injury: The intermediary role of hope. Rehabilitation Counseling Bulletin, 60, 77-87. doi:10.11770034355215621036 
Greenbaum, H., Meyer, L., Smith, C., Barber, A., Henderson, H., \& Riel, D. (2016). Individual and institutional productivity in educational psychology journals from 2009 to 2014. Educational Psychology Review, 28, 215-223. doi:10.1007/s10648-016-9360-8

\section{INVITED SPEAKER}

Wilson, C. Greenbaum, H., \& Dean, P. (10/2016). West Virginia Licensed Psychologists Diversity Training, Knowledge and Leadership. West Virginia Psychological Association (WVPA) Fall Conference, Roanoke, WV.

\section{RESEARCH SYMPOSIA}

Shaw, J., Latorre, C., Molder, A., Shannon, B., Webb, B., Greenbaum, H., Berkey, S. (4/2016). Demystifying human trafficking in the United States. Great Lakes Regional Counseling Psychology Conference, Bloomington, IN.

Greenbaum, H. (8/2015). Results for exploring critical competencies for psychologists working with military populations. In J. Daniels (Discussant), Professional competencies in military psychology. APA Convention, ON, Canada.

\section{POSTER PRESENTATIONS}

Greenbaum, H., Jacqueline Sanz, Ph.D., ABPP, Mary Donofrio, M.D., \& Patrick Callahan, M.D. (4/2019). Neurodevelopmental trajectory in a child with congenital heart disease. American Academy of Pediatric Neuropsychology Annual Conference, Las Vegas, NV.

Greenbaum, H., Taylor, J., \& Blake, J. (8/2016). Training in neuropsychology: What is important for multicultural competence? APA Convention, Division 40, Denver, CO.

Shaw, J., Shannon, B., Scott, O., \& Greenbaum, H. (4/2016). Campus to community: Speak out reach out. Great Lakes Regional Counseling Psychology Conference, Bloomington, IN.

Greenbaum, H., Thieroff, G., Haut, M., \& Pergami, P. (10/2015). White matter myelination and cognitive abilities in pre-adolescent children. West Virginia Clinical and Translational Science Institute Annual Conference, Charleston, WV.

Greenbaum, H., Webb, B., Scott, O., Shaw, J., Shannon, B., Taylor, J. (10/2015). A student led group affirming diversity at WVU and in our local community. WVPA Fall Conference, Morgantown, WV.

Martyi, M., Greenbaum, H., Frum, C., \& Pergami, P. (8/2015). Differences in brain connectivity reflects cognitive abilities in pre-adolescent children. Center for Neuroscience Summer Research Internship Conference, Morgantown, WV.

Taylor, J. M., Neimeyer, G. J. \& Greenbaum, H. (8/2015). Continuing education and competence: Do CE mandates make a difference? APA Convention, Division 17, Toronto, Canada.

Blake, J.P., \& Greenbaum, H. (5/2015). Hope as a mediator of the relationship between attachment. National Counsel on Rehabilitation Education Conference, Newport Beach, CA.

Greenbaum, H., Arab, Y., Shah, S., Phillips, J., Gross, J., Hardan, A., \& Samson, A. (5/2014). Emotion Regulation in Children and Adolescents with Autism Spectrum Disorder. Annual Meeting for the Society for Affective Disorders, Bethesda, MD. 


\section{AD HOC REVIEWER}

Counseling Psychology Quarterly

Public Library of Science

GRANTS \& AWARDS

WVU College of Education and Human Services (CEHS) Robert E. Stitzel Graduate Student Research Award, \$2000 (2016).

\section{ADOVACY/LEADERSHIP EXPERIENCE}

2017- 2018

May 2017

2015-2017

2015-2017

2015-2017

September 2015

2014-2016

2009-2014
Volunteer tutor and playtime facilitator; Sinai Assisted Housing

Foundation, Washington, DC.

Developed Quality Improvement project focused on suicide assessment; WVU School of Medicine, Morgantown, WV.

WVPA Student Representative.

Campus Representative at WVU for the American Psychological Association of Graduate Students (APAGS).

West Virginia State Advocacy Coordinator for APAGS. Organized the $4^{\text {th }}$ bi-annual West Virginia Lobby Day to advocate for mental health care access and funding; Charleston, WV.

Vice President \& Co-Founder, Speak Out Reach Out, student led group focused on diversity at WVU; Morgantown, WV.

Volunteer; Homeless Garden Project, Santa Cruz, CA.

\section{PROFESSIONAL MEMBERSHIPS}

2014-present
Graduate Student Affiliate of APA Division 40: Clinical Neuropsychology; Graduate Student Affiliate of APA Division 17: Counseling Psychology.

\section{REFERENCES}

Jacqueline Sanz, PhD, ABPP-CN

Assistant Professor, Depts. of Psychiatry \& Behavioral

Sciences \& Pediatrics

Division of Pediatric Neuropsychology

Children's National Health System

The George Washington University School of Medicine

(202) 476-5506

JSanz@childrensnational.org

Pamela Dean, PhD, ABPP-CN

VA Puget Sound Healthcare System, Seattle Division

Dept. of Psychiatry \& Behavioral Sciences

University Washington School of Medicine

(206) 277-1265

Pamela.Dean@va.gov 